Universidad de Lima

Facultad de Comunicación

Carrera de Comunicación

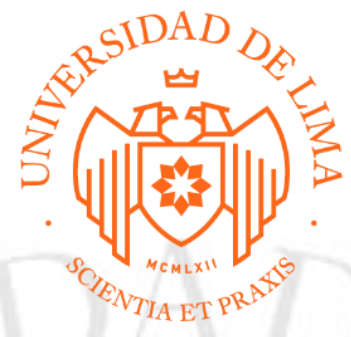

\title{
PLAN DE GESTIÓN DE CRISIS: CASO VIAJE LINDO AIRLINES
}

Trabajo de Suficiencia Profesional para optar el Título Profesional de Licenciado en

Comunicación

\section{Flavio Orlando Murillo Gayoso}

Código 20130876

\section{María Claudia Tang Voysest \\ Código 20131305}

$$
\text { Lima - Perú }
$$

Octubre de 2019 


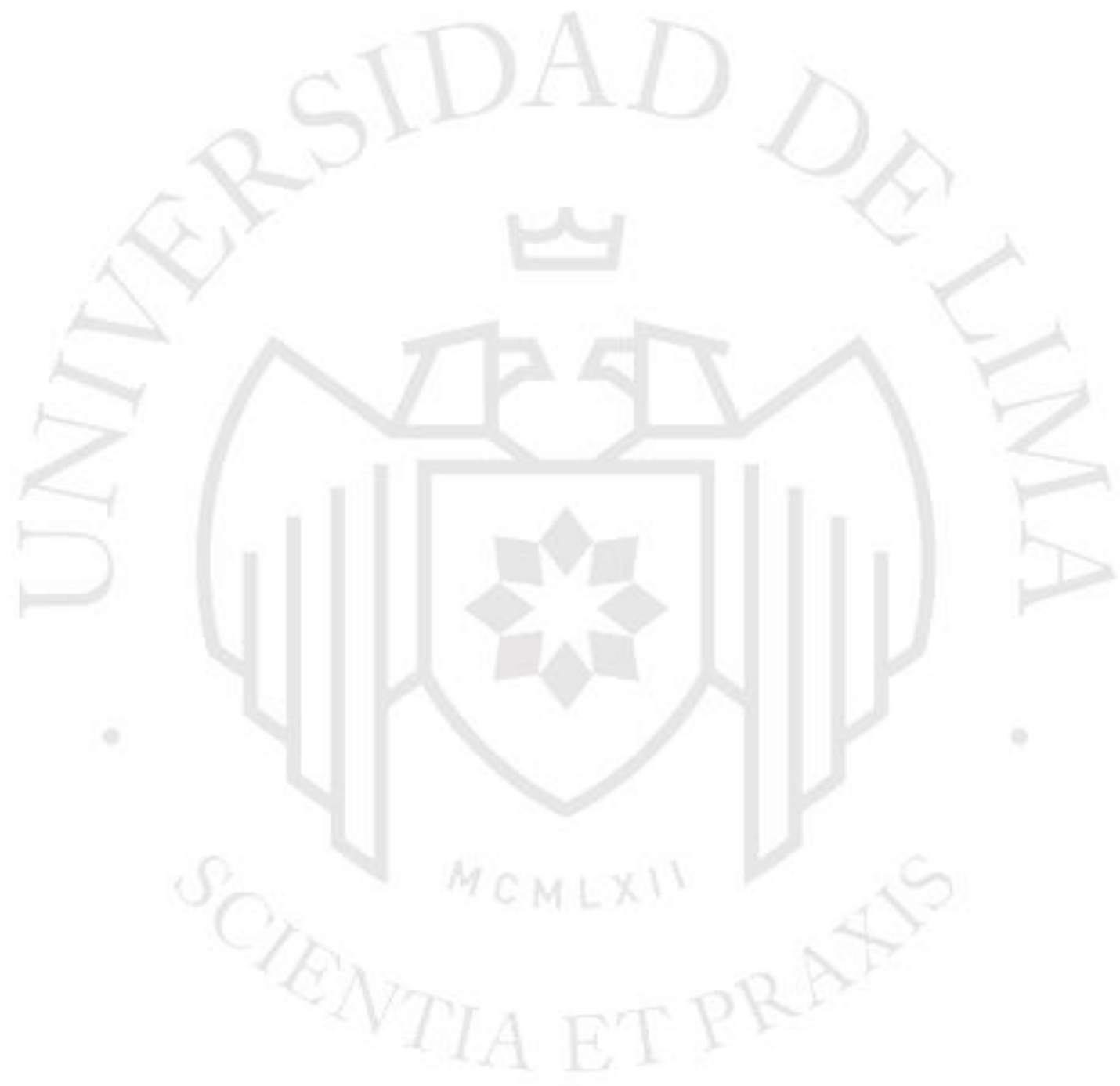




\section{PLAN DE GESTIÓN DE CRISIS: CASO VIAJE LINDO AIRLINES}




\section{ÍNDICE}

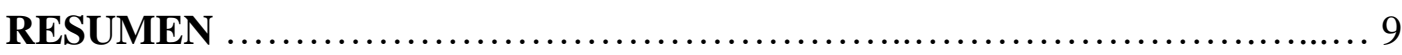

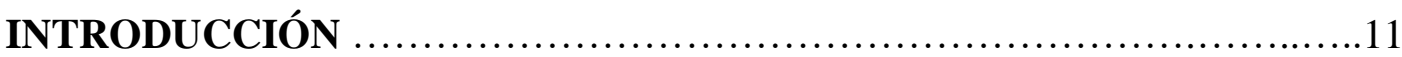

1. ANTECEDENTES DEL TRABAJO ................................... 12

1.1 Macro entorno del sector.......................................12

1.1.1 Político....................................................12

1.1.2 Económico..............................................12

1.1.3 Social.................................................. 16

1.1.4 Tecnológico........................................... 19

1.1.5 Legal..................................................20

1.1.6 Ambiental...........................................23

1.2 Micro entorno del sector.......................................... 25

1.2.1 Consumidores........................................... 25

1.2.1.1 Potencial.........................................25

1.2.1.2 Disponible.....................................25

1.2.1.3 Meta..............................................26

1.2.1.4 Penetrado......................................... 26

1.2.1.5 Perfil del cliente....................................26

1.2.2 Competencia .........................................26

1.2.3 Intermediarios ........................................... 30

1.2.4 Proveedores .............................................. 31

2. DIAGNÓSTICO DE COMUNICACIÓN........................................

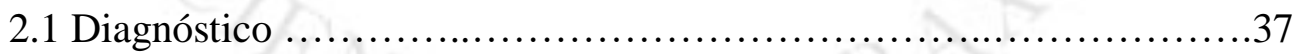

2.1.1 De la compañía ...........................................37

2.1.1 De la identidad y cultura ..................................37

2.1.3 De la comunicación interna ................................37

2.1.4 De la comunicación externa.................................38

2.1.5 De la responsabilidad social empresarial.....................39

2.2 Mapeo de stakeholders....................................... 40

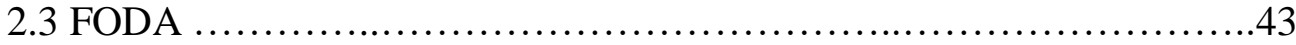

3. PROPUESTA DE COMUNICACIÓN ..................................47

3.1 Plan de Acción........................................................49 


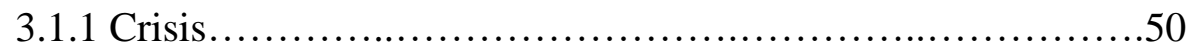

3.1.1.1 Fase crítica............................................51

3.1.1.2 Fase de tensión.......................................56

3.1.1.3 Fase crítica.............................................57

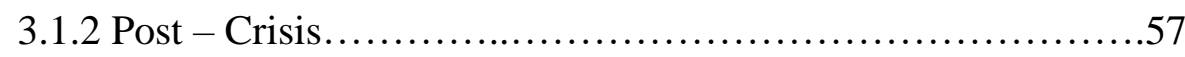

3.1.2.1 Matriz táctica............................................60

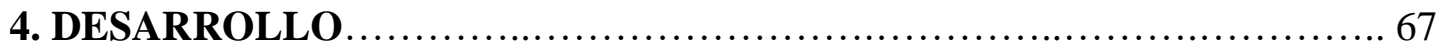

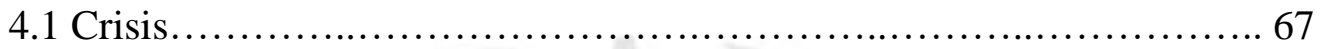

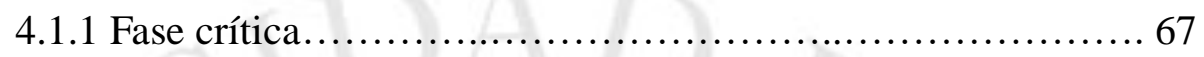

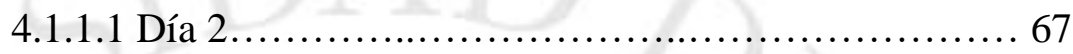

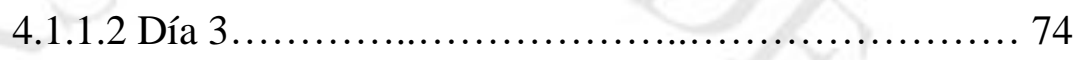

4.1.1.3 Día 4.................................................. 75

4.1.1.4 Día 5 ................................................. 76

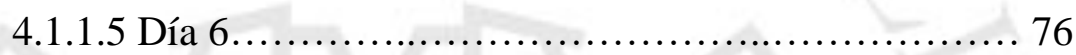

4.1.2 Fase de tensión..................................................... 77

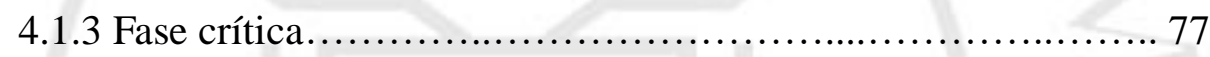

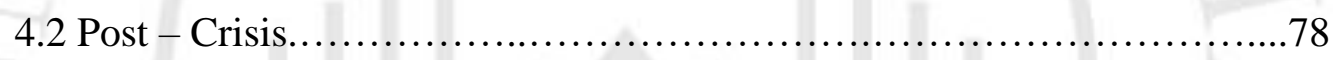

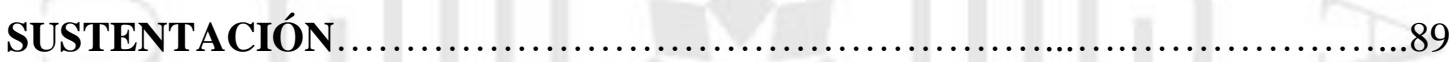

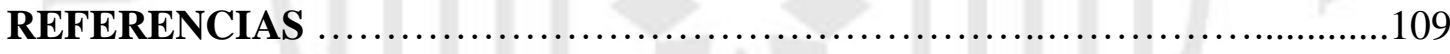

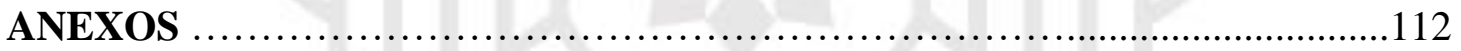


Dirección web de las piezas y producciones de comunicación parte del trabajo

Repositorio digital:

https://drive.google.com/drive/folders/1s4mKrgwyZ8vGQ8f3-

$\underline{\text { hLJIBsqeGId2EJ7? usp=sharing }}$ 


\section{ÍNDICE DE TABLAS}

Tabla 1.1. Contribuición de la aviación al Perú en forma de producción y empleos ......15

Tabla 1.2. Tráfico mensual de pasajeros a nivel nacional según aerolíneas ..................28

Tabla 1. 3. Aerolínes en el Perú ..................................................................................2 29

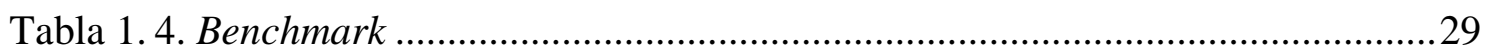

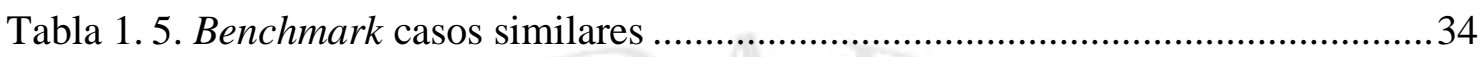

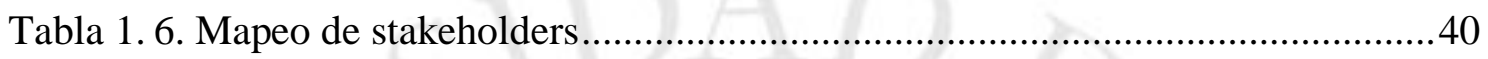

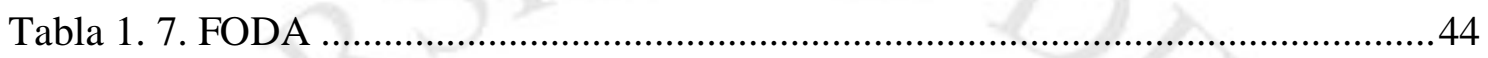

Tabla 1. 8. Objetivos de la gestión de crisis ............................................................ 47

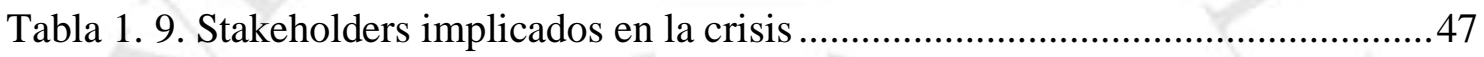

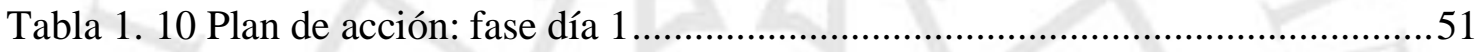

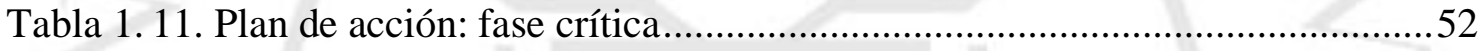

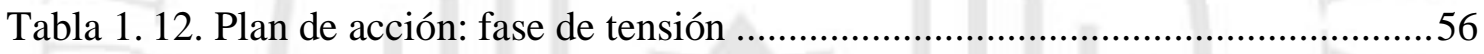

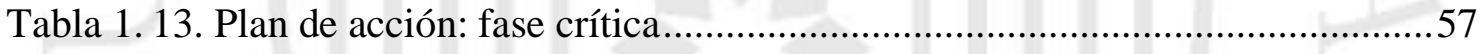

Tabla 1.14. Herramientas post-crisis...........................................58

Tabla 1. 15. Objetivos de la gestión de la post - crisis ...................................................60

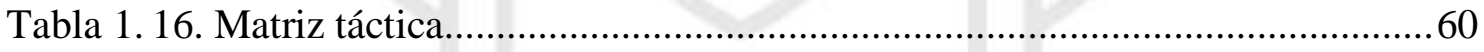

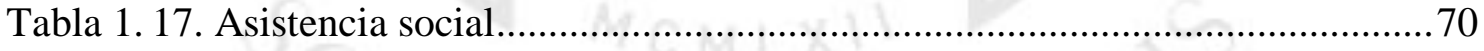

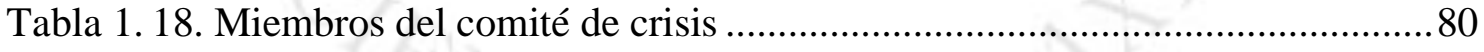

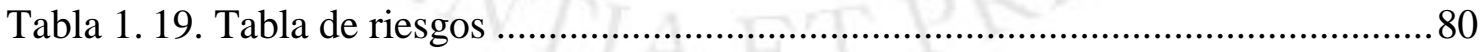

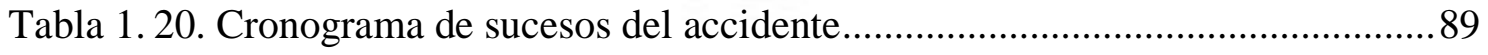

Tabla 1.21. Factores determinantes del accidente .................................................... 91

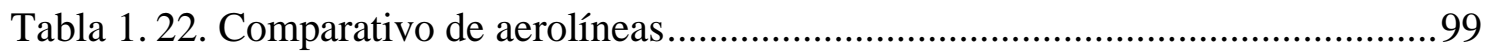




\section{ÍNDICE DE FIGURAS}

Figura 1. 1. Radiografía del mercado.................................................................... 13

Figura 1.2. Tráfico de pasajeros en todo el país según aerolínea.......................13

Figura 1. 3. Empleos y producción peruanos generados por el sector de la aviación....14

Figura 1. 4. Principales ambiciones de los millennials.......................... 17

Figura 1. 5. Evolución de las prioridades y aspiraciones de los millennials..............17 


\section{RESUMEN}

Viaje Lindo Airlines (VLA) es una aerolínea tradicional que opera en el mercado peruano desde 1995. En los últimos años ha expandido sus operaciones incrementando el número de aeronaves y el número de destinos a nivel nacional. Su última adquisición fue de 15 aviones Boeing 737-300.

El domingo 09 de junio de 2019, VLA tuvo un accidente aéreo en el vuelo 335 con destino a la ciudad de Arequipa, dejando la cifra mortal de 70 fallecidos y 72 heridos. Esto se debió a que la información que envió Boeing el día viernes 07 de junio por la noche, reportando fallos en su flota Boeing 737-300, no llegó de forma inmediata a las personas encargadas de las áreas respectivas de la aerolínea.

El siguiente trabajo tiene como objetivo desplegar una estrategia integral de comunicaciones que contribuya a salvaguardar la reputación y mantener el posicionamiento de la compañía luego del fatídico accidente aéreo, teniendo en consideración que no cuentan con un plan de acción de crisis, ni control de riesgos establecidos. Además, diseñaremos una matriz táctica enfocada en el control de daños y en la prevención de futuras posibles crisis para el siguiente año.

Palabras clave: Reputación, crisis, aerolínea, imagen, gestión de crisis, control de daños. 


\begin{abstract}
Viaje Lindo Airlines (VLA) is a traditional airline that has been operating in the Peruvian market since 1995. In recent years it has expanded its operations, increasing the number of aircraft and the number of destinations nationwide. His latest acquisition was 15 Boeing 737-300 aircraft.
\end{abstract}

However, on Sunday, June 9, 2019, VLA had, for the first time, an accident in flight 335 bound for Arequipa, leaving the death toll of 70 dead and 72 injured. A failure in the wings slats of Boeing 737-300 fleet reported by Boeing on Friday, June 7 at night, did not reach timely the responsible team in stopping the airline's flight, and presumably, this is the cause of the accident.

The following work aims to deploy a comprehensive communications strategy that helps to safeguard the reputation and maintain the positioning of the company after the fatal plane crash, taking into account that they do not have a crisis action plan or established risk control. Besides, we will design a tactical matrix focused on damage control and prevention of future crises.

Keywords: Reputation, crisis, airline, image, crisis management, damage control. 


\section{INTRODUCCIÓN}

El sector de transporte aéreo contribuye significativamente a la economía del Perú, aportando más de 4\% al PBI con US\$ 4,400 millones facturados anuales. En 2018 se lograron transportar 24.6 millones de pasajeros de los cuales el $51.7 \%$ corresponden a rutas nacionales. Para 2021, el impacto de esta industria en el PBI peruano alcanzaría la cifra de 4,24\% y el número de puestos de trabajo superaría los 1,27 millones.

Sumado a ello, está la creciente tendencia low cost que vivimos en el país hoy en día, la cual trae consigo beneficios al usuario abriendo una mayor oferta y competencia en el sector. Ambos factores influyen en la estrategia de negocio de la compañía Viaje Lindo Airlines, aerolínea que opera en el Perú desde 1995 y que viene presentando un gran crecimiento en el mercado bajo su promesa de marca: "Seguridad y puntualidad a un mejor precio".

El siguiente plan tiene como finalidad proporcionar las acciones necesarias para gestionar la crisis reputacional que vivió la aerolínea, a causa de un accidente aéreo por una falta de comunicación a tiempo con su proveedor, Boeing. Asimismo, desplegamos un plan de prevención y mitigación de futuras crisis que pueda presentar la compañía aérea. 


\section{ANTECEDENTES DEL TRABAJO}

\section{Macro entorno del sector}

\section{a. Político}

En los últimos 10 años, el tráfico aéreo en Perú ha experimentado un crecimiento rápido. El ingreso de nuevas aerolíneas low cost (bajo costo) está estimulando una alta competitividad en el mercado local. A fines de 2018, el Ministerio de Transportes y Comunicaciones (MTC), a través de la Dirección General de Aeronáutica Civil (DGAC), le otorgó un permiso de operación de aviación comercial a la primera aerolínea modelo low cost Viva Air. Esto trajo consigo beneficios al usuario abriendo una mayor oferta y competencia en el sector. En 2019, entró al mercado Sky Airlines con el mismo modelo.

A pesar de que el turismo en el Perú es uno de los sectores con mayor potencial de crecimiento en el país y Lima fue la 5ta ciudad más visitada en Latinoamérica en el último año; en 2018, la Asociación de Transporte Aéreo Internacional (IATA) la incluyó en la lista de las 6 ciudades de Latinoamérica con mayores obstáculos para el desarrollo de la industria aérea. Esto debido a los altos costos de impuestos y tasas, déficit de infraestructura aeroportuaria, regulaciones que impiden potenciar los beneficios económicos y sociales de la aviación, y la creciente demanda de conectividad aérea. Esta demanda hace que Perú no cuente con la capacidad suficiente de aeropuertos, con una mejor infraestructura y con una reestructuración de los costos y tasas.

Respecto a la infraestructura aeroportuaria, el Estado ha logrado concesionar una gran parte de los aeropuertos, lo cual ha permitido un incremento en el número de pasajeros y cargas; sin embargo, aún hace falta un mayor impulso e inversión para competir con los países de la región. Si bien el Estado peruano ha logrado las concesiones de los principales aeropuertos regionales del país junto con la participación de la empresa privada, la IATA considera que los contratos de concesión no son los más adecuados pues no evalúan la dinámica volátil del mercado aerocomercial y la infraestructura más allá de 10 o 15 años.

\section{b. Económico}


El sector del transporte aéreo contribuye significativamente a la economía de Perú. De acuerdo a LAN Perú (Comercio, 2016), la industria aérea aporta más de 4\% al PBI con US\$ 4,400 millones facturados anuales al Perú. Para 2021, el impacto de esta industria en el PBI peruano alcanzaría la cifra de 4,24\% y el número de puestos de trabajo superaría los 1,27 millones.

Figura 1.1

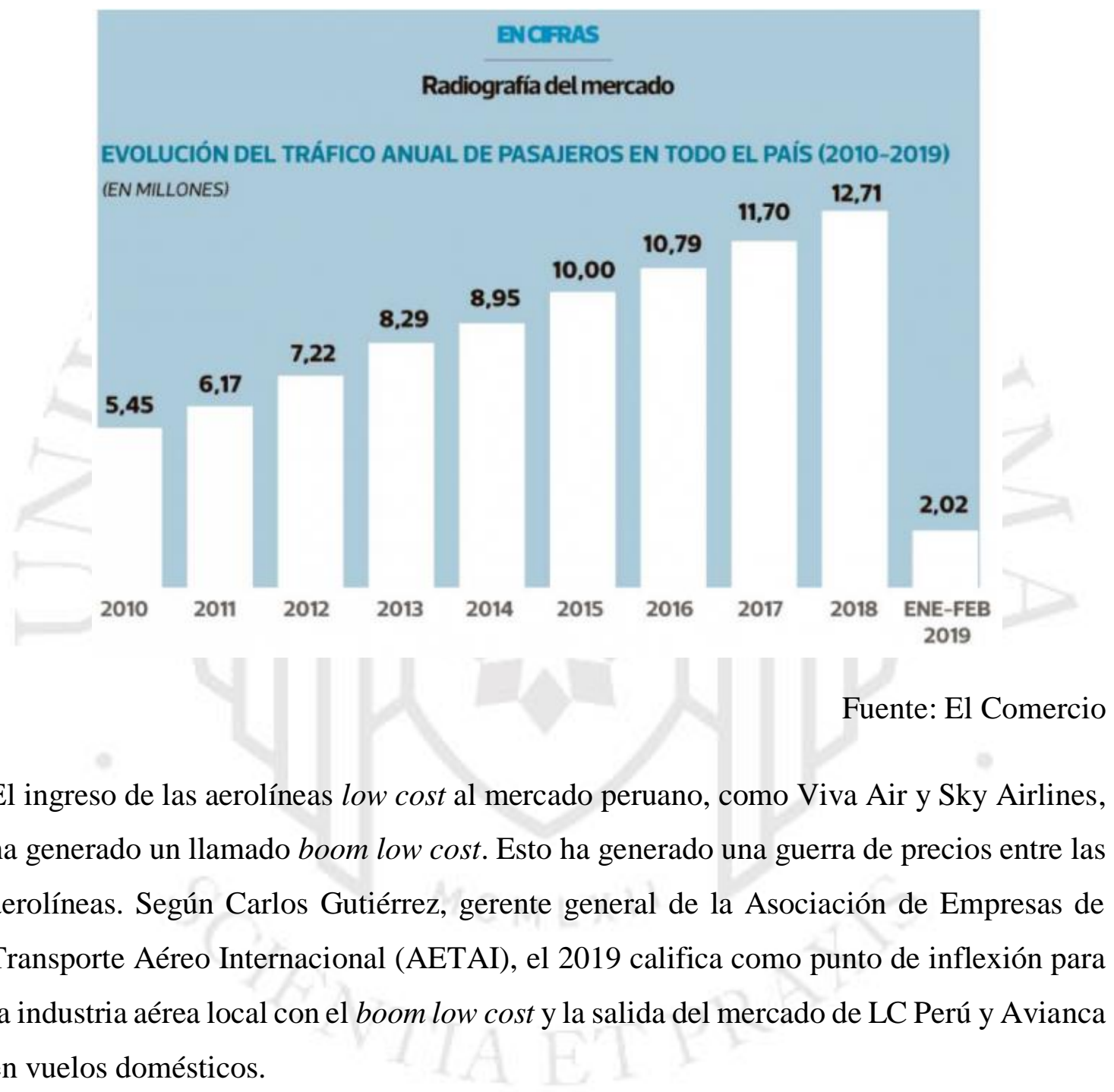

Figura 1.2 


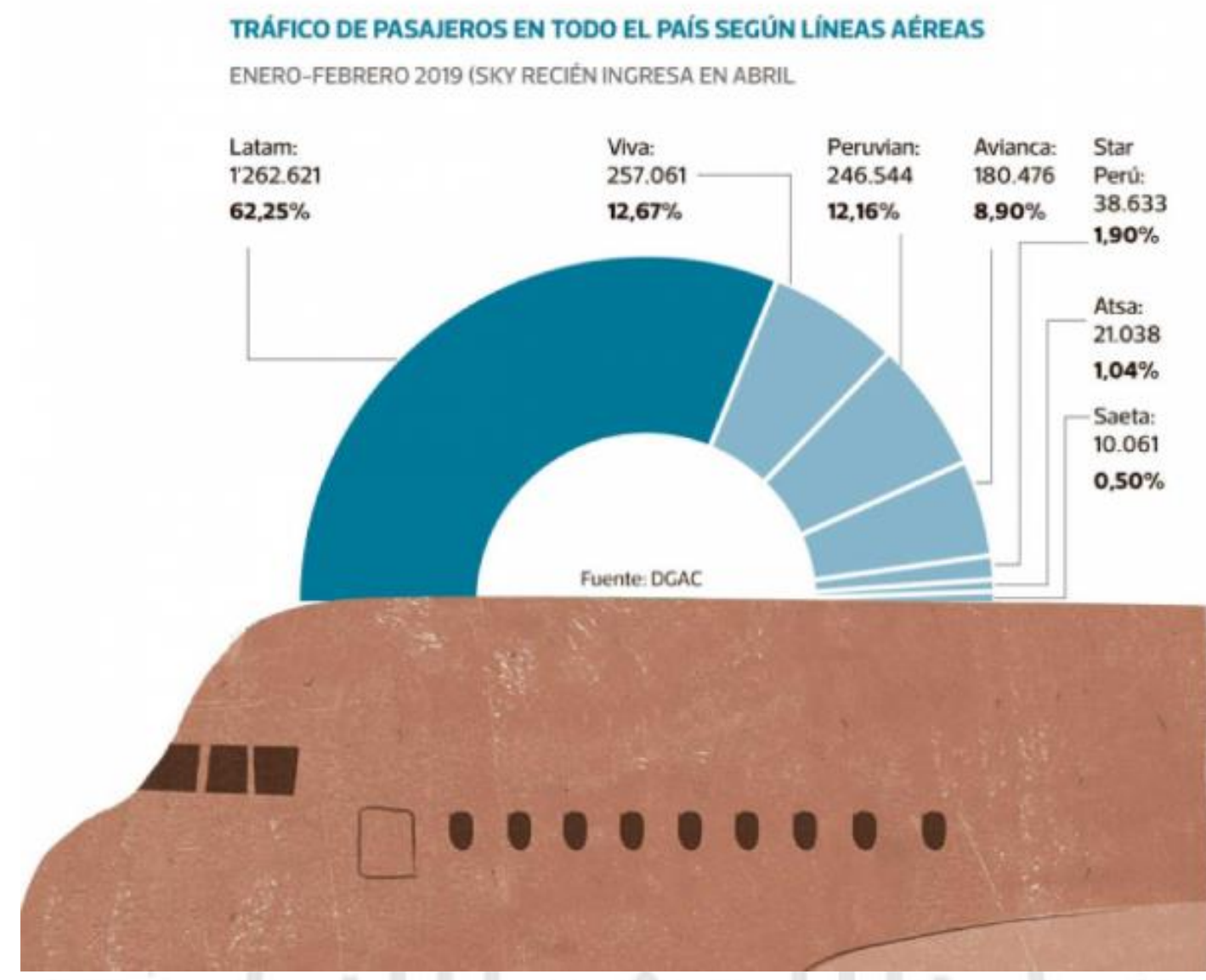

Fuente: El Comercio

Por otro lado, el informe de la Oficina Regional para las Américas de IATA señala que el $61 \%$ de los turistas que llegan al Perú lo hacen vía aérea.

Según Oxford Economics (Economics, 2010) el impacto económico de la aviación ha logrado contribuir con:

- \$349 millones aportados directamente mediante la producción del sector de la aviación (aerolíneas, aeropuertos y servicios en tierra).

- \$196 millones aportados indirectamente mediante la cadena de suministro del sector de la aviación.

- $\$ 157$ millones aportados mediante el gasto de los trabajadores del sector de la aviación y su cadena de suministro.

- \$2,000 millones en beneficios catalíticos a través del turismo, lo que eleva la contribución global a $\$ 2,700$ millones o $1.7 \%$ del PBI.

Figura 1.3 


\section{Empleos y producción peruanos generados por el sector de la aviación}

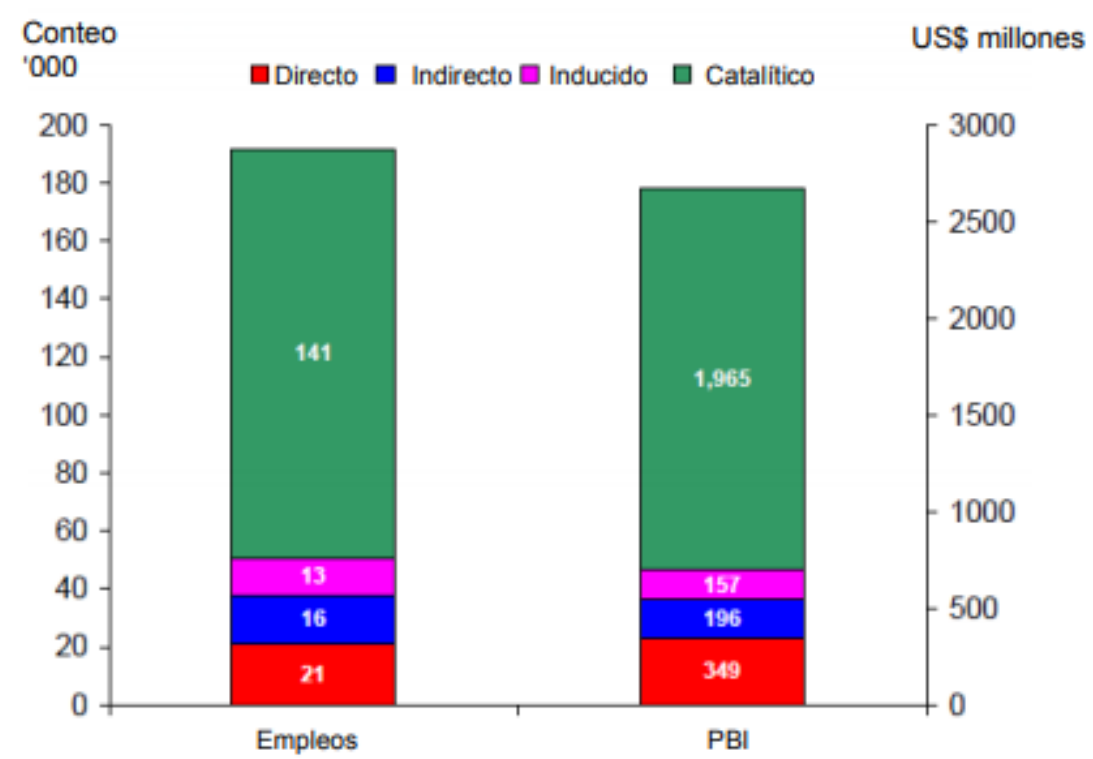

Fuente: IATA, Oxford Economics

El sector de la aviación genera 51,000 empleos en el Perú. Esta cifra total comprende:

- 21,000 empleos generados directamente por el sector de la aviación.

- 16,000 empleos generados indirectamente a través de la cadena de suministro del sector de la aviación.

- 13,000 empleos generados a través del gasto de los empleados del sector de la aviación y su cadena de suministro.

- Además, otras 141,00 personas tienen empleo gracias a los efectos catalíticos (turismo) de la aviación.

Tabla 1.1 
Contribución de la aviación al Perú en forma de producción y empleos

\begin{tabular}{|c|c|c|c|c|c|}
\hline 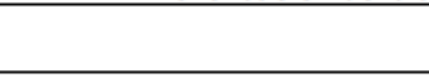 & Directa & Indirecta & Inducida & Total & $\begin{array}{l}\% \text { del total de } \\
\text { la economia }\end{array}$ \\
\hline \multicolumn{6}{|l|}{$\begin{array}{l}\text { Contribución al PBI (US\$ } \\
\text { Millón) }\end{array}$} \\
\hline Aerolineas & 157 & 95 & 60 & 312 & $0.2 \%$ \\
\hline $\begin{array}{l}\text { Aeropuertos y servicios en } \\
\text { tierra }\end{array}$ & 192 & 101 & 97 & 390 & $0.3 \%$ \\
\hline Total & 349 & 196 & 157 & 702 & $0.5 \%$ \\
\hline Efecto catalitico (turismo) & 969 & 580 & 416 & 1,965 & $1.3 \%$ \\
\hline $\begin{array}{l}\text { Total incluyendo efecto } \\
\text { catalitico }\end{array}$ & 1,318 & 777 & 573 & 2,668 & $1.7 \%$ \\
\hline \multicolumn{6}{|l|}{ Contribución al empleo (000) } \\
\hline Aerolineas & 5 & 8 & 5 & 18 & $0.1 \%$ \\
\hline $\begin{array}{l}\text { Aeropuertos y servicios en } \\
\text { tierra }\end{array}$ & 16 & 8 & 8 & 33 & $0.3 \%$ \\
\hline Total & 21 & 16 & 13 & 51 & $0.4 \%$ \\
\hline Efecto catalítico (turismo) & 61 & 44 & 36 & 141 & $1.1 \%$ \\
\hline $\begin{array}{l}\text { Total incluyendo efecto } \\
\text { catalitico }\end{array}$ & 83 & 60 & 49 & 192 & $1.5 \%$ \\
\hline
\end{tabular}

Fuente: IATA, Oxford Economics

La integración del Perú a la red global de transporte aéreo transforma las posibilidades para la economía peruana al (Economics, 2010):

- Abrir mercados extranjeros a las exportaciones peruanas.

- Reducir los costos de transporte, especialmente cuando se recorren grandes distancias, ayudando a incrementar la competencia porque los proveedores pueden atender un área más amplia y posiblemente reduzcan los costos promedio, a través de economías de mayor escala.

- Incrementar la flexibilidad de la oferta laboral, lo que debería mejorar la eficiencia distributiva y reducir la tasa natural de desempleo.

- Animar a las empresas peruanas para que inviertan y se especialicen en ámbitos donde saquen partido de las fortalezas de la economía.

- Acelerar la adopción de nuevas prácticas comerciales.

- Elevar la productividad y, por tanto, la capacidad de suministro de largo plazo de la economía. Se estima que una mejora del $10 \%$ en la conectividad en relación con el PBI produciría a la larga un incremento de \$98 millones al año en el PBI de la economía peruana.

\section{c. Social}

En el Informe de Tendencias Turísticas 2018 realizado por TrekkSoft, hemos encontrado que los turistas ahora son más conscientes de los precios y buscan un producto de mayor calidad a un precio más bajo. 
El pasajero nacional promedio busca que la opción de transporte sea rápida y a buen precio. Por ello la tendencia low cost que vivimos en el país hoy en día fuerza una mayor competencia en el sector. Siguiendo a Fred Jacobsen, Presidente de Viva Colombia, la diferencia entre una aerolínea de bajo costo y una aerolínea tradicional es que ofrece bajas tarifas a cambio de eliminar servicios que no son útiles para un gran número de pasajeros.

Arraigada a esta tendencia se encuentra la generación millennial. Para esta generación viajar es algo muy normal, forma parte de su día a día, sumado a su continuo uso de las nuevas tecnologías; este hecho hace que estén constantemente pensando en realizar algún viaje. Los millennials privilegian el disfrute, el viajar y la inversión en "experiencias" por sobre la posesión física de las cosas (Pancorbo, 2014). Esa accesibilidad a la información a través del internet y lo sensibles que son al precio de los mismos, hace que constituyan un segmento muy importante para el sector, ya que además son un tipo de cliente especializado y sabe lo que quiere. Por ello, el fin de la tendencia low cost, es brindar productos y servicios con calidad pero a buen precio.

Figura 1.4

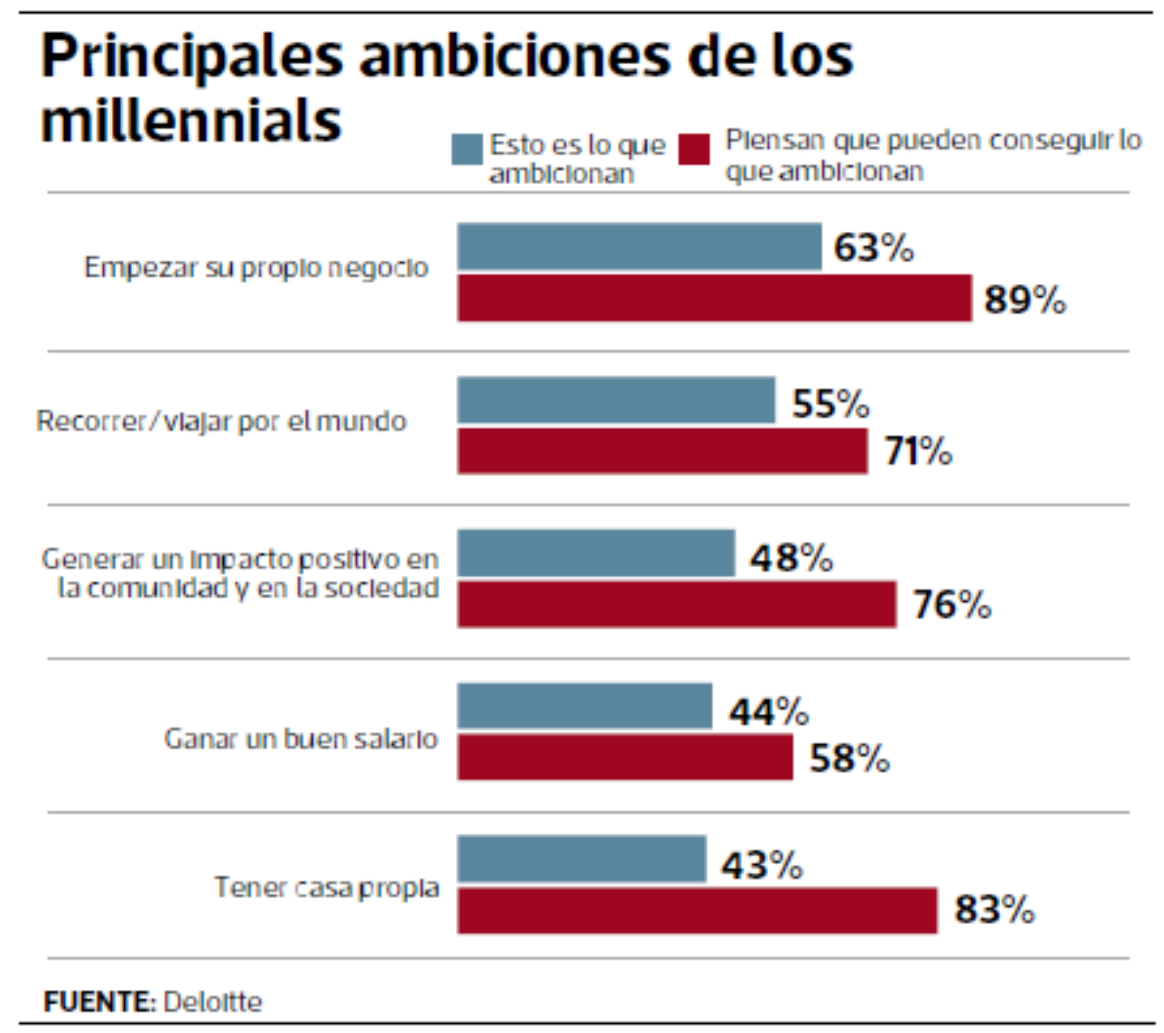

Figura 1.5 


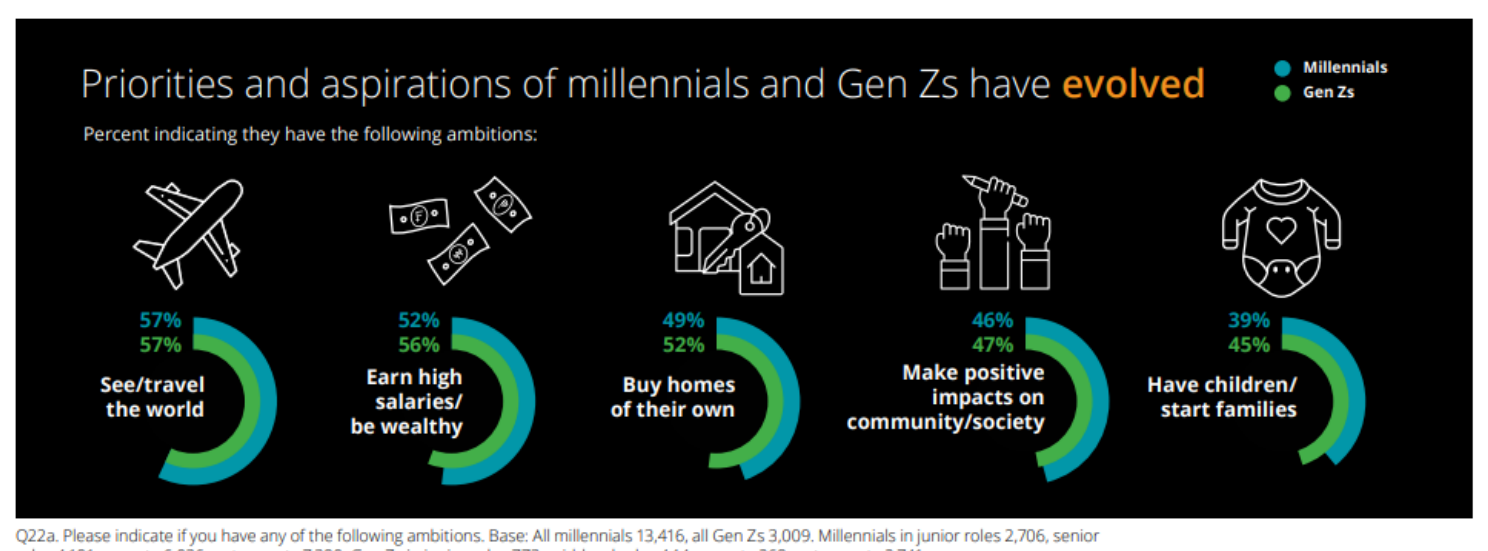

Q22a. Please indicate if you have any of the following ambitions. Base: All millennials 13,416 , all Gen Zs 3,009 . Millennials in junior roles 2,706 , senio
roles 4,101, parents 6,036, not parents 7,380 . Gen Zs in junior roles 773 , mid-level roles 444 , parents 268 , not parents 2,741

Fuente: Deloitte, 2019

La estrategia de las aerolíneas de bajo costo frente a las aerolíneas tradicionales es la de liderazgo en costos, según Porter; es decir, la empresa adopta este modelo de negocios buscando siempre minimizar los costos de operación al máximo de diversas maneras, en beneficio del cliente. Las características de una aerolínea de bajo costo según Eroğlu y Williams son las siguientes:

- Venta digital de tickets: sus ventas son realizadas en su mayor parte a través de Internet o pagos electrónicos. A través de esta medida se eliminan costos artificiales que afectan el valor del ticket aéreo.

- Tercerización de servicios: para la mayoría de servicios eligen a los proveedores de más bajo costo.

- Máxima tasa de ocupación de asientos: buscan ocupar al máximo la tasa de asientos del avión para reducir los costos asociados a la capacidad no utilizada.

- Sin comidas ni bebidas a bordo: no se sirven comida ni bebida en el avión sin costo, no obstante si el pasajero desea comer o beber algo podrá pagar por estos bienes. Mediante esta supresión de alimentos en el avión se minimizan costos.

- Vuelos cortos sin conexiones: los trayectos de viaje son generalmente inferiores a cuatro horas de duración, con esta medida baja el consumo de combustible y se genera un ahorro en este, que es el principal costo directo de una aerolínea.

- Clase única: en el avión no existe diferenciación por clase para los viajeros, y la asignación de silla es aleatoria para quienes no pagan por ella, con esto se reducen tiempos de embarque y por tanto costos asociados. 
- Modelo único de aeronaves: la flota de aviones se caracteriza por ser homogénea, es decir utilizan un solo modelo y tipo de aeronave, esto minimiza los costos de mantenimiento y entrenamiento para el personal de tierra y aire.

Debido a lo anterior descrito, las aerolíneas de bajo costo son capaces de ofrecer precios de vuelos $50 \%$ menores que los de las aerolíneas tradicionales. En la actualidad, las aerolíneas low cost se están trabajando para parecerse más a las tradicionales. (Correa \& Cruz, 2015).

\section{d. Tecnológico}

La llegada de las aerolíneas low cost al Perú marca el inicio de una nueva era para la industria y revolucionará el mercado de transporte aéreo gracias a la crecida de la oferta y al clima de alta competitividad. La industria vive una transformación constante a medida que se diseña y desarrollan nuevas tecnologías. El uso de nuevas tecnologías por parte del consumidor ha contribuido a su evolución, en gran medida por la información que el cliente puede tener sobre destinos, ofertas, proveedores e intermediarios.

La tecnología es fundamental para lograr eficiencias en las operaciones. Por ejemplo, Viva Air entró al mercado con una llamativa propuesta digital: un nuevo sitio web adaptado a dispositivos móviles, el uso de tablets para la venta de servicios abordo, la eliminación de papel en las tareas de vuelo de pilotos y tripulación, el pase de abordar digital, el uso del software de última tecnología para generar mayores eficiencias y seguridad en las operaciones de la aerolínea, y novedades en los sistemas de pago. (Karlosperu, 2019).

Por otro lado, Sky Airlines arrancó sus operaciones en Perú con flotas nuevas (A320neo), las cuales consumen aproximadamente un $30 \%$ menos de combustible por asiento (Villar, 2018). Esta tecnología traída al país permitirá tener una operación socialmente responsable, por el menor impacto ambiental en los nuevos aviones, ya que cuenta con niveles de contaminación $50 \%$ menores que la tecnología que actualmente opera y también una menor contaminación acústica.

Estas iniciativas que trae consigo la tecnología fomentan mayor rapidez y eficiencia en cada servicio ofrecido por las compañías y disminuyen sus costos operacionales, lo cual 
permite trasladar los ahorros a los pasajeros para seguir ofreciendo los precios más bajos del mercado.

\section{e. Legal}

Según la Resolución Legislativa N. ${ }^{\circ} 27261$ (2000), se debe tener en consideración los siguientes artículos y reglamentos sobre los que conciernen el actuar de las autoridades competentes frente a las actividades aeronáuticas y el actuar de Viaje Lindo Airlines frente a un accidente aeronáutico.

\section{Capítulo I -Principios Generales}

\section{Artículo 15.- De las restricciones a la libre circulación}

El Ministerio de Transportes, Comunicaciones, Vivienda y Construcción, por razones de seguridad nacional o interés público, y en su caso, la Dirección General de Aeronáutica Civil, por razones de seguridad de vuelo, pueden restringir, suspender o prohibir las actividades aeronáuticas civiles en todo o en parte del territorio nacional.

\section{Capítulo IV - Autorizaciones para realizar actividades de aviación civil}

\section{Artículo 97.- De las causales de suspensión o revocación de permisos}

97.2 La Dirección General de Aeronáutica Civil, en cualquier momento, podrá suspender o revocar total o parcialmente el Permiso de Operación o el Permiso de Vuelo otorgado para la realización de actividades aeronáuticas civiles, en especial de Aviación Comercial, en los siguientes casos:

a) Si el explotador pierde la capacidad legal, técnica o económico-financiera según la cual le fue otorgado el Permiso de Operación.

b) Si el explotador no cumple con constituir la garantía global o reponerla en el plazo establecido por la reglamentación correspondiente.

c) Si las operaciones no se inician dentro del término de 30 (treinta) días calendario desde la fecha de otorgamiento del Certificado de Explotador para la Aviación Comercial o de la de Conformidad de Operación para la de Aviación General. 
d) Si las operaciones no se inician dentro del término de 90 (noventa) días calendario desde la fecha de otorgamiento del Permiso de Operación Internacional.

e) Si se interrumpen las operaciones por un plazo de 90 (noventa) días calendario sin causa justificada.

f) Si la empresa es declarada en insolvencia, quiebra, liquidación o disolución conforme a ley y no ofrece, a criterio de la Dirección General de Aeronáutica Civil, garantías que resulten adecuadas para asegurar la prestación de los servicios.

g) Si el Permiso de Operación es cedido, transferido o explotado en contravención con lo dispuesto en la presente Ley.

h) Si no se cuenta con los seguros obligatorios establecidos por esta Ley.

i) Cuando se verifique la falta de reciprocidad por parte de otro Estado para la concesión de similares derechos aerocomerciales a los otorgados por el Perú.

j) Si el explotador no cumple con las obligaciones a su cargo.

k) Si el operador lo solicita, previa aceptación de la Autoridad Aeronáutica Civil.

\section{Capítulo VII}

\section{Condiciones técnicas de las aeronaves}

\section{Artículo 58.- De la aeronavegabilidad:}

58.1 Corresponde a la Dirección General de Aeronáutica Civil el otorgar, revalidar, suspender y cancelar los certificados de aeronavegabilidad de las aeronaves civiles peruanas.

\section{Capítulo VII}

\section{Daños y perjuicios causados a terceros en la superficie}

\section{Artículo 130: De la responsabilidad por daños y perjuicios a terceros en la superficie}

La persona que sufra daños y perjuicios en la superficie tiene derecho a la indemnización correspondiente, en las condiciones fijadas en este Capítulo, con sólo probar que los daños provienen de una aeronave en vuelo o de una persona o de cosa caída o arrojada 
de la misma. No procede la indemnización si no existe una relación de causalidad adecuada entre los daños y perjuicios y el acontecimiento que los ha originado.

\section{Título XII - Responsabilidad}

\section{Capítulo I - Daños causados a pasajeros y tripulación}

Artículo 114: De la responsabilidad del transportador por muerte, lesiones físicas o daño moral.

114.1: El transportador es responsable de los daños y perjuicios causados por muerte, lesión o daño sufrido por un pasajero, cuando el accidente que los ocasionó se produjo a bordo de la aeronave o durante las operaciones de embarque o desembarque.

\section{Título XV- Investigación de accidentes de aviación}

\section{Artículo 154.- De la Comisión de Investigación de Accidentes de Aviación}

154.1 Todo accidente de aviación será investigado por la Comisión de Investigación de Accidentes de Aviación, a fin de determinar sus causas y establecer las medidas tendientes a evitar que se repitan. La comisión realiza sus funciones de investigación de acuerdo a criterios técnicos y depende directamente del Ministerio de Transportes, Comunicaciones, Vivienda y Construcción. La reglamentación establece su composición, atribuciones y forma de trabajo.

\section{Reglamento (Decreto Supremo No 050-2001-MTC)}

Artículo 303: La investigación de accidentes de aviación es de interés público. Corresponde al MTC a través de la Comisión de Investigación de Accidentes de Aviación, investigar los accidentes e incidentes de aeronaves civiles que se producen en el territorio nacional.

\section{Autoridades Competentes}

El Ministerio de Transportes y Comunicaciones es la única autoridad aeronáutica civil en el Perú, según dispone la Ley № 27261.

Las entidades del Estado y sus dependencias que tienen responsabilidad en la seguridad de la aviación son las siguientes: 
- Presidencia del Consejo de Ministros

- Ministerio de Transportes y Comunicaciones

- Ministerio de Defensa

- Ministerio de Relaciones Exteriores

- Ministerio de Economía y Finanzas

- Ministerio de Salud

- Ministerio del Interior

- Ministerio Público

- Cualquier otro organismo que se encuentre vinculado con la seguridad de la aviación

Se debe tener en consideración también que, según la Resolución Directoral № 235 2018-MTC/12 (2018), las aerolíneas deben contar con autorizaciones administrativas y/o certificados otorgados por la DGAC para la realización de actividades de aviación civil, tales como:

- Certificado de explotador de servicios aéreos (AOC): Este certificado es el documento público que acredita la capacidad legal, técnica y económicafinanciera del explotador. Este certificado autoriza a un explotador a realizar determinadas operaciones de transporte aéreo y transporte aéreo especial.

- Especificaciones Técnicas de Operación (OpSpecs): Establece y administra estándares de seguridad para controlar muchas variables como la inmensa variedad de aeronaves, las distintas capacidades de los Explotadores, las diferentes situaciones que requieren de diferentes tipos de transporte aéreo, y los cambios rápidos y continuos de la tecnología en la aviación.

Por otro lado, respecto a los derechos de los usuarios de transporte aéreo se encuentran respaldados por el Código de Protección y Defensa del Consumidor, la Ley Aeronáutica Civil del Perú en la Ley $N^{\circ} 29571$ (Código de Protección y Defensa del Consumidor), la Ley N 27261 (Ley de Aeronáutica Civil del Perú) y la Decisión Nº 619 de la Comunidad Andina (Indecopi). Estos derechos del consumidor se activan solo en los casos que exista responsabilidad de la aerolínea en la demora o cancelación de sus vuelos.

\section{f. Ambiental}


La Organización de Aviación Civil Internacional (OACI) lidera asuntos relacionados con el medio ambiente y la aviación civil con el propósito de lograr la mayor compatibilidad posible entre el desarrollo seguro y ordenado de la aviación civil y la calidad del medio ambiente (Corpac, s.f.).

La mayor parte de las actividades de la OACI en el campo del medio ambiente son desarrolladas a través del Comité sobre la protección del medio ambiente y la aviación (CAEP). En 1992 el CAEP presentó ante la Conferencia Mundial Sobre el Medio Ambiente, un inventario de los problemas relacionados con la aviación civil que se resumen en los siguientes impactos:

- Contaminación sonora.

- Calidad del ambiente en las proximidades de los aeropuertos.

- Emisión de Gases de efecto invernadero.

- Problemas ambientales originados por la construcción y la ampliación de infraestructura.

- Contaminación del agua y del suelo en las proximidades de los aeropuertos

- Desechos que producen los aeropuertos.

- Problemas ambientales que surgen de los accidentes/incidentes de aeronaves con mercancías peligrosas y procedimientos de emergencia.

Es por eso que la OACI se ha trazado como objetivo estratégico reducir al mínimo los efectos ambientales adversos de la aviación civil mundial y alcanzar, entre otras, tres metas:

1. Limitar o reducir la cantidad de personas afectadas por un ruido considerable de las aeronaves.

2. Limitar o reducir las repercusiones de las emisiones procedentes de la aviación en la calidad del aire local.

3. Limitar o reducir los efectos de las emisiones de gases de efecto invernadero procedentes de la aviación en el clima mundial.

La aviación contribuye con alrededor del $2 \%$ de las emisiones mundiales de carbono del mundo, según la IATA. Este organismo predice que para 2037 el número de pasajeros aéreos se duplicará a 8.200 millones. El Grupo de Composición Atmosférica de la Universidad de Leicester comenta que el efecto climático de las emisiones de $\mathrm{CO}_{2}$ de la 
aviación es mucho mayor que el equivalente de otros medios de transporte. Estos gases de efecto invernadero persisten por más tiempo en la superficie y también tienen un potencial de calentamiento más fuerte.

Un vuelo de clase económica desde Londres hasta Nueva York emite aproximadamente 0,67 toneladas de $\mathrm{CO}_{2}$ por pasajero, según la $\mathrm{OACI}$, considerada como la calculadora del organismo de aviación civil de la ONU (ICAO, s.f.). Por ello, la industria aeronáutica se propone reducir su huella de carbono hacia un avión de "cero emisiones".

Actualmente las aerolíneas comerciales alrededor del mundo están implementando en sus procesos sistemas que integren la protección ambiental y la responsabilidad social como parte de sus operaciones.

Hoy en día parte de la reputación empresarial de las aerolíneas está intrínsecamente relacionada al control que tienen en sus procesos para mejorar continuamente su desempeño ambiental, el cumplimiento con la legislación ambiental peruana y otras normas de protección ambiental, y a la prevención en la posible contaminación originada por sus actividades, productos y servicios.

\section{Microentorno del sector}

\section{a. Consumidores}

\section{i. Potencial}

Las personas que viven en Perú actualmente hacen un total de 31 millones 865 mil habitantes, según INEI 2018. Nuestro mercado potencial se centra en los NSE A, B y C, los cuales conforman el $48.5 \%$ de la población; a su vez, los adultos jóvenes que comprenden un rango de edades entre 21 - 35 años, suponen aproximadamente el $25 \%$ de la población total.

En el año 2018, se logró transportar a 24.6 millones de pasajeros de los cuales el 51.7\% corresponden a rutas nacionales. Por lo que podemos decir que el mercado potencial que tiene VLA es de 12,718200 personas.

\section{ii. Disponible}

Jóvenes adultos entre 21 - 35 años de los NSE A, B y C, los cuales tienen como principales aspectos motivadores de viaje: descansar, salir con la familia, conocer nuevos lugares y diversión. El medio que más les despierta interés en viajar son los comentarios 
y experiencias de familiares y amigos; en segundo lugar, se encuentran las recomendaciones por internet.

\section{iii. Meta}

Para fines del caso, y conociendo las cifras del mercado aéreo nacional de pasajeros de los últimos 3 años, asumimos que Viaje Lindo Airlines quiere lograr una participación del mercado del 10\% de pasajeros. Bajo esta línea, VLA adquirió los 15 aviones Boeing para seguir incrementando el número de destinos a nivel nacional.

\section{iv. Penetrado}

El mercado actual de VLA está conformado por las personas que realizan vuelos a nivel nacional por medio del transporte aéreo, ya sea por turismo o por motivos laborales.

\section{v. Perfil del cliente}

Luego de haber especificado nuestro mercado, es necesario detallar el perfil y estilo de vida de nuestro consumidor. Este perfil se realizó tomando en cuenta el perfil del vacacionista nacional 2018 de PromPerú.

Nuestro consumidor se encuentra dentro de los 35 años, por lo que pertenece a la Generación Y, o mayormente conocida como "Millennials". Se encuentra dentro de los niveles socioeconómicos A, B y C y su estado civil es, mayormente, casado.

Dentro de los aspectos previos al viaje, el consumidor tiene como principales motivadores de viaje descansar/relajarse y salir con la familia o conocer nuevos lugares. Los medios por los cuales despierta un interés por viajar son los comentarios y experiencias de familiares y amigos, recomendaciones por internet y reportajes televisivos.

Dentro de los aspectos que toma en cuenta para elegir un lugar para viajar se encuentran los paisajes/naturaleza, la variedad de atractivos turísticos y que sea un lugar seguro. Los departamentos que más suelen visitar son Lima, Cusco y Piura.

En relación con las marcas de aerolíneas, los consumidores suelen buscar aerolíneas que le brinden seguridad y precios económicos. Actualmente, se encuentran muy atraídos por las aerolíneas que ofrecen vuelos low cost, lo que ha disminuido, en gran porcentaje. la participación del transporte terrestre.

\section{b. Competencia}


En el año 2016, LATAM Perú tuvo como participación de mercado un total de 6, 104 983 pasajeros, lo que representó el 61.6\% del mercado nacional; Peruvian con 1,218 804 pasajeros (12.3\%), Avianca con 1,180 572 pasajeros (11.9\%), LC Perú con 824729 (8.3\%) y Star Perú con 448245 pasajeros (4.5\%).

De enero a noviembre del 2017 (TNews, 2018), LATAM Perú tuvo más alta participación dentro del tráfico aéreo nacional al transportar 6,185 272 pasajeros, lo que representó el $57.8 \%$ del mercado nacional; seguido por Peruvian Airlines con 1,520 915 pasajeros (14.2\%), Avianca con 1,195 256 pasajeros (11,2\%), LC Perú con 1,038 138 pasajeros (9.7\%) y Star Perú con 347237 pasajeros (3.2\%), de acuerdo a la Dirección General de Aeronáutica Civil (DGAC). Viva Air, que opera desde mayo del 2017, alcanzó una participación de mercado de 2,34\% al transportar hasta noviembre 249,923 pasajeros. En este año se atendieron 31 destinos nacionales, operados por 9 aerolíneas.

Para el 2018, el transporte aéreo nacional de pasajeros creció en $8.6 \%$ entre enero y diciembre respecto al periodo 2017. DGAC informó que en este año la cifra ascendió a 12,710 665 pasajeros. Con respecto al market share doméstico, LATAM Perú tuvo la más alta participación dentro del tráfico nacional al transportar 7,393 426 pasajeros, lo que representó el 58.2\% del mercado, seguido por Peruvian con 1,759 122 (13.8\%), Taca Perú con 1,246 988 pasajeros (9.8\%), LC Perú con 1,004 952 pasajeros (4.9\%) y Viva Air con 797,837 pasajeros (6.3\%). A diferencia de los dos años anteriores, aquí se puede apreciar como Viva Air va creciendo su porcentaje de participación en el mercado por su estrategia de low cost.

Actualmente, en el Perú existen 9 aerolíneas que realizan vuelos nacionales, 21 que realizan vuelos internacionales y 3 que realizan exclusivamente el servicio de carga. Este año el transporte aéreo nacional de pasajeros creció un $5 \%$ entre enero y mayo. Esto representa un aumento de 5,280 936 pasajeros. De todas las empresas que operaron en los meses de enero a abril del 2019, LATAM Perú tuvo nuevamente la más alta participación al transportar 3,270 042 pasajeros, lo que representó el 61.9\% del mercado nacional. Fue seguido por Viva Air con 690,765 pasajeros (13.1\%), Peruvian Airlines con 619,069 pasajeros (11.7\%), Avianca Perú con 334,016 pasajeros (10.2\%) y Star Perú con 101,665 (1.9\%). Sky Airline Perú en solo dos meses ha transportado 147,232 pasajeros. 
Como se puede notar en las estadísticas, la llegada de Viva Air ha significado un cambio importante en el mercado del transporte aéreo nacional de pasajeros. Bajo esta nueva tendencia, las aerolíneas con destinos nacionales han decidido realizar una serie de estrategias de defensa frente al ingreso de nuevos competidores. LATAM Airlines Perú, líder en el mercado de aerolíneas local, anunció una nueva tarifa en sus precios denominada "tarifa basic" para vuelos domésticos. Con ella, se permitirá llevar en cabina solo un bolso o cartera, algo muy similar a las aerolíneas low cost que ofrecen estos mismos precios en sus tarifas más económicas. Esta acción es una respuesta al incremento de la competencia en el mercado y las alternativas de precios bajos que éstas ofrecen a las demandas cada vez más exigentes de los pasajeros.

Tabla 1.2

\begin{tabular}{|c|c|c|c|c|c|c|c|c|c|c|c|c|c|c|}
\hline DGÄAPEREY & & PERUं: & RÁFIC & ENSUA & $\begin{array}{l}\text { DE PAS } \\
\text { EI }\end{array}$ & $\begin{array}{l}\text { EROS } \\
\text { O-FE: }\end{array}$ & REL 20 & AL SE & INEA & EAS & & & & \\
\hline \begin{tabular}{|lr} 
Lineas Aéreas & Meses \\
\end{tabular} & Ene & Feb & Mar & Abr & May & Jun & Jul & Ago & Sep & Oct & Nov & Dic & $\begin{array}{l}\text { Total } \\
\text { General } \\
\end{array}$ & \begin{tabular}{|l|} 
Particip. \\
Porcentual
\end{tabular} \\
\hline $\begin{array}{l}\text { AN PERÜ S.A. } \\
\text { IVA ARUINES PERU SAC. }\end{array}$ & $\begin{array}{l}655,496 \\
122681\end{array}$ & $\begin{array}{l}607,125 \\
134,380\end{array}$ & & & & & & & & & & & $\begin{array}{l}1,262621 \\
257061\end{array}$ & $\begin{array}{l}62.25 \% \\
12.67 \%\end{array}$ \\
\hline 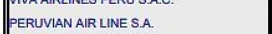 & $\begin{array}{l}{\left[\begin{array}{l}12,681 \\
127,455\end{array}\right.} \\
1\end{array}$ & $\begin{array}{l}134,380 \\
119,089\end{array}$ & & & & & & & & & & & $\begin{array}{l}247,0.51 \\
246,54\end{array}$ & $\begin{array}{l}12.16 \% \\
12.16 \%\end{array}$ \\
\hline IfACA PERU & 94.512 & 85,964 & & & & & & & & & & & 180,476 & $8.90 \%$ \\
\hline$\|$ ITAR PERU & 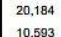 & \begin{tabular}{|l|l|}
18,449 \\
10445
\end{tabular} & & & & & & & & & & & $\begin{array}{l}38,633 \\
21398\end{array}$ & $1.90 \%$ \\
\hline & $\begin{array}{l}10,593 \\
5.205\end{array}$ & $\begin{array}{l}\begin{array}{l}10.45 \\
4,456\end{array} \\
4\end{array}$ & & & & & & & & & & & $\begin{array}{l}21,038 \\
10.61\end{array}$ & $1.04 \%$ \\
\hline MuSOQ WAYra & 2,148 & 2,504 & & & & & & & & & & & $\begin{array}{c}4,652 \\
4.552\end{array}$ & $0.23 \%$ \\
\hline AIR MANORO S.A. & 959 & 873 & & & & & & & & & & & 1,832 & $0.09 \%$ \\
\hline | AEROPROP & $\begin{array}{l}781 \\
654\end{array}$ & $\begin{array}{l}950 \\
732\end{array}$ & & & & & & & & & & & $\begin{array}{l}1,731 \\
1,366\end{array}$ & $0.09 \%$ \\
\hline WAVE PERU & 550 & 42 & & & & & & & & & & & 592 & 0.03\% \\
\hline SERVA. DE LOS ANDES S.AC & 279 & 258 & & & & & & & & & & & 537 & $0.03 \%$ \\
\hline RED WING SRL & 276 & 214 & & & & & & & & & & & 490 & $0.02 \%$ \\
\hline |LLAS DEL ORIENTE S.AC & 168 & 140 & & & & & & & & & & & 308 & $0.02 \%$ \\
\hline $\begin{array}{l}\text { TRADEN AAC. } \\
\text { ARROUNK }\end{array}$ & 60 & 86 & & & & & & & & & & & 146 & 0.01\% \\
\hline $\begin{array}{l}\text { EEROUNKK } \\
\text { MOVIL AIR }\end{array}$ & & 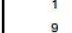 & & & & & & & & & & & ${ }_{9}^{41}$ & 0.00\% \\
\hline $\begin{array}{l}\text { HELISUR } \\
\text { Hen }\end{array}$ & & 1 & & & & & & & & & & & 1 & $0.00 \%$ \\
\hline TOTAL GENERAL & \# & 986,118 & & & & & & & & & & & $2,028,159$ & $100.00 \%$ \\
\hline
\end{tabular}

(Fuente: Reporte de transporte aéreo - servicios de pasajeros DGAC)

Tabla 1.3

\begin{tabular}{|c|c|c|}
\hline \multicolumn{3}{|c|}{ Aerolíneas en el Perú } \\
\hline $\begin{array}{c}\text { Aerolíneas con vuelos } \\
\text { nacionales }\end{array}$ & $\begin{array}{c}\text { Aerolíneas con vuelos } \\
\text { internacionales }\end{array}$ & $\begin{array}{c}\text { Aerolíneas que realizan } \\
\text { servicio de carga }\end{array}$ \\
\hline ATSA & Aerolíneas Argentinas & Martinair Holland \\
\hline Avianca Perú & AeroMéxico & Arrow Air \\
\hline LATAM Perú & Air Canada & Cielos del Perú \\
\hline Peruvian Airlines & Air Europa & \\
\hline Star Perú & Air France & \\
\hline
\end{tabular}




\begin{tabular}{|c|c|l|}
\hline Viva Air Perú & American Airlines & \\
\hline Wayraperú & Avianca & \\
\hline Sky Airline Perú & British Airways & \\
\hline & Copa Airlines & \\
\hline & Delta Airlines & \\
\hline & Estelar Latinoamérica & \\
\hline & Gol Transportes Aéreos & \\
\hline & Iberia & \\
\hline & Interjet & \\
\hline & JetBlue Airways & \\
\hline & JetSmart & \\
\hline & KLM & \\
\hline
\end{tabular}

Fuente: Propia

\section{Benchmark}

Tabla 1.4

\begin{tabular}{|c|l|l|l|l|}
\hline Aerolíneas & \multicolumn{1}{c|}{ Logo } & \multicolumn{1}{c|}{ Ciudades } & Aeronave & \multicolumn{1}{c|}{ Promesa } \\
\hline $\begin{array}{c}\text { Atsa } \\
\text { Airlines }\end{array}$ & ○AtSA AIRLINES & $\begin{array}{l}\text { Nacionales: (4) } \\
\text { Atalaya / } \\
\text { Chachapoyas / } \\
\text { Huánuco / Tingo } \\
\text { María }\end{array}$ & Fokker 50 & $\begin{array}{l}\text { En nuestros vuelos } \\
\text { de Atsa Airlines } \\
\text { nuestra prioridad } \\
\text { son nuestros } \\
\text { pasajeros. }\end{array}$ \\
\hline $\begin{array}{c}\text { Avianca } \\
\text { Perú }\end{array}$ & $\begin{array}{l}\text { Avianca } \\
\text { Airlines }\end{array}$ & $\begin{array}{l}\text { Nacionales: (1) } \\
\text { Cusco }\end{array}$ & $\begin{array}{l}\text { Airbus A319, } \\
\text { Airbus A320, } \\
\text { Airbus A321, } \\
\text { Airbus A330- } \\
200\end{array}$ & $\begin{array}{l}\text { Para nosotros no } \\
\text { solo se trata de } \\
\text { darte buenos } \\
\text { precios, también se } \\
\text { trata de } \\
\text { garantizarte la } \\
\text { mejor experiencia. }\end{array}$ \\
\hline
\end{tabular}




\begin{tabular}{|c|c|c|c|c|}
\hline $\begin{array}{c}\text { LATAM } \\
\text { Perú }\end{array}$ & $\begin{array}{l}\text { LATAM } \\
\text { AIRLINES }\end{array}$ & $\begin{array}{l}\text { Nacionales: (18) } \\
\text { Arequipa/ Ayacucho/ } \\
\text { Cajamarca / } \\
\text { Chiclayo/ Cusco/ Ilo/ } \\
\text { Iquitos/ Jaén/ Jauja/ } \\
\text { Juliaca/ Piura/ } \\
\text { Pucallpa/ Puerto } \\
\text { Maldonado/ Tacna/ } \\
\text { Talara/ Tarapoto/ } \\
\text { Trujillo/ Tumbres }\end{array}$ & $\begin{array}{l}\text { Airbus A319, } \\
\text { Airbus A320, } \\
\text { Airbus A321, } \\
\text { Boeing 767- } \\
\text { 300ER, } \\
\text { Boeing 787- } \\
\text { 8, Boeing } \\
787-9\end{array}$ & $\begin{array}{l}\text { Para ti, la mejor } \\
\text { experiencia en el } \\
\text { cielo. }\end{array}$ \\
\hline $\begin{array}{c}\text { Peruvian } \\
\text { Airlines }\end{array}$ & PERUVIA & $\begin{array}{l}\text { Nacionales: (11) } \\
\text { Arequipa/Chiclayo/ } \\
\text { Cajamarca/ Cusco/ } \\
\text { Ilo/ Iquitos/ Jauja/ } \\
\text { Piura/Pucallpa/ } \\
\text { Tacna/ Tarapoto }\end{array}$ & $\begin{array}{l}\text { Boeing 737- } \\
300, \\
\text { Boeing 737- } \\
400, \\
\text { Boeing 737- } \\
500\end{array}$ & $\begin{array}{l}\text { Peruvian es la línea } \\
\text { aérea de todos los } \\
\text { peruanos. }\end{array}$ \\
\hline $\begin{array}{l}\text { Sky } \\
\text { Airline } \\
\text { Perú }\end{array}$ & & $\begin{array}{l}\text { Nacionales: (9) } \\
\text { Arequipa/ Ayacucho/ } \\
\text { Cusco/ Iquitos/ } \\
\text { Piura/ Pucallpa/ } \\
\text { Tarapoto/ Trujillo/ } \\
\text { Tumbes }\end{array}$ & $\begin{array}{l}\text { Airbus } \\
\text { A320Neo }\end{array}$ & $\begin{array}{l}\text { Dar a las personas } \\
\text { la oportunidad de } \\
\text { viajar en avión a } \\
\text { precios bajos. }\end{array}$ \\
\hline Star Perú & & $\begin{array}{l}\text { Nacionales: (6) } \\
\text { Cajamarca/ } \\
\text { Chiclayo/ Cusco/ } \\
\text { Iquitos/ Pucallpa/ } \\
\text { Tarapoto }\end{array}$ & $\begin{array}{l}\text { Boeing 737- } \\
300\end{array}$ & f \\
\hline $\begin{array}{l}\text { Viva Air } \\
\text { Perú }\end{array}$ & & $\begin{array}{l}\text { Nacionales: (11) } \\
\text { Arequipa/ } \\
\text { Cajamarca/ } \\
\text { Chiclayo/ Cusco/ } \\
\text { Iquitos/ Jaén/ } \\
\text { Juliaca/ Piura/ } \\
\text { Tacna/ Talara/ } \\
\text { Tarapoto }\end{array}$ & Airbus A320 & $\begin{array}{l}\text { Cumplimos tu } \\
\text { sueño de volar. }\end{array}$ \\
\hline $\begin{array}{c}\text { Wayra } \\
\text { Perú }\end{array}$ & wayraperu & $\begin{array}{l}\text { Nacionales: (1) } \\
\text { Huánuco }\end{array}$ & Fokker 70 & - \\
\hline
\end{tabular}

Fuente: Propia.

\section{c. Intermediarios}

\section{Aeropuertos a nivel nacional}


Definitivamente los aeropuertos a nivel nacional son un aspecto clave dentro de las operaciones de las aerolíneas, ya que de ellos dependen los despegues y aterrizajes de los vuelos.

\section{Agencias de Viaje}

Se podría considerar a las agencias de viaje como una fuerza de venta que trabaja para las aerolíneas. Mediante la venta de paquetes turísticos completos, suelen tener convenios con algunas aerolíneas para poder adquirir precios especiales para sus clientes.

\section{Indecopi}

En caso una aerolínea cancele o retrase un vuelo sin motivo aparente, Indecopi es el ente donde el consumidor puede presentar un reclamo a través de sus oficinas físicas a nivel nacional. Ellos promoverán la conciliación entre el usuario y la aerolínea, con el fin de que puedan llegar a un acuerdo.

\section{d. Proveedores}

\section{Boeing}

The Boeing Company es una empresa multinacional estadounidense que diseña, fabrica y vende aviones, helicópteros, misiles y satélites y proporciona asesoramiento y servicio técnico. "Boeing" es uno de los mayores fabricantes de aeronaves del mundo, el segundo contratista de defensa del mundo, según datos de 2013, y el mayor exportador de Estados Unidos en función del valor del dólar.

Viaje Lindo Airlines realizó este año la adquisición de 15 aviones Boeing 737-300 para seguir incrementando el número de vuelos a nivel nacional y consolidarse como un serio competidor en el mercado de vuelos low cost en el Perú.

\section{Pratt \& Whitney}

Pratt \& Whiteny es una compañía dedicada a la industria aeroespacial establecida en Estados Unidos, con operaciones a nivel mundial. Entre sus principales productos se encuentran los motores recíprocos, turborreactores, turbofan, turbohélices y turboejes, entre otros. Además, ofrece un servicio de mantenimiento de motores con el apoyo de Ecopower Services, la cual consiste en un lavado a alta presión con atomización de agua mediante varias boquillas permitiendo remover suciedad y 
contaminantes de las partes de un motor, mejorando la eficiencia operativa de los motores y reduciendo el consumo de combustible.

\section{Rolls-Royce plc:}

"Rolls Royce plc" es una sociedad anónima multinacional británica que diseña, fabrica y distribuye sistemas de energía para la aviación y otras industrias. Es el segundo fabricante mundial de motores aeronáuticos.

\section{Air France (Componentes MRO)}

Como brazo MRO del grupo AIR FRANCE KLM, AFI KLM E\&M ofrece la gama completa de servicios de mantenimiento, reparación y revisión para su aeronave, incluyendo su fuselaje, motores, FTR, componentes y tren de aterrizaje.

\section{Thales Group (Entretenimiento)}

El Grupo Thales es una compañía francesa de electrónica dedicada al desarrollo de sistemas de información y servicios para los mercados aeroespacial, de defensa y seguridad. Viaje Lindo Airlines cuenta con los servicios de Thales para el servicio de entretenimiento abordo.

\section{Goodrich (Reversores)}

Goodrich Corporation es una empresa aeronáutica estadounidense fabricante de neumáticos y de caucho. Actualmente dentro de sus productos ofrece sistemas de actuación, aero estructuras, ruedas y frenos de aviones, polímeros, interiores, sistemas ISR, trenes de aterrizajes, sensores y sistemas integrados, entre otros.

\section{Messier Bugatti (Frenos)}

Messier Bugatti es una compañía dedicada al diseño, desarrollo, fabricación y atención al cliente de todo tipo de trenes de aterrizaje de aeronaves.

\section{Repsol YPF y Shell (Combustible)}

Repsol YPF y Shell son los más grandes proveedores de combustible para el sector aeronáutico en el Perú. Ambas empresas son consideradas como líderes en el sector por su calidad y experiencia en el mercado. 


\section{Casos similares: accidentes aéreos.}

Para contar con una referencia de métricas y acciones sobre casos similares, hemos analizado 4 accidentes aéreos ocurridos en los últimos 5 años.

Tabla 1.5

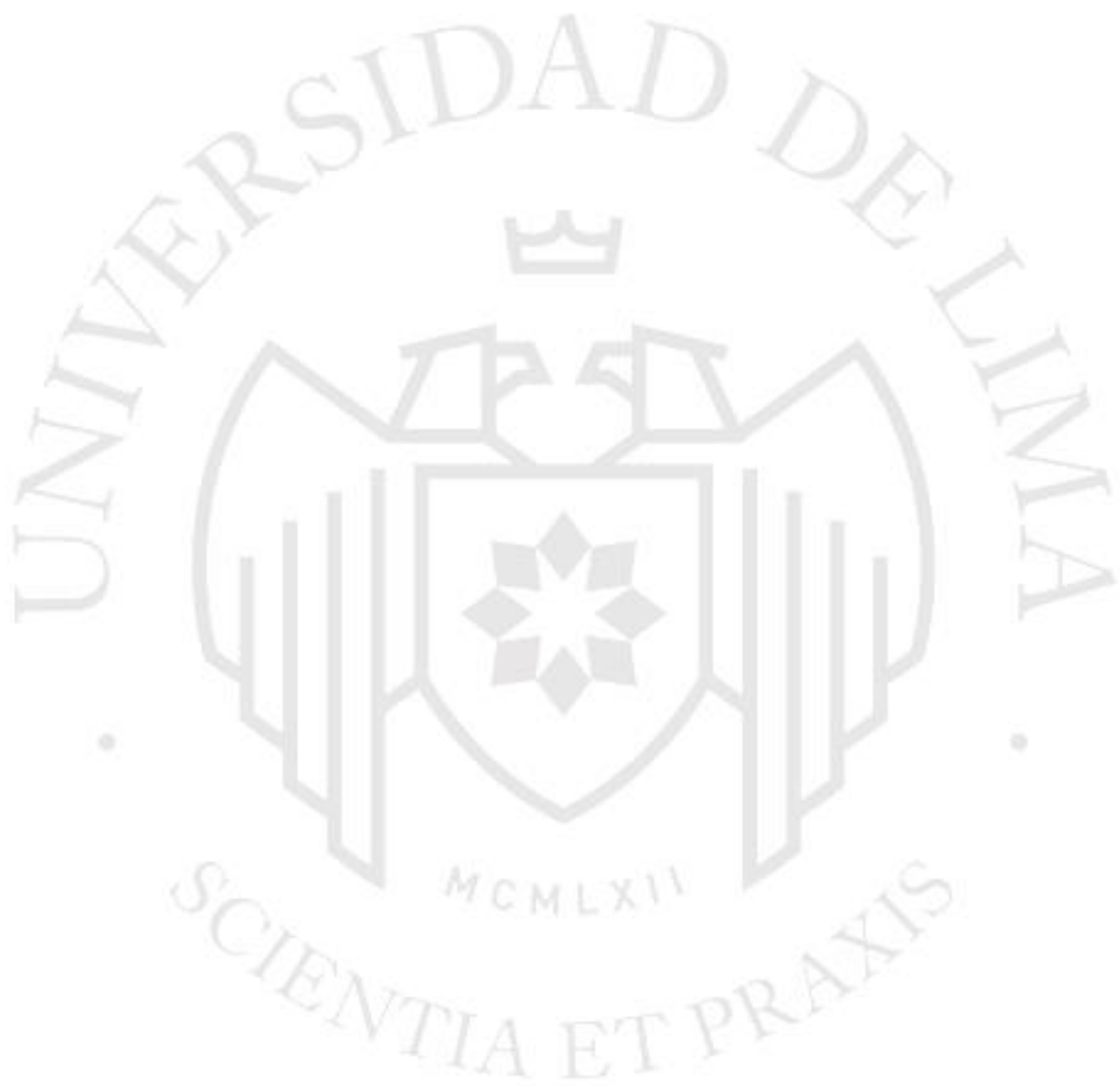




\begin{tabular}{|c|c|c|c|c|}
\hline Aerolínea & Fecha & Causa y consecuencia & Acciones tomadas & Redes sociales \\
\hline $\begin{array}{c}\text { Germanwings } \\
\text { 4U9525 }\end{array}$ & $24 / 03 / 2015$ & $\begin{array}{l}\text { - Lugar del accidente: } \\
\text { Barcelonnette, Alpes } \\
\text { Franceses (Francia) } \\
\text { - Fallecidos o } \\
\text { desaparecidos: } 150 \\
\text { Supervivientes } \\
\text { - registrados: 0 } \\
\text { - Causa: La caída de la } \\
\text { aeronave fue provocada } \\
\text { intencionadamente por el } \\
\text { copiloto. } \\
\text { - Situación: La aerolínea } \\
\text { continúa operando. }\end{array}$ & $\begin{array}{l}\text { - Tardaron menos de una hora en reaccionar a través de sus } \\
\text { canales corporativos. } \\
\text { - El mismo día de la tragedia, los CEOs realizaron sendas ruedas } \\
\text { de prensa para informar sobre el accidente y se mostraron abiertos } \\
\text { a todo tipo de preguntas por parte de los medios de comunicación. } \\
\text { - Lufthansa puso a disposición de los familiares de las víctimas } \\
\text { dos vuelos para acercarles al lugar de la tragedia. } \\
\text { - Logo de Germanwings teñido de negro y retirada del número de } \\
\text { vuelo. } \\
\text { - Incorporó en su web un apartado de condolencias. } \\
\text { - CEO visitó la zona } 8 \text { días después del accidente y pidió } \\
\text { disculpas. } \\
\text { - Germanwings retiró precipitadamente una campaña de } \\
\text { publicidad que había sido lanzada la semana del accidente. } \\
\text { - Lufthansa decidió no celebrar su } 60^{\circ} \text { aniversario dadas las } \\
\text { circunstancias. }\end{array}$ & $\begin{array}{l}\text { - La compañía aérea utilizó Twitter } \\
\text { como canal para difundir sus } \\
\text { comunicados de prensa. } \\
\text { - Difundió la etiqueta } \\
\text { \#IndeepSorrow. } \\
\text { - Lazo negro en la información de } \\
\text { Wikipedia y en los perfiles de las } \\
\text { redes sociales. } \\
\text { - Lufthansa usó las redes sociales } \\
\text { para solidarizarse con las víctimas } \\
\text { del siniestro y con sus familiares, } \\
\text { cambiando las cuentas a tonos } \\
\text { grises de luto. } \\
\text { - El CEO de Lufthansa lanzó un } \\
\text { mensaje en vídeo apenas } 24 \text { horas } \\
\text { después del accidente, pero } \\
\text { posterior al mensaje de Hollande. }\end{array}$ \\
\hline
\end{tabular}




\begin{tabular}{|c|c|c|c|c|}
\hline $\begin{array}{l}\text { Indonesia } \\
\text { AirAsia }\end{array}$ & $28 / 12 / 2014$ & $\begin{array}{l}\text { - Lugar del accidente: Mar } \\
\text { de Java (Indonesia) } \\
\text { - Fallecidos o } \\
\text { desaparecidos: } 162 \\
\text { - Supervivientes } \\
\text { registrados: 0 } \\
\text { - Causa: Bajo } \\
\text { investigación. } \\
\text { - Situación: Es la aerolínea } \\
\text { asociada en Indonesia a la } \\
\text { compañía AirAsia. } \\
\text { Inhabilitada para operar en } \\
\text { la UE desde 2008. } \\
\text { Actualmente sigue } \\
\text { volando. }\end{array}$ & $\begin{array}{l}\text { - En total la compañía emitió más de } 58 \text { notas de prensa sobre el } \\
\text { accidente. Al principio con frecuencia diaria. } \\
\text { • Call center de información para familiares de pasajeros y } \\
\text { tripulación, un centro de emergencias en los aeropuertos de salida } \\
\text { y llegada prevista del vuelo, y teléfonos de contacto para los } \\
\text { países de procedencia del pasaje. } \\
\text { - Cambio del color corporativo rojo por el gris. } \\
\text { - Fernandes, fundador de la compañía, viajó inmediatamente a } \\
\text { Surabaya, punto de partida del vuelo desaparecido y origen de la } \\
\text { mayoría de los pasajeros a bordo. } \\
\text { - Se eliminaron las fotos de aviones de la web y, con fondo gris } \\
\text { muy destacado, se ofrecía la información sobre el vuelo. Días más } \\
\text { tarde aparecía en la web el apartado "Update on QZ8501 } \\
\text { \#togetherwestand" con información actualizada. } \\
\text { - Fernandes envió una carta a todos los clientes que alguna vez } \\
\text { usaron los servicios de Air Asia en la que trasmitía los duros } \\
\text { momentos por los que pasaba la aerolínea y agradecía el apoyo a } \\
\text { quienes, pese al accidente, les seguían eligiendo. }\end{array}$ & $\begin{array}{l}\text { - Tony Fernandes, fundador de Air Asia } \\
\text { estuvo muy activo en Twitter, con } \\
\text { mensajes dirigidos a familiares de las } \\
\text { víctimas. } \\
\text { - Las cuentas en los medios sociales se } \\
\text { emplearon para difundir información } \\
\text { sobre el accidente, para publicar } \\
\text { novedades y en el caso de Facebook para } \\
\text { contestar preguntas. } \\
\text { - En los primeros días se utilizaron los } \\
\text { hashtags \#StayStrong y \#QZ8501. } \\
\text { Posteriormente cuando se confirmó la } \\
\text { existencia de víctimas se pasó a } \\
\text { \#TogetherWeStand. }\end{array}$ \\
\hline $\begin{array}{l}\text { Vuelo } 610 \text { de } \\
\text { Lion Air }\end{array}$ & $29 / 10 / 2018$ & $\begin{array}{l}- \text { Fallas en el vuelo Boeing } \\
737 \text { MAX } 8 \\
\text { - } 189 \text { fallecidos } 0 \\
\text { supervivientes } \\
\text { - Situación: La aerolínea } \\
\text { continúa operando. }\end{array}$ & $\begin{array}{l}\text { - Priorizó comunicaciones del accidente durante } 3 \text { semanas. } \\
\text { - Suspendió temporalmente un pedido de cuatro aviones Boeing } \\
737 \text { Max } 8 \\
\text { - Realizó un homenaje de los fallecidos en el mar de Indonesia. }\end{array}$ & $\begin{array}{l}\text { - Colocó fotos en redes sociales en } \\
\text { homenaje a los fallecidos. }\end{array}$ \\
\hline
\end{tabular}




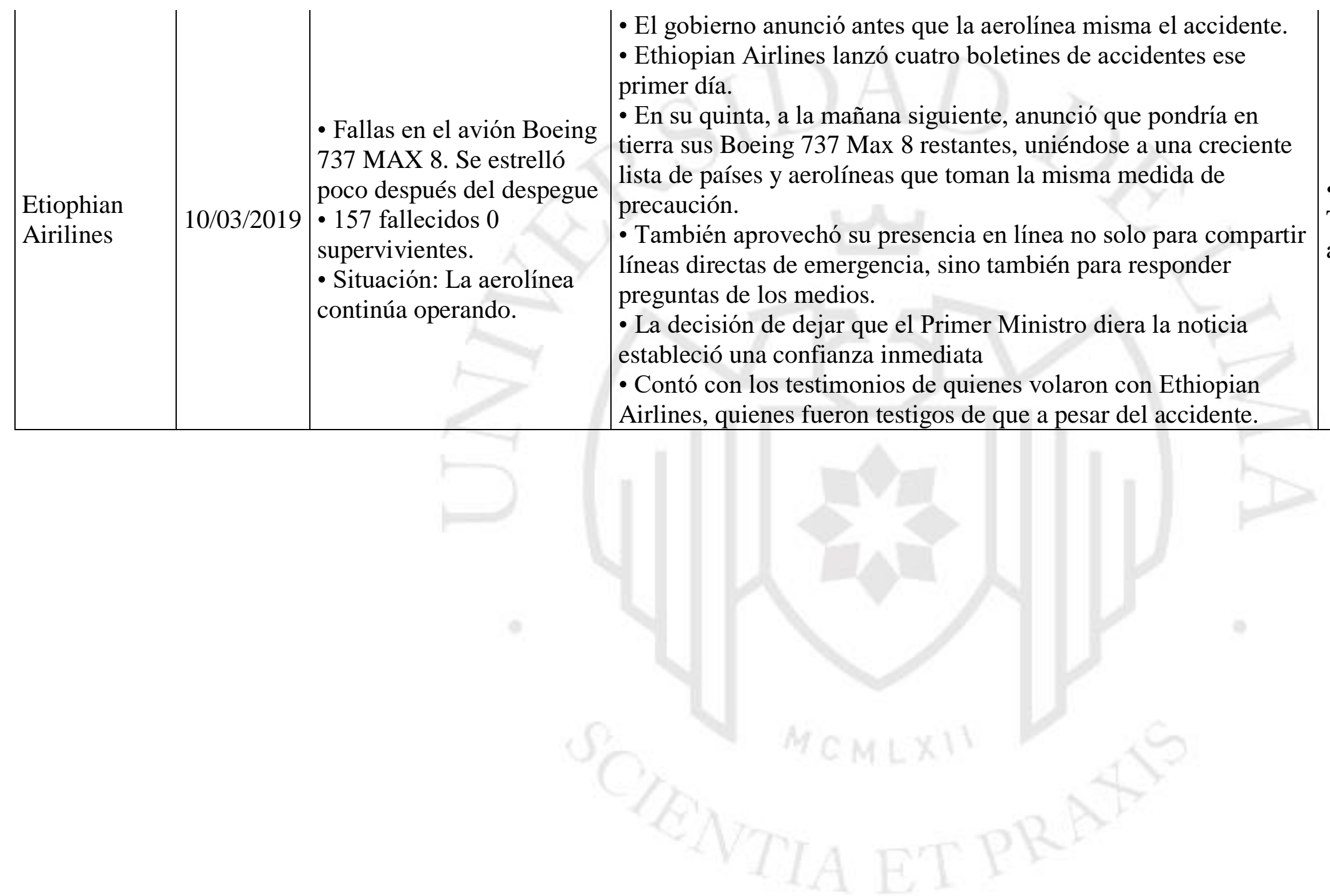

- La aerolínea hizo uso de su cuenta en Twitter para aclarar todos los hechos del accidente. 


\section{DIAGNÓSTICO DE COMUNICACIÓN}

1. Diagnóstico

\section{a. De la compañía}

- Viaje Lindo Airlines, es una aerolínea que opera en el mercado peruano desde 1995.

- A lo largo de los años ha incrementado el número de aeronaves y el número de destinos a nivel nacional. Actualmente opera en 8 rutas nacionales.

- A inicios de 2019, Viaje Lindo solicitó la adquisición de 15 Boeing 737-300 que se sumarían a los otros 15 aviones de la serie 200 y a los 10 BAe 146-300 con la que ya contaba.

- Estos aviones empezaron a cubrir las rutas nacionales en la primera semana de junio de 2019, haciendo que la compañía se convierta en un potente competidor frente a las aerolíneas low cost.

- A pesar de que la aerolínea ha mantenido una conservadora política de comunicación con poca inversión publicitaria, cuenta con un importante posicionamiento en el mercado.

\section{b. De la identidad y cultura}

- Su promesa de marca es: "Seguridad y puntualidad a un mejor precio". Este se traduce en su compromiso por realizar un riguroso control y mantenimiento en sus aeronaves y su puntualidad, reflejado en ser la aerolínea con menos retrasos en minutos a nivel nacional.

- Sus principales pilares son:

1. La seguridad.

2. El cuidado. (Tanto de las personas encargadas de las operaciones como de los pasajeros)

3. La puntualidad.

- Las últimas encuestas del clima laboral realizadas fueron hace tres años. Sin embargo, es sabido que los colaboradores han visto una sobrecarga laboral este último año y no se les ha otorgado reconocimientos ni incentivos.

\section{c. De la comunicación interna}


- La empresa cuenta con un área de comunicaciones que ha tenido diversos cambios en el equipo y en su dirección a lo largo de los años, por lo que no se le ha podido dar sostenibilidad y continuidad a los planes de comunicación propuestos.

- Existen canales de comunicación que no son administrados por el área de C.I.

Canales:

$\checkmark$ Oficiales:

- Intranet.

- Mailing.

$\checkmark$ Extraoficiales (se desconoce la cantidad de grupos y no hay control sobre la información que se transmite en ellos):

- Grupos cerrados en Facebook

- Grupos en WhatsApp

\section{d. De la comunicación externa}

- La comunicación externa es trabajada por el área de Comunicaciones.

- No cuentan con un área interna especializada en Relaciones Públicas.

- No trabajan con una agencia de Relaciones Públicas.

- No hay una relación cercana con los medios de comunicación.

- La compañía no cuenta con voceros identificados para representar a la empresa frente a los medios.

- Ninguno de los directivos de la empresa ha llevado un entrenamiento de vocería.

- El gabinete de crisis estuvo constituido por 7 miembros desde hace 8 años. Actualmente, 6 de ellos son nuevos y desconocen su rol y función en él.

- El Manual de Crisis es un documento desconocido por el gabinete de crisis.

Canales:

- Fanpage en Facebook

- Twitter

- Instagram

- LinkedIn.

- Página web: tienda virtual a través de la cual se realizan ventas de boletos principalmente. 
App: se dan alertas de asientos vacíos en los vuelos programados en las siguientes 48 horas, donde los viajeros pueden obtener un mayor descuento en viajes muy próximos.

\section{e. De la Responsabilidad Social Empresarial}

Desde el inicio de sus operaciones, Viaje Lindos Airlines se enfoca en trabajar acciones de Sostenibilidad desde el área de Responsabilidad Social enfocándose en el impacto hacia el pilar "Medio Ambiente".

\section{Acciones externas:}

- Viaje Lindo cuenta con una flota moderna que permite reducir las turbulencias del aire y el combustible. Sumado a ello, desde 2016, se comenzó a utilizar biocombustible logrando que los vuelos sean más eficientes y la reducción emisiones de $\mathrm{CO}_{2}$ sea significativa.

- Por tercer año consecutivo, Viaje Lindos reafirma su compromiso con el medio ambiente presentando su reporte de sostenibilidad bajo el estándar GRI, uno de los más importantes a nivel internacional. En este reporte se detalla y transparenta el impacto económico, ambiental y social de la aerolínea a todos sus grupos de interés.

- Dentro de estos servicios, Viajes Lindos Airlines, mediante su App se brinda alertas de asientos vacíos en los vuelos programados en las siguientes 48 horas, de tal manera que la empresa no pierde el valor del asiento vacío.

- Todas estas acciones han sumado a la reputación de Viaje Lindos, que se vio reflejado en la entrega de diversos premios y reconocimientos.

- En sus planes de proyección tienen previsto realizar más intervenciones sobre el medio ambiente a nivel externo.

Acciones internas:

- Los colaboradores cuentan con una cultura participativa de aporte al medio ambiente por un tema de compromiso con la sociedad, no por indicaciones de la compañía.

- La empresa ha recibido diversos premios y reconocimientos por sus campañas de sensibilidad ambiental a nivel interno. 


\section{Mapeo de Stakeholders}

Como diagnóstico realizamos un mapeo de stakeholders para poder conocer a detalle todos nuestros grupos de interés:

Tabla 1.6

\begin{tabular}{|c|c|}
\hline Grupo de interés & Rol, impactos y expectativas de la compañía \\
\hline \multicolumn{2}{|r|}{ Primarios } \\
\hline Empleados & $\begin{array}{l}\text { - No hay una gestión de clima laboral. } \\
\text { - Hay una sobrecarga laboral en la compañía. } \\
\text { - No hay programas de reconocimiento ni } \\
\text { incentivos para ellos. } \\
\text { - No cuentan con canales de comunicación donde } \\
\text { puedan compartir experiencias. } \\
\text { - Se percibe una cultura de aporte al medio } \\
\text { ambiente porque sienten que es realmente } \\
\text { importante para la sociedad, no por indicación de } \\
\text { la compañía. }\end{array}$ \\
\hline Clientes & $\begin{array}{l}\text { - Son conscientes de los precios y buscan un } \\
\text { producto de calidad a un precio más bajo. } \\
\text { - Posicionan a la aerolínea bajo } 3 \text { atributos: } \\
\text { seguridad, cuidado y puntualidad. } \\
\text { - Los reconocen como una empresa socialmente } \\
\text { responsable por los premios y reconocimientos } \\
\text { que han obtenido por sus prácticas en favor al } \\
\text { medio ambiente. }\end{array}$ \\
\hline $\begin{array}{c}\text { Dirección General de } \\
\text { Aeronáutica Civil (DGAC) }\end{array}$ & 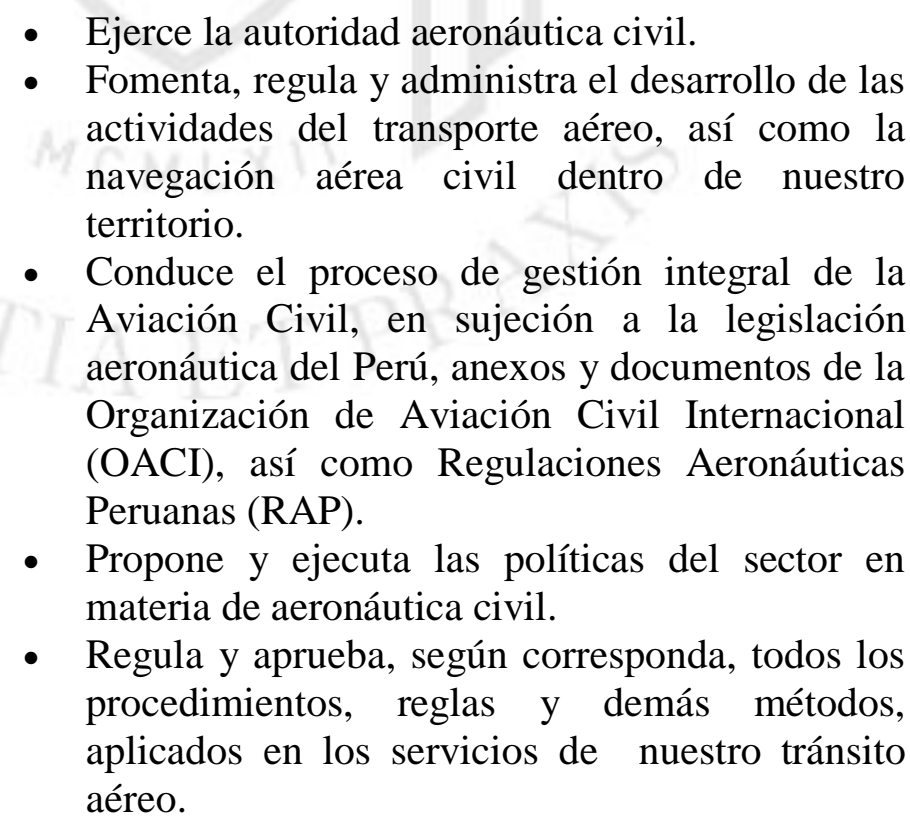 \\
\hline
\end{tabular}




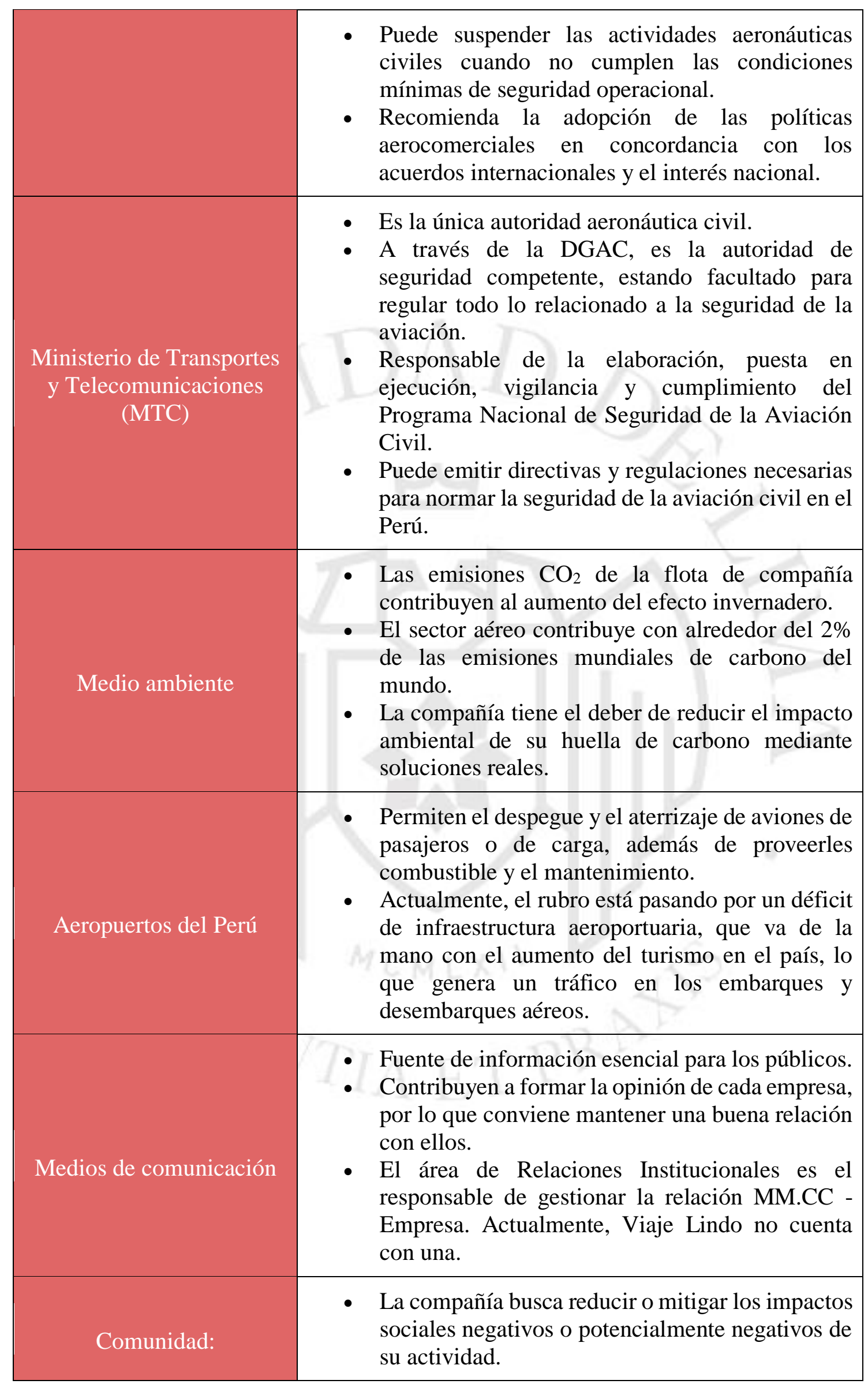




\begin{tabular}{|c|c|}
\hline $\begin{array}{l}\text { Vecinos de los } \\
\text { aeropuertos donde } \\
\text { radica Viaje Lindo } \\
\text { Airlines. }\end{array}$ & $\begin{array}{l}\text { - Con campañas de Responsabilidad Social se } \\
\text { pretende impactar positivamente a los vecinos y } \\
\text { comunidades cercanas a los aeropuertos en donde } \\
\text { se radica la compañía. } \\
\text { - La comunidad espera ser incluida en los procesos } \\
\text { de planificación estratégica de las empresas. }\end{array}$ \\
\hline Accionistas & $\begin{array}{l}\text { - Buscan maximización de su riqueza: liquidez en } \\
\text { su inversión, solvencia de la empresa, y } \\
\text { rentabilidad a corto y largo plazo. } \\
\text { - La empresa vela por su salud financiera y por } \\
\text { aumentar sus ganancias año a año para satisfacer } \\
\text { los intereses de los accionistas. } \\
\text { - Deben estar informados de los cambios de } \\
\text { envergadura de la compañía como: el mercado, } \\
\text { ganancias, pérdidas, cambios en la directiva, } \\
\text { crisis económicas, etc. }\end{array}$ \\
\hline Proveedores & $\begin{array}{l}\text { - Brindan los materiales y mantenimientos con los } \\
\text { más altos estándares de calidad para que las } \\
\text { operaciones de la aerolínea cumplan las } \\
\text { expectativas de los clientes. } \\
\text { - Un buen relacionamiento entre ambas partes. } \\
\text { - Pagos realizados en las fechas pactadas por } \\
\text { ambas partes. }\end{array}$ \\
\hline \multicolumn{2}{|r|}{ Secundarios } \\
\hline Gobierno & $\begin{array}{l}\text { - Presentar proyectos de leyes para el sector } \\
\text { aeronáutico. } \\
\text { - Tiene un rol de subsidiario. } \\
\text { - Ha logrado concesionar una gran parte de los } \\
\text { aeropuertos, lo cual ha permitido un incremento } \\
\text { en el número de pasajeros y cargas; sin embargo, } \\
\text { aún hace falta un mayor impulso e inversión para } \\
\text { competir con los países de la región }\end{array}$ \\
\hline $\begin{array}{l}\text { Competidores: } \\
\text { - Sky Airlines } \\
\text { - Viva Air } \\
\text { - Peruvian Airlines } \\
\text { - Latam Airlines }\end{array}$ & $\begin{array}{l}\text { - La compañía se ha posicionado en el mercado } \\
\text { bajo los atributos "puntualidad, seguridad y bajo } \\
\text { costo", lo que le ha permitido tener un factor } \\
\text { diferencial ante la competencia. } \\
\text { - Actualmente el entorno muestra un alto nivel de } \\
\text { competitividad y la llegada de nuevas aerolíneas } \\
\text { low cost. } \\
\text { - Actualmente, en el Perú existen } 9 \text { aerolíneas que } \\
\text { realizan vuelos nacionales, } 21 \text { que realizan vuelos } \\
\text { internacionales y } 3 \text { que realizan exclusivamente } \\
\text { el servicio de carga. }\end{array}$ \\
\hline
\end{tabular}




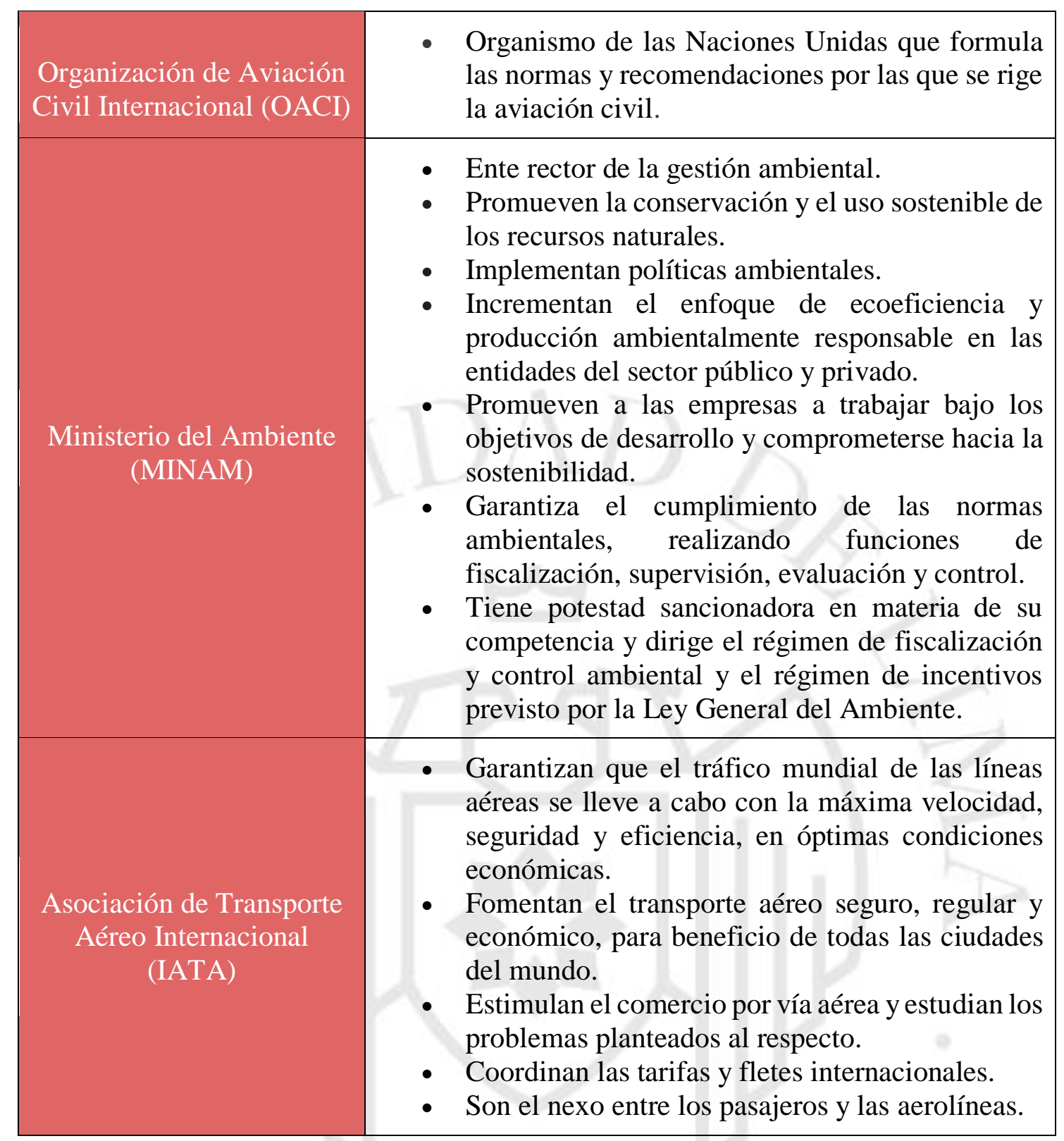

\section{FODA}

Para conocer los puntos débiles y oportunidades de mejora de la aerolínea, utilizaremos el FODA cruzado. Esta herramienta nos ayudará a conocer la situación actual de la empresa y, en base a ello, planear objetivos a corto, mediano y largo plazo.

\section{Tabla 1.7}




\section{Fortalezas}

F1. Experiencia en el sector de transporte aéreo peruano frente a las nuevas aerolíneas low cost (23 años).

F2. La empresa ha venido creciendo y expandiéndose en el número de aeronaves y de destinos a nivel nacional.

F3. Su promesa de marca "Seguridad y puntualidad a un mejor precio" lo ha posicionado en el mercado y le ha permitido tener un factor diferencial ante la competencia.

F4. Considerada como una compañía responsable con el medio ambiente por sus acciones de RSE que han recibido reconocimientos y distintivos.

F5. Utiliza canales de comunicación diversos, actualizados y acordes a su público externo: App, redes sociales y página web.

F6. Calificada como la aerolínea con menos retraso de atención en minutos a nivel nacional.

\section{Debilidades}

D1. Clima de descontento. No se han realizado acciones en beneficio a los colaboradores.

D2. Limitado control en los canales de comunicación internos.

D3. Alta rotación en el área de Comunicaciones.

D4. Directivos sin experiencia en manejo de equipos de trabajo, ni conocimiento en el manejo de crisis.

D5. Se desconoce la existencia de un plan de crisis.

D6. Sobrecarga laboral en los colaboradores.

D7. No existe un flujo de comunicación entre áreas. 
Oportunidades

01. Crecimiento en el sector con un estimado de $8.7 \%$ para el 2019 .

O2. Alta competitividad en el mercado por la entrada del formato low cost al país.

03. Crecimiento de la

generación millennial: Segmento que tiene, entre sus principales, actividades viajar.

04. Crecimiento del turismo en el país: tasas de crecimiento

cercanas al $10 \%$ y generación de divisas por US\$5.322 millones.

05. Apertura de nuevos canales de venta por medio de la digitalización.

O6. Implementación de nuevas rutas a nivel nacional.

\section{Estrategias FO (Fortalezas + Oportunidades)}

F4 + O3 + O4 + O5: Implementación de programas de Sostenibilidad que involucren a los clientes.

F3 + F6 + O2 + O5: Enfatizar los atributos "seguridad y puntualidad" en la imagen institucional, valores y promesa de marca.

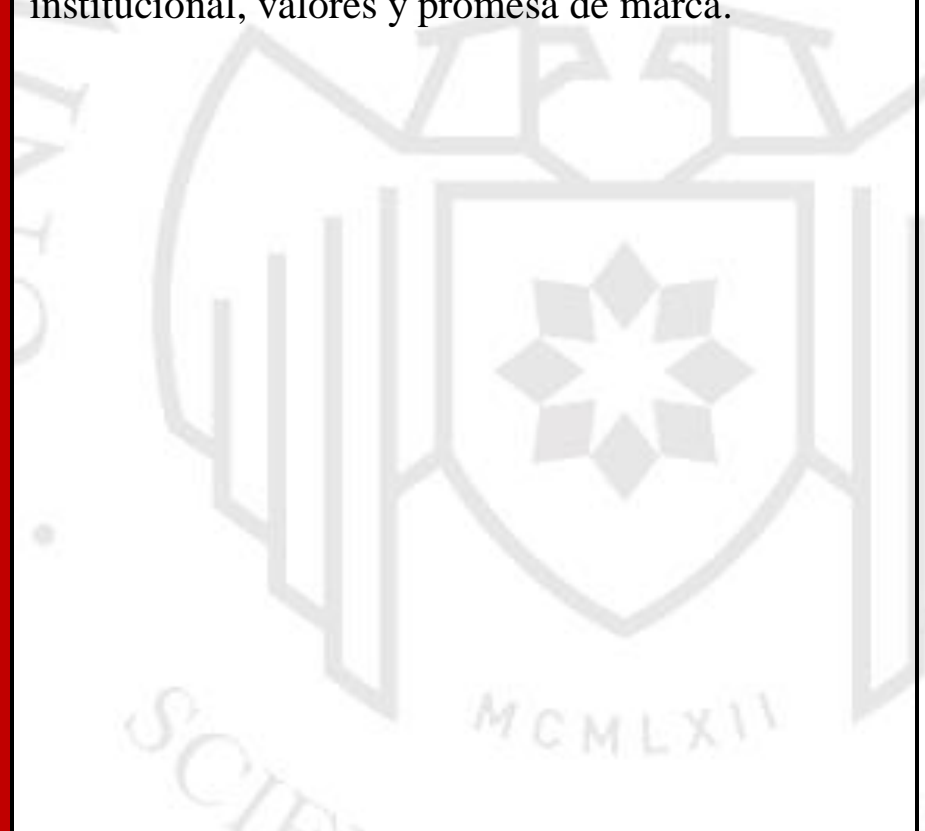

\section{Estrategias DO (Debilidades + Oportunidades)}

D1 + D6 + D3 + 01: Realizar una encuesta de clima laboral para conocer la situación interna actual de la empresa y poder gestionar programas en beneficio los colaboradores, a partir de los resultados hallados.

D1 + O1 + O2: Implementar estrategias de comunicación que permitan promover una cultura de orgullo a los colaboradores bajo los atributos

"seguridad y puntualidad".

D1 + D4 + 01: Fortalecer el liderazgo de nuestros líderes para promover un buen clima laboral. 
Amenazas

A1. Entrada de nuevos

competidores al mercado.

A2. Guerra de precios entre las aerolíneas.

A3. Gran demanda de

conexiones aéreas pueden llegar

a saturar los espacios del

aeropuerto y paralizar el

crecimiento de las aerolíneas.

A4. El mercado es dominado por un solo operador con un $58.2 \%$.

A5. Factores climáticos que afectan las operaciones de las aerolíneas.

A6. Variabilidad de la demanda.

\section{Estrategias FA (Fortalezas + Amenazas)}

F4 + A1 + A2: Posicionarnos como una empresa socialmente responsable frente a los nuevos competidores.

A1 + A2 + F4 + F6: Implementar una estrategia de diferenciación con las nuevas aerolíneas low cost por medio de nuestros canales de comunicación enfocándonos en que somos la aerolínea con menos retrasos y socialmente responsables.

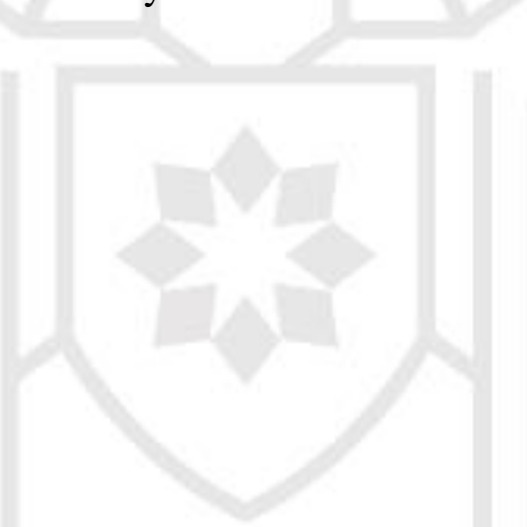

\section{$\underline{\text { Estrategias DA (Debilidades + Amenazas) }}$}

D4 + A1: Creación de un área de Asuntos

Corporativos que vele por la imagen y reputación de la empresa

D4 + D5 + A3 +A5: Implementación de un programa de manejo de crisis: Actualización del manual de crisis y renovación del comité de crisis.

D1 + D6 + A1: Implementación de programas de RSE y voluntariado con los colaboradores. 


\section{PROPUESTA DE COMUNICACIÓN}

En primera instancia, buscamos afrontar y resolver de manera rápida y eficaz las dificultades que en este momento afronta la empresa, mediante un plan de control de daños, a partir del día 2 (lunes 10 de junio). Dentro de esta propuesta, estamos considerando a los grupos de interés prioritarios afectados para plantear un objetivo con cada uno. En base a ello, realizaremos un cuadro de acciones e identificaremos qué stakeholders pueden ser nuestros frentes para evitar riesgos mayores que puedan agravar la crisis.

\section{Tabla 1.8}

\begin{tabular}{|c|c|}
\hline \multicolumn{2}{|c|}{ Objetivo general } \\
\hline \multicolumn{2}{|c|}{$\begin{array}{l}\text { Resguardar la reputación y continuidad de la compañía, protegiendo su imagen frente a } \\
\text { todos los grupos de interés, durante la crisis del accidente aéreo n }{ }^{\circ} 335 \text {. }\end{array}$} \\
\hline \multicolumn{2}{|c|}{ Objetivos específicos } \\
\hline Identificar un equipo de crisis & Atención hacia los stakeholders \\
\hline $\begin{array}{c}\text { Reorganizar, durante la crisis del accidente } \\
\text { aéreo } \mathrm{n}^{\circ} 335 \text {, un nuevo comité de crisis } \\
\text { provisional, delimitando las funciones y } \\
\text { responsabilidad que le compete a cada uno } \\
\text { de los miembros mediante un plan de } \\
\text { trabajo. }\end{array}$ & $\begin{array}{l}\text { Mantener a todos los grupos de interés, } \\
\text { implicados en el accidente, } \\
\text { constantemente informados de los } \\
\text { pasos que tomará la compañía desde el } \\
\text { primer día del accidente hasta el } \\
\text { término de su investigación. }\end{array}$ \\
\hline
\end{tabular}

Identificamos a los stakeholders implicados en el accidente para poder diagnosticar su situación frente a la crisis:

Tabla 1.9

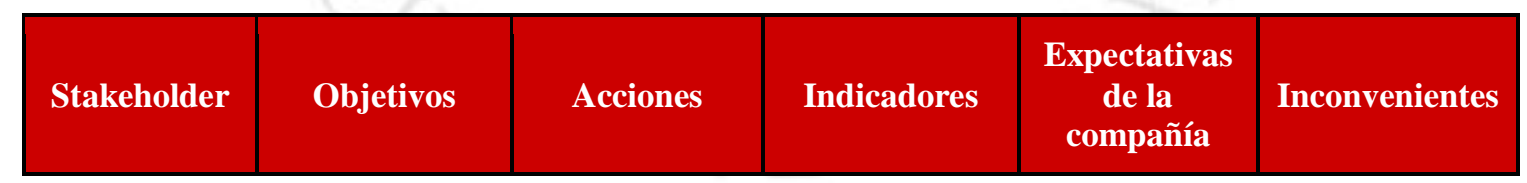




\begin{tabular}{|c|c|c|c|c|c|}
\hline Familiares & $\begin{array}{l}\text { - Mostrar una } \\
\text { postura de } \\
\text { sensibilización y } \\
\text { soporte a los } \\
\text { familiares de las } \\
\text { víctimas del } \\
\text { accidente. } \\
\text { - Atender lo más } \\
\text { pronto posible, al } \\
\text { 100\% de familias } \\
\text { afectadas } \\
\text { - Mantenerlos } \\
\text { informados el } \\
\text { estado sobre su } \\
\text { familiar. }\end{array}$ & $\begin{array}{l}\text { - Llamar a todos } \\
\text { los familiares de } \\
\text { los pasajeros. } \\
\text { - Abrir un } \\
\text { espacio en la } \\
\text { web con el } \\
\text { nombre de los } \\
\text { fallecidos y } \\
\text { accidentados. } \\
\text { - Abrir un centro } \\
\text { de atención } \\
\text { presencial en } \\
\text { Lima y } \\
\text { Arequipa. } \\
\text { - Abrir una línea } \\
\text { de atención de } \\
\text { call center } \\
\text { especializada en } \\
\text { derivar a los } \\
\text { familiares con el } \\
\text { área social de la } \\
\text { empresa. } \\
\text { - Indemnizar a } \\
\text { las familias. } \\
\text { - Cubrir costos } \\
\text { de viaje de las } \\
\text { familias a la } \\
\text { ciudad de } \\
\text { Arequipa. } \\
\text { - Homenaje a los } \\
\text { accidentados: } \\
\text { cambiar el logo } \\
\text { de la compañía. } \\
\text { - Enviar } \\
\text { constantes } \\
\text { comunicados } \\
\text { sobre el } \\
\text { accidente: \# de } \\
\text { heridos, \# de } \\
\text { personas a salvo, } \\
\text { \# de fallecidos. }\end{array}$ & $\begin{array}{l}\text { •\# de llamadas } \\
\text { recibidas por } \\
\text { familiares. } \\
\text { •\# de atenciones } \\
\text { de familiares al } \\
\text { centro de } \\
\text { atención } \\
\text { presencial. } \\
\text { •\# de demandas } \\
\text { y/o denuncias. } \\
\text {-\# de personal } \\
\text { recuperado vs. \# } \\
\text { de pasajeros } \\
\text { heridos. } \\
\text {-\# de viajes de } \\
\text { familiares hacia } \\
\text { Arequipa. } \\
\text { • Costo de } \\
\text { indemnizaciones. } \\
\text { - Costo de } \\
\text { sepelios. }\end{array}$ & $\begin{array}{l}100 \% \text { de los } \\
\text { familiares } \\
\text { recurran a la } \\
\text { compañía como } \\
\text { principal canal } \\
\text { de ayuda. }\end{array}$ & $\begin{array}{l}\text { Familiares } \\
\text { denuncian y/o } \\
\text { demandan a la } \\
\text { empresa. }\end{array}$ \\
\hline Colaboradores & $\begin{array}{l}\text { Mantenerlos } \\
\text { informados sobre } \\
\text { las acciones que } \\
\text { realiza la } \\
\text { empresa. }\end{array}$ & $\begin{array}{l}\text { - Reuniones de } \\
\text { todas las áreas } \\
\text { para aclarar el } \\
\text { momento que } \\
\text { pasa la } \\
\text { compañía. } \\
\text { - Salida de } \\
\text { comunicados } \\
\text { internos. } \\
\text { - Atención a los } \\
\text { colaboradores } \\
\text { afectados por el } \\
\text { accidente por } \\
\text { área de trabajo } \\
\text { social }\end{array}$ & $\begin{array}{l}\text {-\# de reuniones } \\
\text { internas. } \\
\text { •\# de } \\
\text { comunicados } \\
\text { enviados. } \\
\text {-\# de atenciones } \\
\text { a colaboradores } \\
\text { registrados por el } \\
\text { área de trabajo } \\
\text { social. }\end{array}$ & $\begin{array}{l}\text { Transmitir } \\
\text { correctamente } \\
\text { la información } \\
\text { del suceso: que } \\
\text { sean voceros } \\
\text { internos de la } \\
\text { compañía. }\end{array}$ & $\begin{array}{l}\text { Filtrar } \\
\text { información } \\
\text { hacia el público } \\
\text { que no esté } \\
\text { alineada a la } \\
\text { postura de la } \\
\text { empresa. }\end{array}$ \\
\hline
\end{tabular}




\begin{tabular}{|c|c|c|c|c|c|}
\hline $\begin{array}{l}\text { Medios de } \\
\text { comunicación }\end{array}$ & $\begin{array}{l}\text { Convertir a los } \\
\text { medios de } \\
\text { comunicación en } \\
\text { aliados. }\end{array}$ & $\begin{array}{l}\text { - Envío de } \\
\text { comunicados. } \\
\text { - } \\
\text { Relacionamiento } \\
\text { con medios de } \\
\text { comunicación. }\end{array}$ & $\begin{array}{l}\text { •\# de } \\
\text { comunicados } \\
\text { enviados. } \\
\text { •\# de } \\
\text { conferencias de } \\
\text { prensa. } \\
\text { •\# de } \\
\text { entrevistas. } \\
\text { - Impacto PR de } \\
\text { las notas de } \\
\text { prensa de la } \\
\text { compañía. } \\
\text { - Alcance de las } \\
\text { notas de prensa } \\
\text { de la compañía. } \\
\text { - Sentimiento de } \\
\text { las notas de } \\
\text { prensa de la } \\
\text { compañía. }\end{array}$ & $\begin{array}{l}\text { Trabajar de la } \\
\text { mano con los } \\
\text { medios de } \\
\text { comunicación } \\
\text { para llegar a } \\
\text { todos los } \\
\text { familiares } \\
\text { afectados. }\end{array}$ & $\begin{array}{l}\text { Incrementar las } \\
\text { especulaciones y } \\
\text { malos } \\
\text { comentarios } \\
\text { hacia la empresa. }\end{array}$ \\
\hline Boeing & $\begin{array}{l}\text { Mantenernos en } \\
\text { constante } \\
\text { comunicación } \\
\text { con la compañía } \\
\text { a fin de } \\
\text { esclarecer más y } \\
\text { mejor los hechos }\end{array}$ & $\begin{array}{l}\text { - Reuniones de } \\
\text { los directivos de } \\
\text { ambas } \\
\text { compañías. }\end{array}$ & - \# de reuniones. & $\begin{array}{l}\text { Contar con su } \\
\text { apoyo para } \\
\text { poder enfrentar } \\
\text { juntos la crisis }\end{array}$ & $\begin{array}{l}\text { Mala relación } \\
\text { entre ambas } \\
\text { compañías que } \\
\text { alargue más la } \\
\text { crisis. }\end{array}$ \\
\hline Clientes & $\begin{array}{l}\text { Asegurar la } \\
\text { integridad de } \\
\text { nuestros clientes. }\end{array}$ & $\begin{array}{l}\text { - Cancelar todos } \\
\text { los vuelos del } \\
\text { modelo Boeing } \\
737-300 .\end{array}$ & $\begin{array}{l}\text { - \# de vuelos } \\
\text { cancelados. }\end{array}$ & $\begin{array}{l}\text { Que nos } \\
\text { perciban como } \\
\text { una empresa } \\
\text { preocupada por } \\
\text { sus clientes. }\end{array}$ & $\begin{array}{l}\text { Que no quisieran } \\
\text { viajar con } \\
\text { nosotros por } \\
\text { desconfianza. } \\
\text { Que no crean en } \\
\text { nuestra promesa } \\
\text { de marca. }\end{array}$ \\
\hline Autoridades & $\begin{array}{l}\text { Apoyar en la } \\
\text { investigación del } \\
\text { accidente }\end{array}$ & $\begin{array}{l}\text { - Brindarles } \\
\text { toda la } \\
\text { información } \\
\text { respecto al } \\
\text { vuelo. } \\
\text { - Darles acceso } \\
\text { a las oficinas de } \\
\text { Viaje Lindo } \\
\text { Airlines. }\end{array}$ & $\begin{array}{l}\text { - \# de informes. } \\
\text { - \# de reuniones. }\end{array}$ & $\begin{array}{l}\text { Mantener } \\
\text { buenas } \\
\text { relaciones con } \\
\text { las autoridades } \\
\text { para acelerar las } \\
\text { investigaciones. }\end{array}$ & $\begin{array}{l}\text { Prohibir la } \\
\text { operación de la } \\
\text { aerolínea. }\end{array}$ \\
\hline
\end{tabular}

\section{Plan de acción}

\section{a. Crisis}

Dividimos nuestro Plan de Acción en tres etapas de acuerdo con los avances de la investigación del accidente. En cada fase desarrollaremos una estrategia adecuada para poder hacer frente a la crisis. Cada una marca un antes y un después en la exposición de la compañía frente a la opinión pública: 


\section{Fase crítica:}

- Inicia: Con el accidente y su investigación.

- Termina: 1 semana después del accidente (aproximadamente)

\section{- Fase de tensión:}

- Inicia: 1 semana después del accidente.

- Termina: Los resultados de la investigación del accidente.

\section{- Fase de crítica:}

- Inicia: Se conocen los resultados de la investigación del accidente.

- Termina: La respuesta de la compañía.

\section{Crisis vuelo 335}

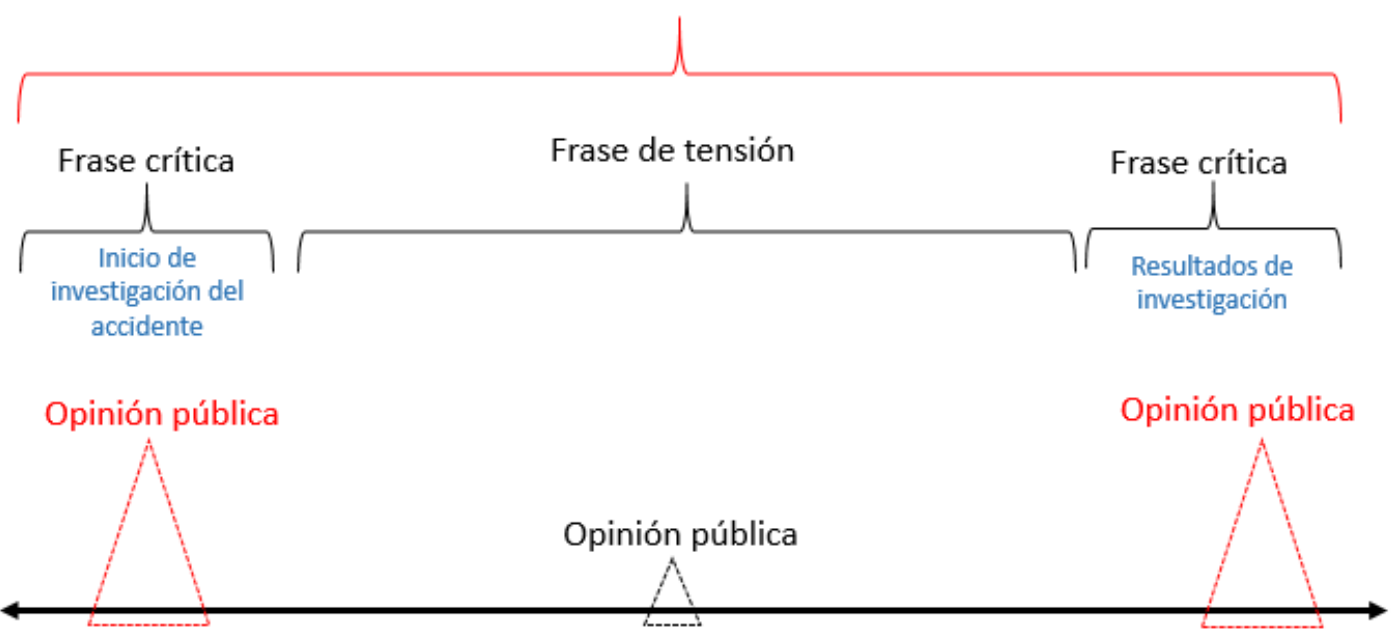

Accidente

\begin{tabular}{l} 
Característica \\
\hline Duración: 1 semana aproximadamente. \\
- El accidente es el centro de la \\
opinión pública. \\
- La compañia toma una posición \\
proactiva. \\
Menciones diarias en medios de \\
comunicación y redes sociales \\
- La compañia es tendencia en redes \\
sociales.
\end{tabular}

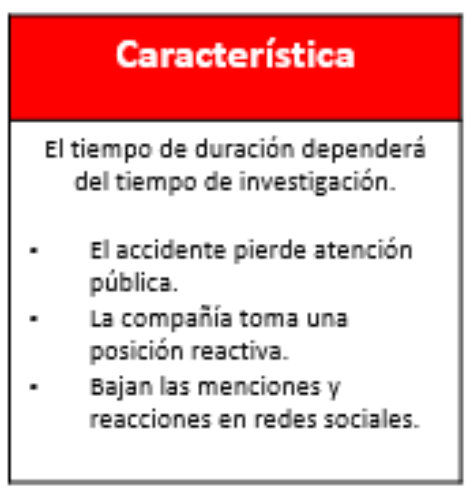

\section{Característica}

Duración: 3 dias aproximadamente, dependiendo de las reacciones de los involucrados.

El accidente es el centro de la opinión pública, nuevamente.

- La compañía toma una posición proactiva.

- La compañía es el centro de la opinión pública y tendencia en redes sociales.

A continuación, se especificará las acciones concretas para cada fase: 


\section{i. Fase crítica}

Tabla 1.10

\begin{tabular}{|c|c|c|c|c|c|c|}
\hline \multicolumn{7}{|c|}{ 1er día } \\
\hline Día & Hora & Acción & Descripción & Stakeholder & Responsable & $\begin{array}{c}\text { Miembro } \\
\text { del comité } \\
\text { supervisor } \\
\text { de la } \\
\text { acción }\end{array}$ \\
\hline \multirow{2}{*}{ 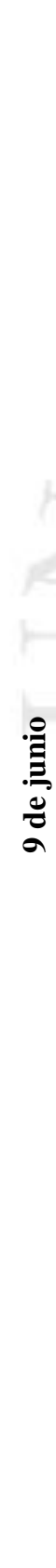 } & $\begin{array}{l}7: 30 \\
\text { p.m. }\end{array}$ & $\begin{array}{c}\text { Lanzamiento } \\
\text { de } \\
\text { comunicado } \\
\text { oficial }\end{array}$ & $\begin{array}{l}\text { Se lanzó } 7 \text { horas } \\
\text { después del } \\
\text { accidente. } \\
\text { Es el primer canal } \\
\text { por el que la } \\
\text { empresa da la } \\
\text { cara después del } \\
\text { accidente. } \\
\text { No emite ningún } \\
\text { mensaje de } \\
\text { lamento, empatía } \\
\text { con los familiares } \\
\text { y acciones } \\
\text { tomadas con } \\
\text { ellos. } \\
\text { Se centra solo en } \\
\text { culpar a } \\
\text { "Boeing". }\end{array}$ & $\begin{array}{c}\text { Medios de } \\
\text { Comunicación }\end{array}$ & $\begin{array}{c}\text { Gerencia de } \\
\text { Comunicaciones }\end{array}$ & $\begin{array}{c}\text { No existía } \\
\text { comité de } \\
\text { crisis }\end{array}$ \\
\hline & $\begin{array}{l}8: 30 \\
\text { p.m. }\end{array}$ & $\begin{array}{c}\text { Conferencia } \\
\text { de prensa }\end{array}$ & $\begin{array}{l}\text { Se realizó } 8 \text { horas } \\
\text { después del } \\
\text { accidente. } \\
\text { Se realizó en hora } \\
\text { punta: muchos } \\
\text { noticieros } \\
\text { emitieron en vivo } \\
\text { la conferencia. } \\
\text { El vocero (CEO) } \\
\text { no conocía a } \\
\text { fondo los detalles } \\
\text { del accidente. } \\
\text { El vocero no } \\
\text { había llevado } \\
\text { entrenamiento de } \\
\text { vocería. }\end{array}$ & $\begin{array}{c}\text { Medios de } \\
\text { Comunicación }\end{array}$ & $\begin{array}{c}\text { Gerencia de } \\
\text { Comunicaciones }\end{array}$ & $\begin{array}{l}\text { No existía } \\
\text { comité de } \\
\text { crisis }\end{array}$ \\
\hline
\end{tabular}

A partir de este punto, se desarrollarán las nuevas acciones para afrontar esta crisis bajo el objetivo planteado. 
Tabla 1.11

\begin{tabular}{|c|c|c|c|c|c|c|}
\hline \multicolumn{7}{|c|}{ 2do día } \\
\hline Día & Hora & Acción & Descripción & $\begin{array}{l}\text { Stakeholde } \\
\text { r afectado }\end{array}$ & $\begin{array}{c}\text { Responsabl } \\
\text { e de la } \\
\text { acción }\end{array}$ & $\begin{array}{l}\text { Miembro } \\
\text { del comité } \\
\text { supervisor } \\
\text { de la } \\
\text { acción }\end{array}$ \\
\hline \multirow{4}{*}{ 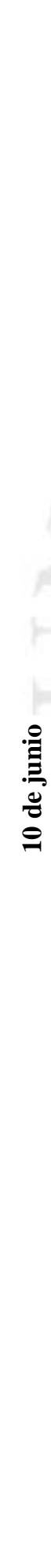 } & $\begin{array}{l}\text { 7:00- } \\
11: 00 \\
\text { am }\end{array}$ & $\begin{array}{l}\text { Reunión } \\
\text { de } \\
\text { Gabinete } \\
\text { de Crisis }\end{array}$ & $\begin{array}{l}\text { La Gerencia } \\
\text { de } \\
\text { Comunicaci } \\
\text { ones solicita } \\
\text { una reunión } \\
\text { de } \\
\text { emergencia } \\
\text { al CEO } \\
\text { junto con } \\
\text { los Gerentes } \\
\text { Centrales de } \\
\text { la empresa. } \\
\text { Aquí se } \\
\text { forma al } \\
\text { gabinete de } \\
\text { crisis actual } \\
\text { para } \\
\text { afrontar la } \\
\text { crisis. }\end{array}$ & $\begin{array}{c}\text { Colaborador } \\
\text { es }\end{array}$ & $\begin{array}{c}\text { Gerencia de } \\
\text { Comunicaci } \\
\text { ones }\end{array}$ & $\begin{array}{c}\text { Gerencia de } \\
\text { Comunicaci } \\
\text { ones }\end{array}$ \\
\hline & $\theta$ & $\begin{array}{l}\text { Flujo de } \\
\text { respuesta } \\
\text { s }\end{array}$ & $\begin{array}{l}\text { Se entrega } \\
\text { un flujo de } \\
\text { respuestas al } \\
\text { community } \\
\text { manager de } \\
\text { la compañía } \\
\text { como guía } \\
\text { para } \\
\text { responder } \\
\text { las quejas o } \\
\text { reclamos de } \\
\text { los clientes. }\end{array}$ & Clientes & $\begin{array}{c}\text { Gerencia de } \\
\text { Marketing }\end{array}$ & $\begin{array}{l}\text { Gerencia de } \\
\text { Comunicaci } \\
\text { ones }\end{array}$ \\
\hline & \multirow[t]{2}{*}{$\begin{array}{l}11: 30 \\
\text { am }\end{array}$} & $\begin{array}{l}\text { Impleme } \\
\text { ntación } \\
\text { del dark } \\
\text { site }\end{array}$ & $\begin{array}{l}\text { El equipo de } \\
\text { Comunicaci } \\
\text { ones solicita } \\
\text { colocar un } \\
\text { dark site en } \\
\text { la página } \\
\text { web. }\end{array}$ & $\begin{array}{l}\text { Familiares } \\
\text { de víctimas }\end{array}$ & $\begin{array}{c}\text { Canal } \\
\text { Online }\end{array}$ & $\begin{array}{l}\text { Gerencia de } \\
\text { Comunicaci } \\
\text { ones }\end{array}$ \\
\hline & & $\begin{array}{l}\text { Reunión } \\
\text { con el } \\
\text { área de } \\
\text { asistencia } \\
\text { social }\end{array}$ & $\begin{array}{l}\text { El Gerente } \\
\text { de Recursos } \\
\text { Humanos } \\
\text { alinea el } \\
\text { papel del } \\
\text { área de } \\
\text { Asistencia } \\
\text { Social frente } \\
\text { a los }\end{array}$ & $\begin{array}{c}\text { Familiares } \\
\text { de víctimas } \\
\text { y } \\
\text { colaborador } \\
\text { es de la } \\
\text { compañía }\end{array}$ & $\begin{array}{c}\text { Jefatura de } \\
\text { Personal }\end{array}$ & $\begin{array}{l}\text { Gerencia de } \\
\text { Recursos } \\
\text { Humanos }\end{array}$ \\
\hline
\end{tabular}




\begin{tabular}{|c|c|c|c|c|c|}
\hline & & $\begin{array}{l}\text { familiares } \\
\text { de los } \\
\text { afectados. }\end{array}$ & & & \\
\hline $\begin{array}{l}\text { 12:00 } \\
\mathrm{pm}\end{array}$ & $\begin{array}{l}\text { Reunión } \\
\text { de con } \\
\text { Gerentes }\end{array}$ & $\begin{array}{l}\text { Vocero } \\
\text { comunica } \\
\text { los hechos } \\
\text { del } \\
\text { accidente a } \\
\text { los Gerentes } \\
\text { de la } \\
\text { compañía. }\end{array}$ & $\begin{array}{c}\text { Colaborador } \\
\text { es }\end{array}$ & $\begin{array}{c}\text { Gerencia de } \\
\text { Comunicaci } \\
\text { ones }\end{array}$ & $\begin{array}{c}\text { Gerencia de } \\
\text { Recursos } \\
\text { Humanos y } \\
\text { Agencia de } \\
\text { Relaciones } \\
\text { Públicas }\end{array}$ \\
\hline $\begin{array}{c}12: 30 \\
\mathrm{pm}\end{array}$ & $\begin{array}{c}\text { Reunión } \\
\text { con jefes } \\
\text { de áreas } \\
\text { de } \\
\text { atención } \\
\text { al cliente }\end{array}$ & $\begin{array}{l}\text { Se } \\
\text { comunican } \\
\text { los hechos } \\
\text { del } \\
\text { accidente y } \\
\text { se entregan } \\
\text { los } \\
\text { statements a } \\
\text { decir por } \\
\text { asesores que } \\
\text { atienden al } \\
\text { público: } \\
\text { venta } \\
\text { presencial, } \\
\text { online y vía } \\
\text { telefónica. }\end{array}$ & $\begin{array}{l}\text { Áreas de } \\
\text { Atención al } \\
\text { cliente, } \\
\text { ventas, } \\
\text { online y call } \\
\text { center. }\end{array}$ & $\begin{array}{c}\text { Gerencia de } \\
\text { Comunicaci } \\
\quad \text { ones }\end{array}$ & $\begin{array}{c}\text { Gerencia de } \\
\text { Márketing }\end{array}$ \\
\hline $\begin{array}{l}12: 30 \\
\mathrm{pm}\end{array}$ & $\begin{array}{c}\text { Salida de } \\
\text { primer } \\
\text { comunica } \\
\text { do } \\
\text { interno }\end{array}$ & $\begin{array}{l}\text { Se emite un } \\
\text { comunicado } \\
\text { lamentando } \\
\text { lo sucedido } \\
\text { y de } \\
\text { homenaje a } \\
\text { los } \\
\text { colaborador } \\
\text { es fallecidos } \\
\text { en el vuelo. }\end{array}$ & $\begin{array}{c}\text { Colaborador } \\
\text { es }\end{array}$ & $\begin{array}{l}\text { Gerencia de } \\
\text { Comunicaci } \\
\text { ones }\end{array}$ & $\begin{array}{c} \\
\text { Gerencia de } \\
\text { Recursos } \\
\text { Humanos }\end{array}$ \\
\hline \multirow{2}{*}{$\begin{array}{c}12: 30 \\
\mathrm{pm}\end{array}$} & \multirow{2}{*}{$\begin{array}{c}\text { Acciones } \\
\text { de } \\
\text { contingen } \\
\text { cia } \\
\text { externas }\end{array}$} & $\begin{array}{l}\text { Se cambia } \\
\text { el logo de } \\
\text { todas las } \\
\text { redes } \\
\text { sociales. }\end{array}$ & Todos & $\begin{array}{c}\text { Área de } \\
\text { Canal Online }\end{array}$ & $\begin{array}{c}\text { Gerencia de } \\
\text { Marketing y } \\
\text { Agencia de } \\
\text { Relaciones } \\
\text { Públicas }\end{array}$ \\
\hline & & $\begin{array}{l}\text { Apertura de } \\
\text { oficinas de } \\
\text { atención a } \\
\text { familiares } \\
\text { en Lima y } \\
\text { Arequipa. }\end{array}$ & $\begin{array}{l}\text { Familiares } \\
\text { de víctimas }\end{array}$ & $\begin{array}{c}\text { Jefatura de } \\
\text { Personal }\end{array}$ & $\begin{array}{c}\text { Gerencia de } \\
\text { Recursos } \\
\text { Humanos }\end{array}$ \\
\hline
\end{tabular}




\begin{tabular}{|c|c|c|c|c|c|c|}
\hline & $\begin{array}{c}2: 00 \\
\mathrm{pm}\end{array}$ & & $\begin{array}{l}\text { Se realizan } \\
\text { las } \\
\text { reuniones } \\
\text { extraordinar } \\
\text { ias en toda } \\
\text { la } \\
\text { compañía. }\end{array}$ & $\begin{array}{c}\text { Colaborador } \\
\text { es }\end{array}$ & $\begin{array}{c}\text { Gerente / } \\
\text { Jefe de área }\end{array}$ & $\begin{array}{c}\text { Gerencia de } \\
\text { Recursos } \\
\text { Humanos }\end{array}$ \\
\hline & $\begin{array}{c}2: 00 \\
\mathrm{pm}\end{array}$ & $\begin{array}{l}\text { Envío de } \\
\text { comunica } \\
\text { do }\end{array}$ & $\begin{array}{l}\text { Se emite un } \\
\text { comunicado } \\
\text { público a la } \\
\text { prensa y se } \\
\text { sube a redes } \\
\text { sociales }\end{array}$ & Todos & $\begin{array}{l}\text { Área de } \\
\text { Canal } \\
\text { Online }\end{array}$ & $\begin{array}{c}\text { Gerencia de } \\
\text { Comunicaci } \\
\text { ones y } \\
\text { Agencia de } \\
\text { Relaciones } \\
\text { Públicas }\end{array}$ \\
\hline & 4:30pm & $\begin{array}{l} \\
\text { Para de } \\
\text { la flota } \\
\text { Boeing } \\
737-300\end{array}$ & $\begin{array}{l}\text { Se detiene } \\
\text { los } 15 \\
\text { aviones de } \\
\text { la flota } 737- \\
300 \text { hasta } \\
\text { que } \\
\text { finalicen las } \\
\text { investigacio } \\
\text { nes }\end{array}$ & Clientes & $\begin{array}{c}\text { Área de } \\
\text { Operacione } \\
\text { s }\end{array}$ & $\begin{array}{l}\text { Gerencia de } \\
\text { Marketing }\end{array}$ \\
\hline & $\begin{array}{c}5: 00 \\
\mathrm{pm}\end{array}$ & $\begin{array}{l}\text { Viaje de } \\
\text { vocero }\end{array}$ & $\begin{array}{l}\text { El CEO } \\
\text { acude al } \\
\text { lugar del } \\
\text { incidente } \\
\text { para } \\
\text { recaudar } \\
\text { información }\end{array}$ & dos & $\begin{array}{c}\text { Gerencia de } \\
\text { Comunicaci } \\
\text { ones }\end{array}$ & $\begin{array}{l}\text { Agencia de } \\
\text { Relaciones } \\
\text { Públicas }\end{array}$ \\
\hline & $\begin{array}{c}5: 00 \\
\mathrm{pm}\end{array}$ & $\begin{array}{l}\text { Cambio } \\
\text { de } \\
\text { horarios } \\
\text { y vuelos }\end{array}$ & $\begin{array}{l}\text { Se publica } \\
\text { un post en } \\
\text { RR. SS } \\
\text { anunciando } \\
\text { los cambios } \\
\text { de horarios } \\
\text { de algunos } \\
\text { vuelos. }\end{array}$ & Clientes & $\begin{array}{l}\text { Área de } \\
\text { Canal Online }\end{array}$ & $\begin{array}{c}\text { Gerencia de } \\
\text { Marketing }\end{array}$ \\
\hline \multicolumn{7}{|c|}{ 3er día } \\
\hline \multirow{2}{*}{ 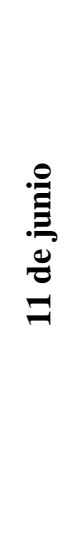 } & \multirow[t]{2}{*}{$\begin{array}{l}\text { 8:00 } \\
\mathrm{am}\end{array}$} & $\begin{array}{c}\text { Reunión } \\
\text { de } \\
\text { Gabinete } \\
\text { de Crisis }\end{array}$ & $\begin{array}{l}\text { Se comenta } \\
\mathrm{n} \text { los hechos } \\
\text { ocurridos en } \\
\text { las primeras } \\
48 \text { horas. }\end{array}$ & Todos & $\begin{array}{c}\text { Gerencia de } \\
\text { Comunicaci } \\
\text { ones }\end{array}$ & $\begin{array}{l}\text { Gerencia de } \\
\text { Comunicaci } \\
\text { ones }\end{array}$ \\
\hline & & $\begin{array}{l}\text { Dictamen } \\
\text { de } \\
\text { promesa } \\
\text { de marca }\end{array}$ & $\begin{array}{l}\text { Se } \\
\text { dictamina } \\
\text { eliminar la } \\
\text { oración de } \\
\text { la promesa } \\
\text { de marca } \\
\text { "Seguridad }\end{array}$ & Todos & $\begin{array}{c}\text { Gerencia de } \\
\text { Marketing }\end{array}$ & $\begin{array}{l}\text { Gerencia de } \\
\text { Marketing }\end{array}$ \\
\hline
\end{tabular}




\begin{tabular}{|c|c|c|c|c|c|c|}
\hline & & & $\begin{array}{l}\text { y } \\
\text { puntualidad } \\
\text { a un mejor } \\
\text { precio" de } \\
\text { toda } \\
\text { comunicaci } \\
\text { ón, tanto } \\
\text { interna } \\
\text { como } \\
\text { externa. }\end{array}$ & & & \\
\hline & $\begin{array}{l}\text { 9:00 } \\
\text { am }\end{array}$ & $\begin{array}{c}\text { Reunión } \\
\text { de con } \\
\text { Gerentes }\end{array}$ & $\begin{array}{l}\text { Vocero } \\
\text { comunica el } \\
\text { status del } \\
\text { accidente a } \\
\text { los Gerentes } \\
\text { de la } \\
\text { compañía. }\end{array}$ & $\begin{array}{c}\text { Colaborador } \\
\text { es }\end{array}$ & $\begin{array}{l}\text { Gerencia de } \\
\text { Comunicaci } \\
\text { ones }\end{array}$ & $\begin{array}{c}\text { Gerencia de } \\
\text { Recursos } \\
\text { Humanos y } \\
\text { Agencia de } \\
\text { Relaciones } \\
\text { Públicas }\end{array}$ \\
\hline & $\begin{array}{c}\text { 10:00 } \\
\text { am }\end{array}$ & $\begin{array}{l}\text { Reunione } \\
\mathbf{S} \\
\text { extraordi } \\
\text { narias }\end{array}$ & $\begin{array}{l}\text { Se realizan } \\
\text { las } \\
\text { reuniones } \\
\text { extraordinar } \\
\text { ias en toda } \\
\text { la } \\
\text { compañía. }\end{array}$ & $\begin{array}{c}\text { Colaborador } \\
\text { es }\end{array}$ & $\begin{array}{l}\text { Gerente / } \\
\text { jefe de área }\end{array}$ & $\begin{array}{l}\text { Gerencia de } \\
\text { Recursos } \\
\text { Humanos }\end{array}$ \\
\hline 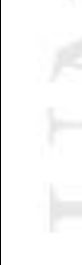 & $\begin{array}{l}\text { 10:30 } \\
\text { am }\end{array}$ & $\begin{array}{c}\text { Salida de } \\
\text { segundo } \\
\text { comunica } \\
\text { do } \\
\text { interno }\end{array}$ & $\begin{array}{l}\text { Se emite un } \\
\text { comunicado } \\
\text { contando la } \\
\text { situación de } \\
\text { la empresa. }\end{array}$ & $\begin{array}{c}\text { Colaborador } \\
\text { es }\end{array}$ & $\begin{array}{l}\text { Gerencia de } \\
\text { Comunicaci } \\
\text { ones }\end{array}$ & $\begin{array}{l}\text { Gerencia de } \\
\text { Recursos } \\
\text { Humanos }\end{array}$ \\
\hline & $\begin{array}{l}2: 00 \\
\mathrm{pm}\end{array}$ & $\begin{array}{c}\text { Envío de } \\
\text { comunica } \\
\text { do }\end{array}$ & $\begin{array}{l}\text { Se emite un } \\
2 \text { do } \\
\text { comunicado } \\
\text { público. }\end{array}$ & Todos & $\begin{array}{l}\text { Área de } \\
\text { Canal } \\
\text { Online }\end{array}$ & $\begin{array}{c}\text { Gerencia de } \\
\text { Comunicaci } \\
\text { ones y } \\
\text { Agencia de } \\
\text { Relaciones } \\
\text { Públicas }\end{array}$ \\
\hline \multicolumn{7}{|c|}{ 4to día } \\
\hline 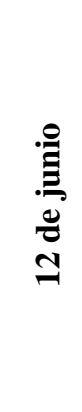 & $\begin{array}{l}\text { 9:00 } \\
\text { a.m. }\end{array}$ & $\begin{array}{c}\text { Reunión } \\
\text { con el } \\
\text { área de } \\
\text { Operacio } \\
\text { nes } \\
\text { (Pilotos y } \\
\text { tripulant } \\
\text { es de } \\
\text { cabina) }\end{array}$ & $\begin{array}{l}\text { Reforzar las } \\
\text { políticas de } \\
\text { seguridad } \\
\text { en las } \\
\text { operaciones } \\
\text { con los } \\
\text { pilotos y } \\
\text { tripulantes } \\
\text { de cabina. }\end{array}$ & Clientes & $\begin{array}{c}\text { Gerencia de } \\
\text { comunicaci } \\
\text { ones }\end{array}$ & $\begin{array}{l}\text { Gerencia de } \\
\text { RR. HH y } \\
\text { Gerencia de } \\
\text { Márketing }\end{array}$ \\
\hline
\end{tabular}




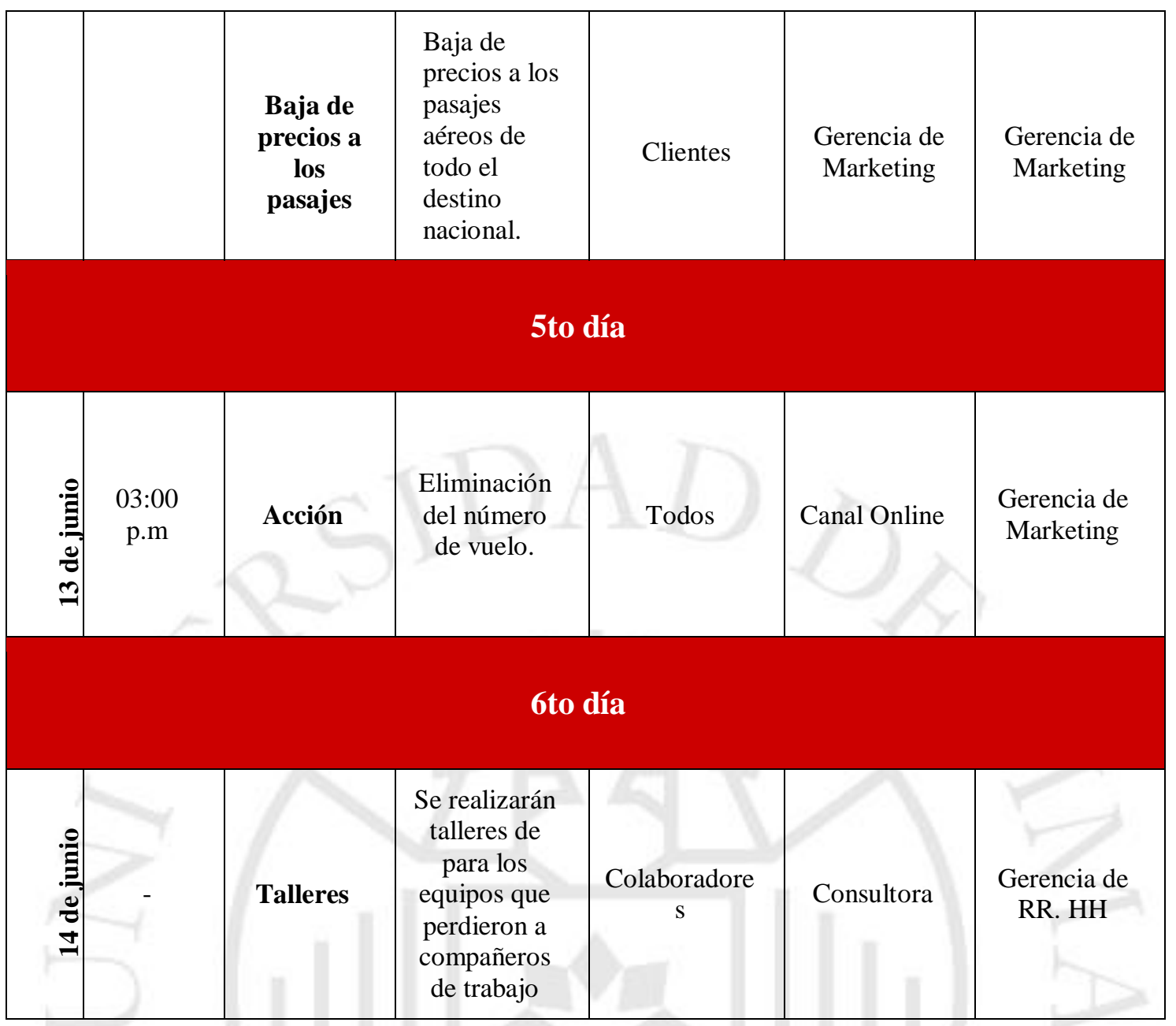

\section{ii. Fase de tensión}

Tabla 1.12

\begin{tabular}{|c|c|c|c|c|}
\hline Acción & Descripción & $\begin{array}{c}\text { Stakeholde } \\
\text { r afectado }\end{array}$ & $\begin{array}{c}\text { Responsable } \\
\text { de la acción }\end{array}$ & $\begin{array}{c}\text { Miembro del } \\
\text { comité } \\
\text { supervisor de } \\
\text { la acción }\end{array}$ \\
\hline $\begin{array}{c}\text { Relacionamient } \\
\text { o con Boeing }\end{array}$ & $\begin{array}{c}\text { Se mantiene } \\
\text { constante } \\
\text { comunicación con } \\
\text { la empresa Boeing: } \\
\text { Reuniones del CEO } \\
\text { con el presidente de } \\
\text { Boeing. }\end{array}$ & Boeing & $\begin{array}{c}\text { Gerencia de } \\
\text { Comunicacione } \\
\text { s }\end{array}$ & $\begin{array}{c}\text { Comunicacione } \\
\text { s y Agencia de } \\
\text { Relaciones } \\
\text { Públicas }\end{array}$ \\
\hline $\begin{array}{c}\text { Redacción de } \\
\text { nota de prensa }\end{array}$ & $\begin{array}{c}\text { Se redacta un } \\
\text { comunicado } \\
\text { explicando la razón } \\
\text { del accidente }\end{array}$ & Todos & $\begin{array}{c}\text { Gerencia de } \\
\text { Comunicacione } \\
\text { s }\end{array}$ & $\begin{array}{c}\text { Comunicacione } \\
\text { s y Agencia de } \\
\text { Relaciones } \\
\text { Públicas }\end{array}$ \\
\hline
\end{tabular}




\begin{tabular}{|c|c|c|c|c|}
\hline & $\begin{array}{c}\text { Comunicación a } \\
\text { Envío de } \\
\text { comunicado } \\
\text { sobre la situación } \\
\text { de la empresa }\end{array}$ & Proveedores & $\begin{array}{c}\text { Gerencia de } \\
\text { Comunicacione } \\
\mathrm{s}\end{array}$ & $\begin{array}{c}\text { Gerencia de } \\
\text { Recursos } \\
\text { Humano }\end{array}$ \\
\hline
\end{tabular}

\section{iii. $\quad$ Fase crítica}

Tabla 1.13

\begin{tabular}{|c|c|c|c|c|}
\hline Acción & Descripción & $\begin{array}{c}\text { Stakeholder } \\
\text { afectado }\end{array}$ & $\begin{array}{l}\text { Responsable } \\
\text { de la acción }\end{array}$ & $\begin{array}{l}\text { Miembro del } \\
\text { comité } \\
\text { supervisor de la } \\
\text { acción }\end{array}$ \\
\hline $\begin{array}{l}\text { Envío de } \\
\text { comunicado }\end{array}$ & $\begin{array}{c}\text { Se emite un } \\
\text { comunicado } \\
\text { público a la prensa. }\end{array}$ & t & $\begin{array}{c}\text { Área de } \\
\text { Canal Online }\end{array}$ & $\begin{array}{l}\text { Gerencia de } \\
\text { Comunicaciones y } \\
\text { Agencia de } \\
\text { Relaciones } \\
\text { Públicas }\end{array}$ \\
\hline $\begin{array}{l}\text { Comunicación } \\
\text { de blindaje }\end{array}$ & $\begin{array}{c}\text { Líderes de opinión } \\
\text { / aliados / expertos } \\
\text { en aeronáutica } \\
\text { comparten noticias } \\
\text { sobre el estado de } \\
\text { los accidentados o } \\
\text { afectados y de la } \\
\text { falla de los aviones } \\
\text { Boeing }\end{array}$ & $\begin{array}{l}\text { Medio de } \\
\text { comunicación }\end{array}$ & $\begin{array}{c}\text { Agencia de } \\
\text { Relaciones } \\
\text { Públicas }\end{array}$ & $\begin{array}{c}\text { Gerencia de } \\
\text { Comunicaciones }\end{array}$ \\
\hline $\begin{array}{c}\text { Evaluación de } \\
\text { la crisis }\end{array}$ & $\begin{array}{l}\text { Se realiza un } \\
\text { análisis de } \\
\text { reputación y } \\
\text { valoración de } \\
\text { marca }\end{array}$ & $\begin{array}{c}\text { Todos los } \\
\text { Stakeholders }\end{array}$ & $\begin{array}{l}\text { Gerencia de } \\
\text { Marketing }\end{array}$ & $\begin{array}{l}\text { Gerencia de } \\
\text { Marketing }\end{array}$ \\
\hline
\end{tabular}

b. Post - Crisis

Es importante resaltar que, luego de la crisis ocurrida en VLA, a corto plazo vamos a implementar herramientas y procedimientos que servirán, en adelante, para contener y mitigar los riesgos de la Compañía en caso de futuras crisis. Estas serán:

Tabla 1.14 


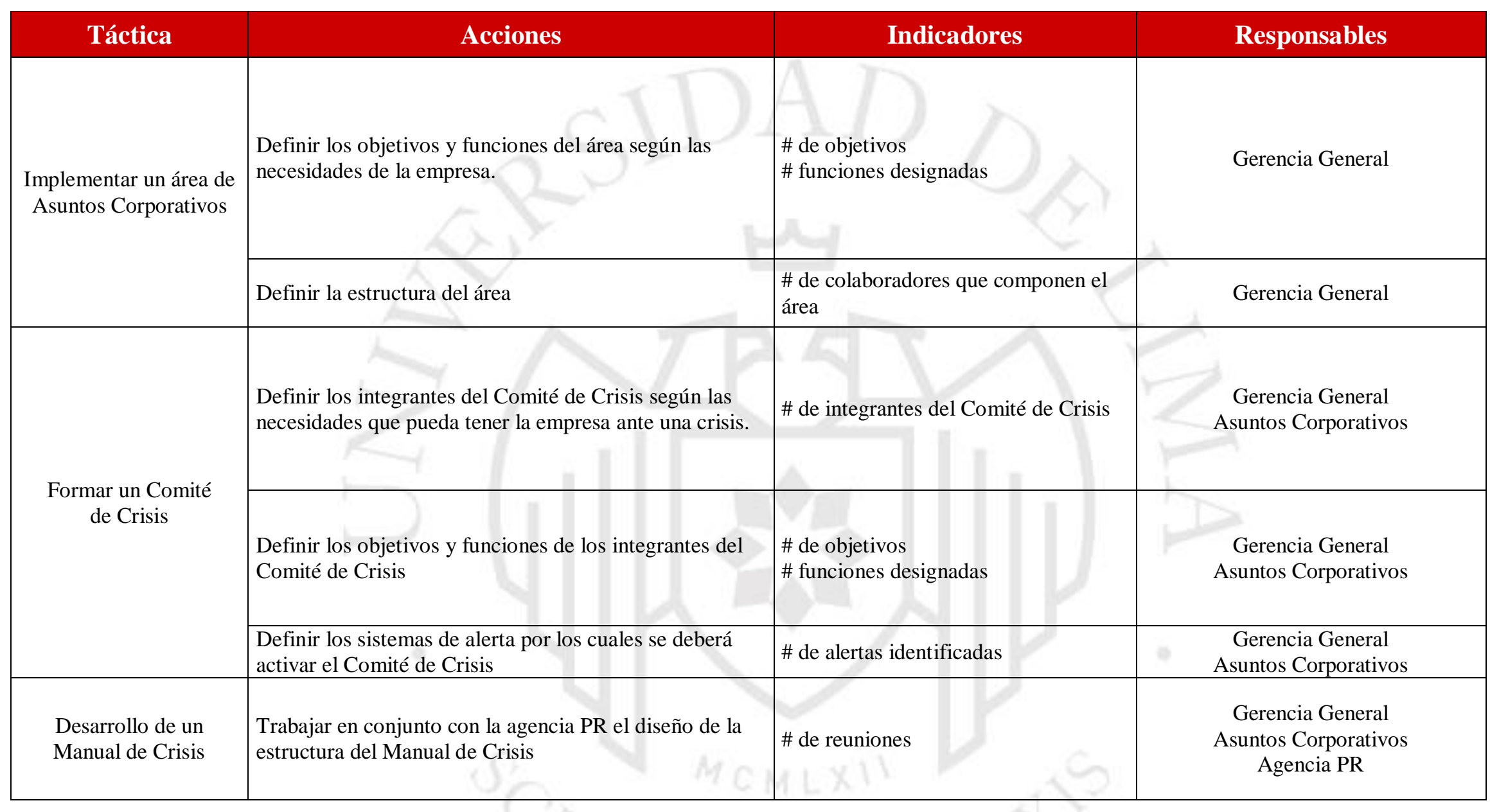




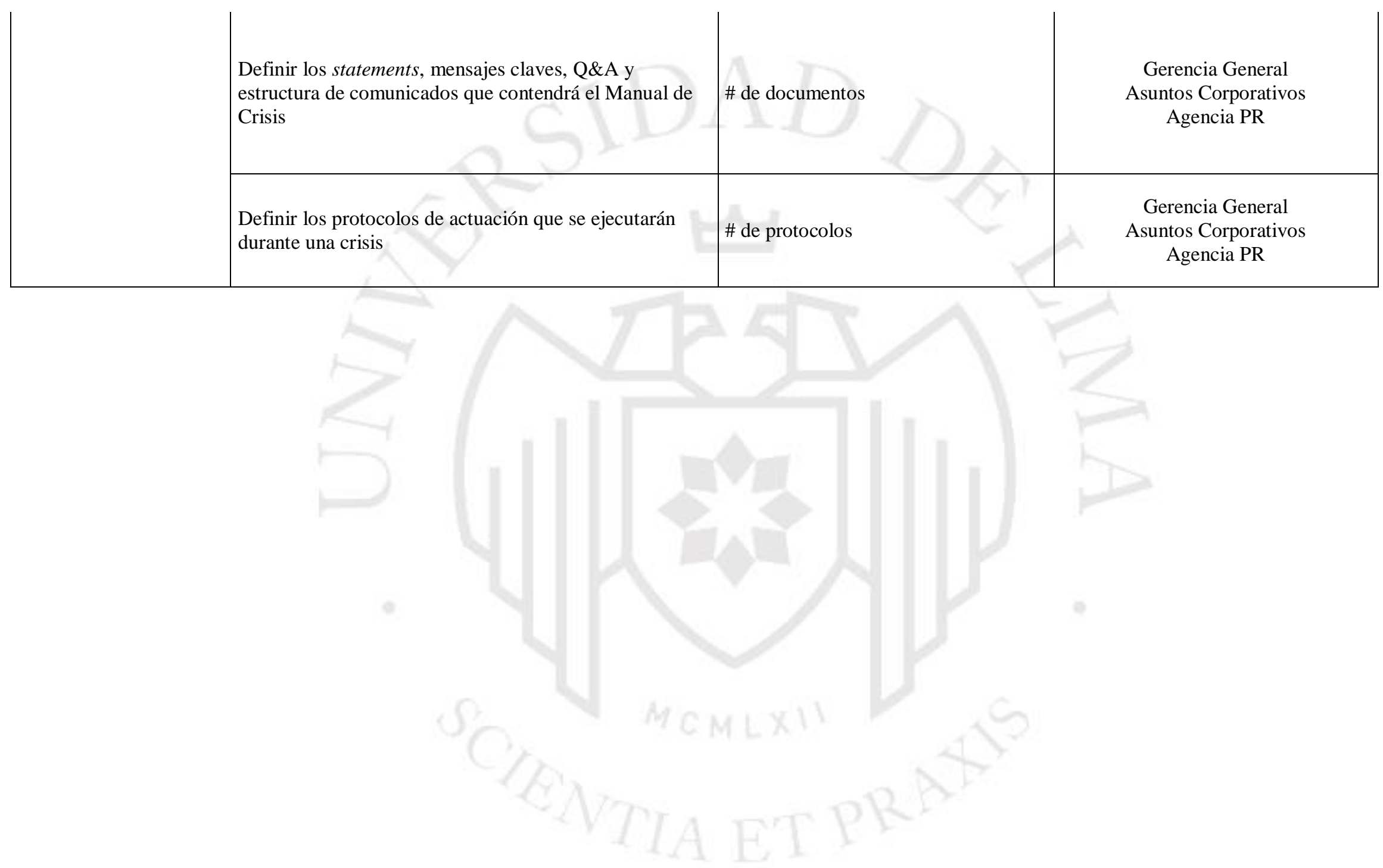


Para mediano plazo, diseñaremos una matriz táctica y frentes estratégicos enfocados en acciones de control de daños y en la prevención de futuras posibles crisis.

Tabla 1.15

\begin{tabular}{|c|c|c|c|}
\hline \multicolumn{3}{|c|}{ Plan de Control de Daños y Prevención de Futuras Crisis } \\
\hline \multicolumn{4}{|c|}{ Frentes estratégicos } \\
\hline Restaurar el posicionamiento de la imagen institucional de Viaje Lindo Airlines, con \\
todos sus públicos de interés, en el plazo de un año.
\end{tabular}

i. Matriz táctica

Tabla 1.16 


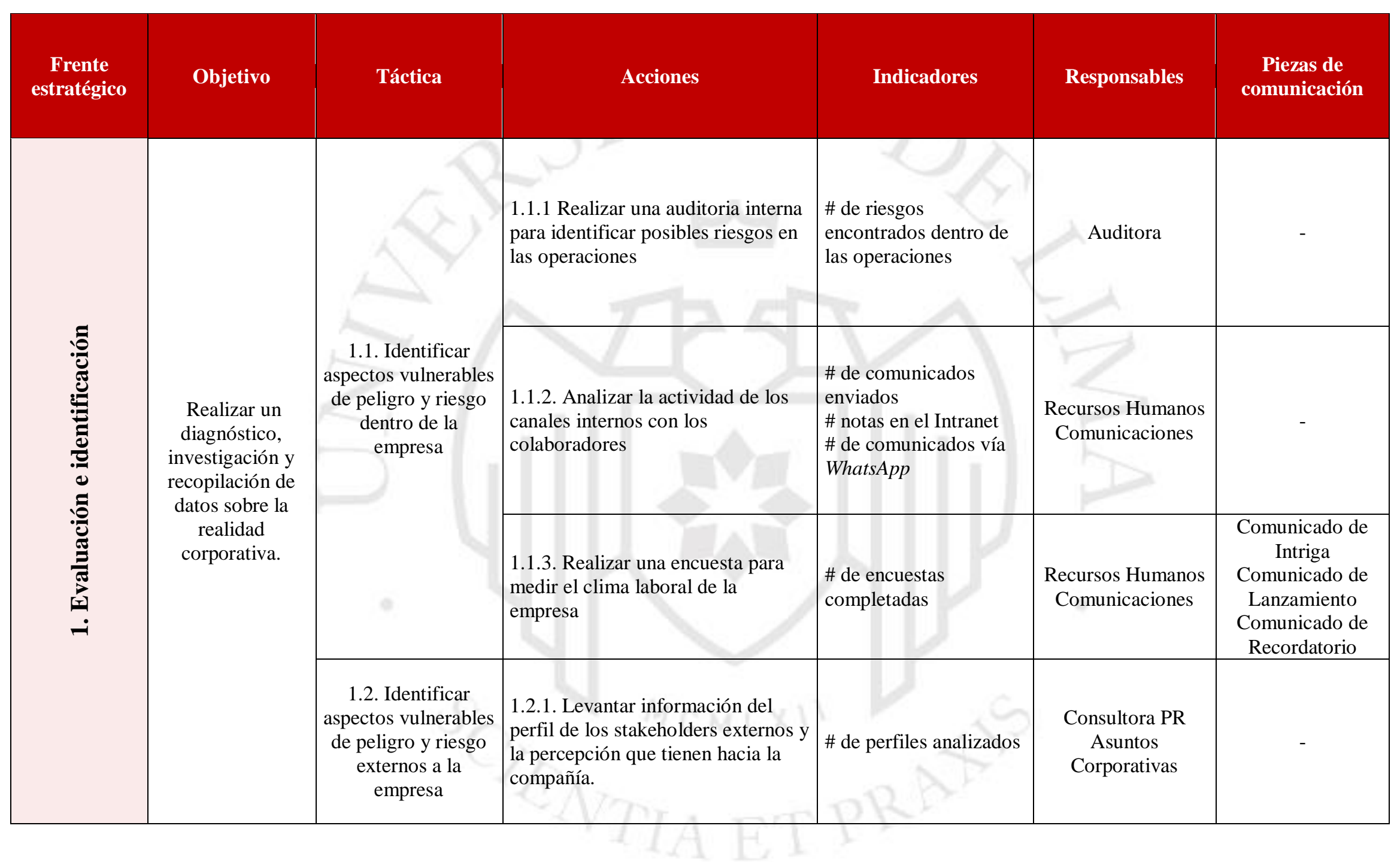




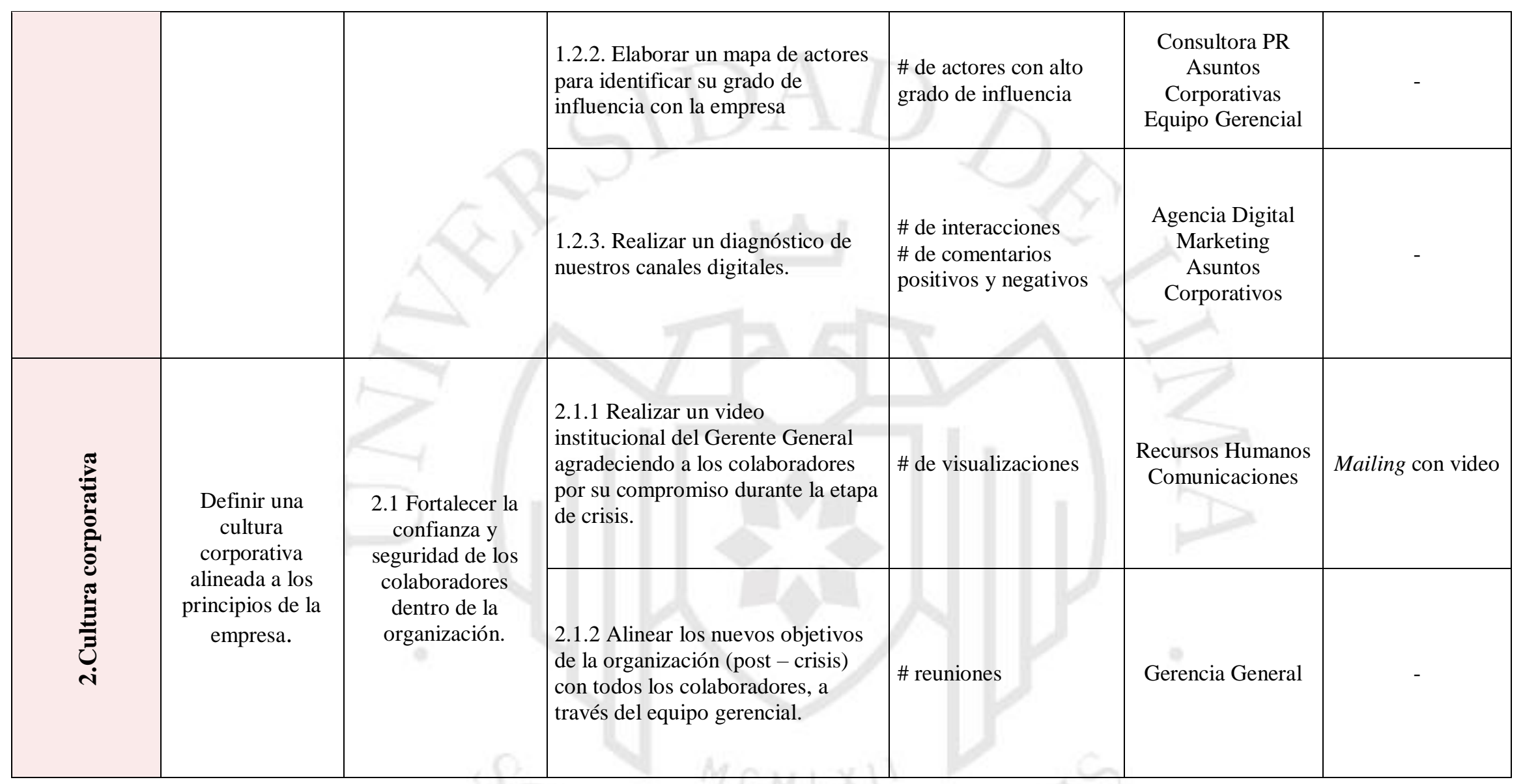




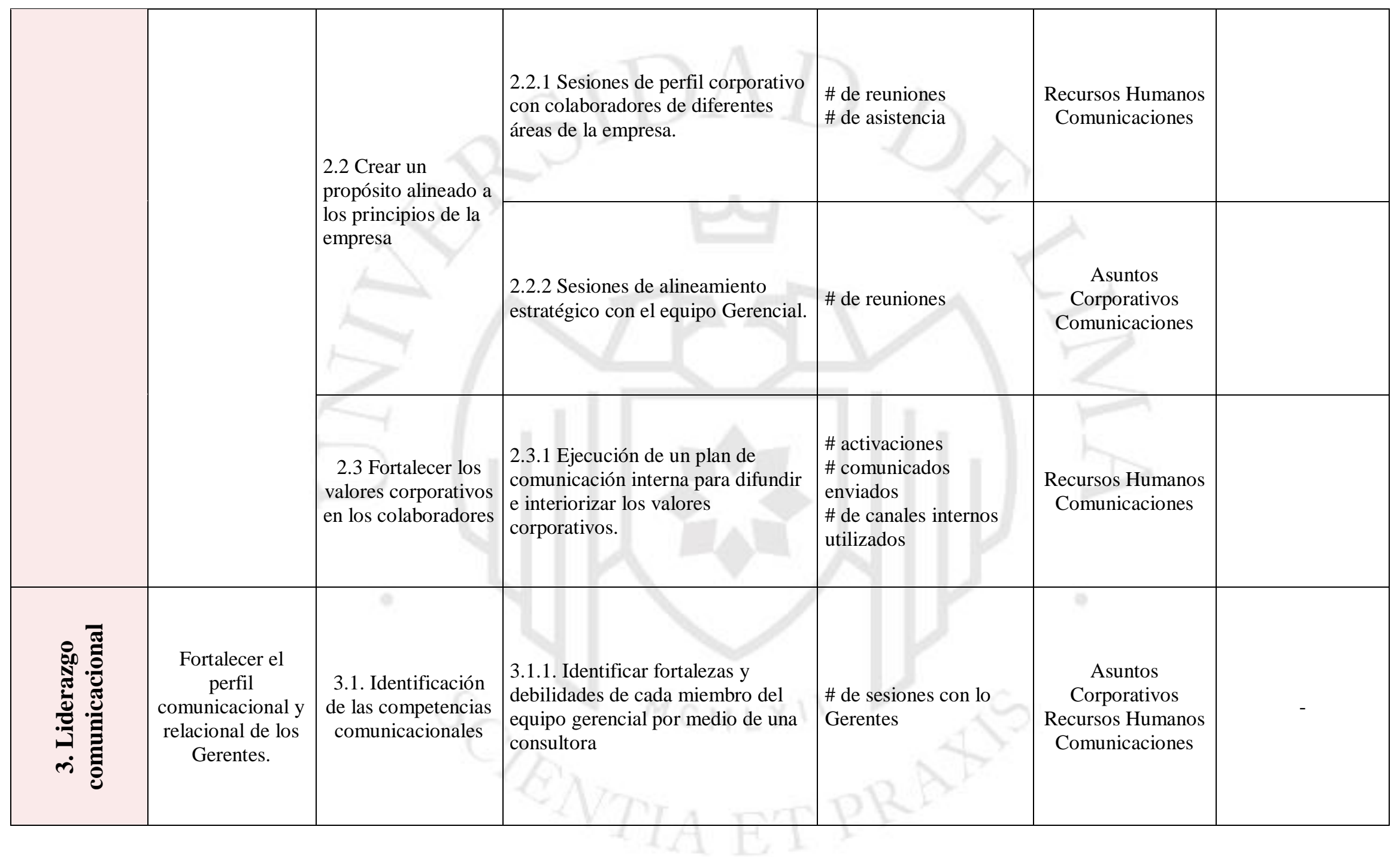




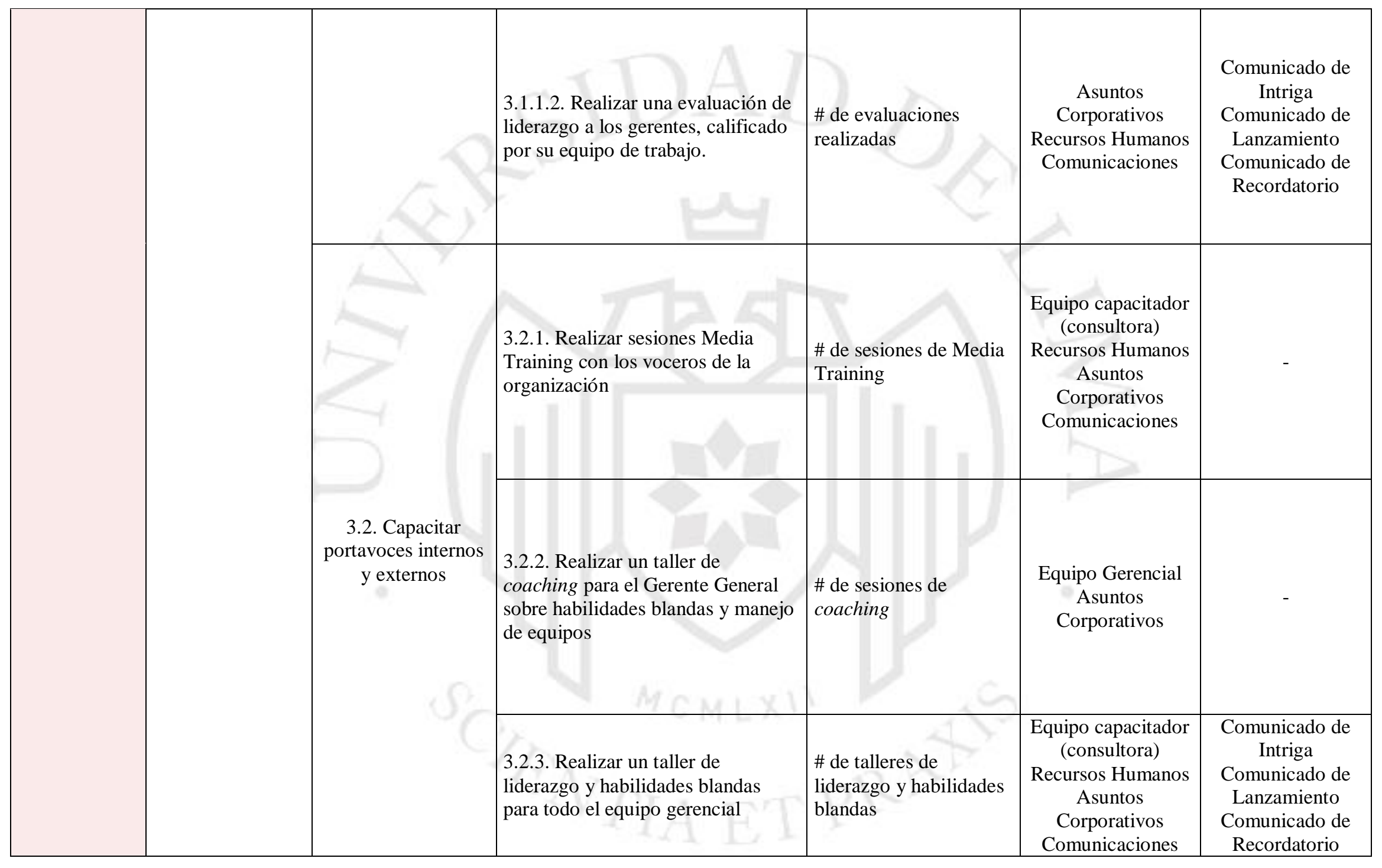




\begin{tabular}{|c|c|c|c|c|c|c|}
\hline \multirow{6}{*}{ 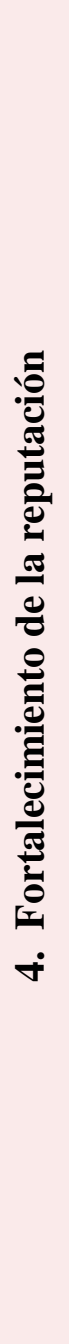 } & \multirow{6}{*}{$\begin{array}{c}\text { Gestionar una } \\
\text { buena imagen } \\
\text { corporativa para } \\
\text { tener una } \\
\text { reputación que } \\
\text { nos sirva como } \\
\text { recurso } \\
\text { estratégico } \\
\text { durante una crisis. }\end{array}$} & \multirow{3}{*}{$\begin{array}{l}4.1 . \\
\text { Relacionamiento } \\
\text { con medios de } \\
\text { comunicación }\end{array}$} & $\begin{array}{l}\text { 4.1.1 Realizar conferencias de } \\
\text { prensa para comunicar logros y } \\
\text { novedades de la empresa. }\end{array}$ & Valor PR (US\$) & $\begin{array}{c}\text { Asuntos } \\
\text { Corporativos } \\
\text { Equipo Gerencial }\end{array}$ & Notas de prensas \\
\hline & & & $\begin{array}{l}\text { 4.1.2. Brindar entrevistas } 1 \text { a } 1 \text { por } \\
\text { parte de nuestros voceros sobre } \\
\text { temas relacionados al sector. }\end{array}$ & \# de entrevistas & $\begin{array}{c}\text { Asuntos } \\
\text { Corporativos } \\
\text { Equipo Gerencial }\end{array}$ & $\begin{array}{c}\text { Ficha de Mensajes } \\
\text { Fuerza }\end{array}$ \\
\hline & & & $\begin{array}{l}\text { 4.1.3. Tener participación en } \\
\text { medios escritos a través de notas } \\
\text { prensas/artículos/columnas de } \\
\text { opinión de nuestros voceros. }\end{array}$ & $\begin{array}{l}\text { \# audiencia/lectoría del } \\
\text { medio }\end{array}$ & $\begin{array}{c}\text { Asuntos } \\
\text { Corporativos } \\
\text { Equipo Gerencial }\end{array}$ & $\begin{array}{l}\text { Notas de prensas } \\
\text { Artículos } \\
\text { Columnas de } \\
\text { opinión }\end{array}$ \\
\hline & & \multirow{3}{*}{$\begin{array}{l}\text { 4.2. Rectificar el } \\
\text { compromiso de la } \\
\text { compañía con el } \\
\text { medio ambiente y la } \\
\text { sociedad, } \\
\text { alcanzando } \\
\text { estándares de } \\
\text { seguridad y medio } \\
\text { ambiente en todas } \\
\text { sus actividades } \\
\text { operativas y } \\
\text { administrativas. }\end{array}$} & $\begin{array}{l}\text { 4.2.1. Implementar una política de } \\
\text { gestión ambiental. }\end{array}$ & & $\begin{array}{l}\text { Asuntos } \\
\text { Corporativos }\end{array}$ & $\begin{array}{c}\text { Documento de la } \\
\text { política }\end{array}$ \\
\hline & & & $\begin{array}{l}\text { 4.2.2. Identificar oportunidades y } \\
\text { comprometer las principales } \\
\text { actividades de la compañía con los } \\
\text { Objetivos de Desarrollo Sostenible } \\
\text { (ODS). }\end{array}$ & $\begin{array}{l}\text { \# de ODS impactado } \\
\text { \# de actividades que } \\
\text { impactan a los ODS }\end{array}$ & $\begin{array}{l}\text { Asuntos } \\
\text { Corporativos }\end{array}$ & \\
\hline & & & $\begin{array}{l}\text { 4.1.2.3. Implementar las normas de } \\
\text { seguridad desarrolladas por la ISO } \\
\text { para garantizar la calidad y } \\
\text { seguridad de los procesos. }\end{array}$ & \# de certificaciones ISO & $\begin{array}{l}\text { Seguridad } \\
\text { Ocupacional } \\
\text { Asuntos } \\
\text { Corporativos }\end{array}$ & - \\
\hline
\end{tabular}




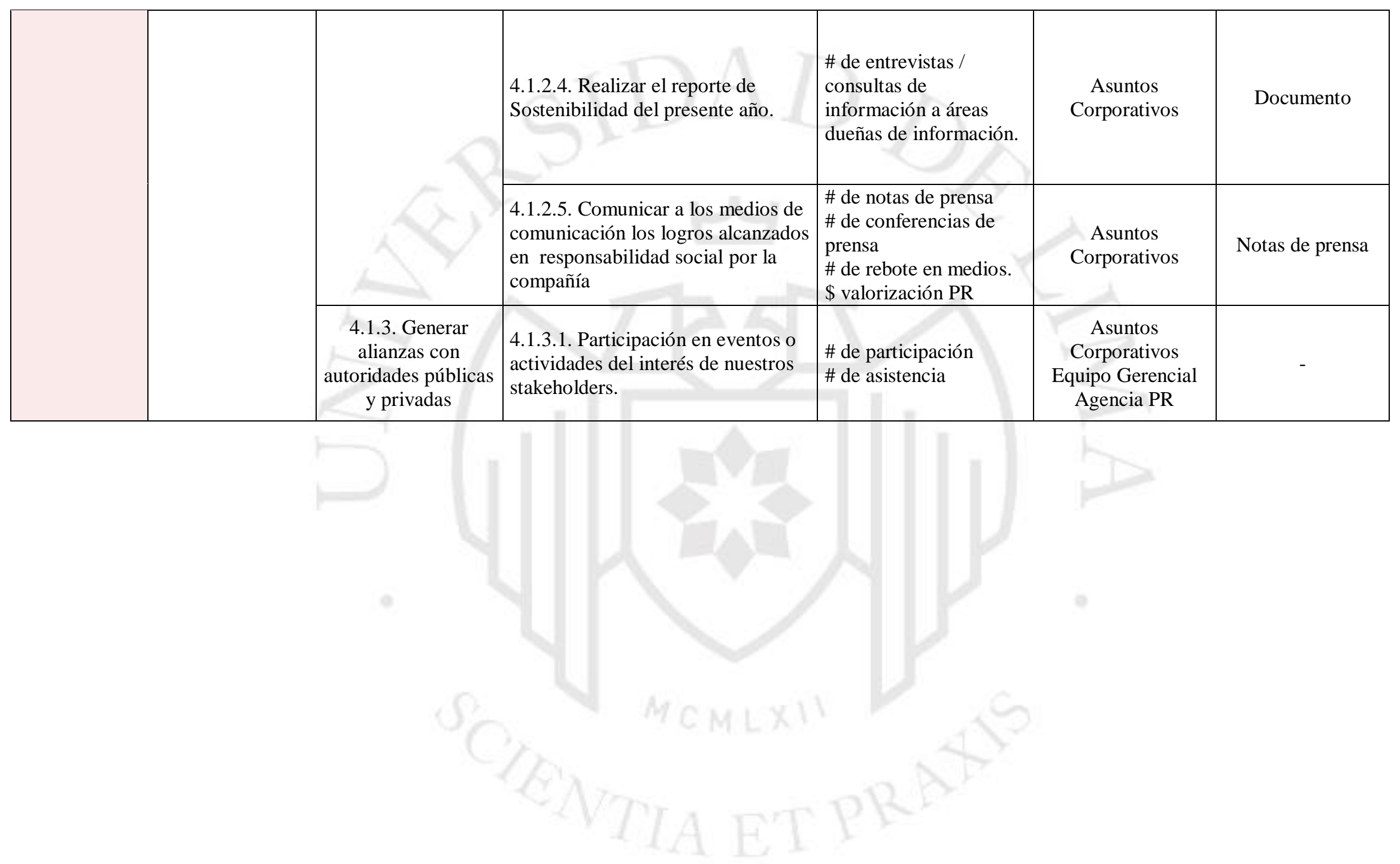




\section{DESARROLLO}

A raíz de los planes desarrollados, uno para contener y mitigar una crisis ya iniciada, y otro para prever una futura, describiremos las acciones tomadas en ambos casos para entender mejor el despliegue de cada una.

\section{Crisis}

\section{a. Fase crítica}

\section{i. 2do día}

\section{7:00 - 11:00 a.m. - Reunión de Gabinete de crisis}

A primera hora del día se realizará una reunión con el Gabinete de Crisis actual, del cual se creará un "Gabinete de crisis provisional", conformado por los Gerentes de primera línea encargados de cubrir la necesidad de los stakeholders afectados y de evitar agudizar más la crisis externa e interna. En esta reunión es importante que se conozcan los riesgos a los que se enfrenta la compañía y las consecuencias de no comenzar un plan de acción inmediato para remediar la crisis. En este sentido, la categorización de responsabilidades, la definición de roles y la planificación de procedimientos de gestión, resulta clave en el proceso.

\section{Acciones:}

- Luego de los resultados del día 1, la Gerencia de Comunicaciones toma nota de lo poco preparados que están para afrontar esta crisis, por lo que le solicita al CEO reunirse con el Comité de Crisis a primera hora.

- La Gerencia de Comunicaciones se contacta, por medio de llamadas telefónicas, con los directivos del comité actual.

- A primera hora de la mañana la Gerencia de Comunicaciones explica la necesidad de un Gabinete de Crisis Provisional, ya que se necesitan varios frentes para afrontar esta situación. Cada Gerente ha sido escogido para ser el encargado y responsable de cubrir un frente de la compañía que puede aumentar la crisis al no ser atendida.

- Se realiza un diagnóstico sobre los errores cometidos el primer día, en donde se identifican los riesgos, escenarios y consecuencias por lo ocurrido. 
- Se limita la atención a los grupos de interés implicados en el accidente; es decir, quiénes son los grupos que pueden impactar directamente en la compañía al no ser informados y atendidos de manera rápida.

- Se definen las funciones de cada miembro del gabinete con su grupo de interés.

- Se establece el reglamento a cumplir por el gabinete.

- Se designa que el vocero externo de la compañía será el Gerente de Comunicaciones, quien es el que más destreza tiene en habilidades de comunicación. El CEO, será el vocero interno de la compañía al ser la máxima autoridad y representante de la aerolínea. Externamente, estará enfocado en ayudar a los familiares de las víctimas. Ambos estarán en constante comunicación con las áreas involucradas del accidente durante el día anterior para conocer las razones del suceso.

- Se solicita contar de manera urgente con una agencia de medios que dé soporte en el transcurso de la crisis, ya que no se cuenta con un área propia de Relaciones Públicas. Por medio de un acuerdo en el gabinete, se elige a la empresa que más experiencia tiene en el sector aeronáutico. Esta ayudará en las siguientes funciones:

- Monitoreo de medios: Control las 24 horas del día sobre todas las menciones que la empresa reciba, tanto en medios digitales como tradicionales.

- Redacción de comunicados y mensajes claves: Soporte en las nuevas notas de prensas y comunicados que realizará la organización.

- Monitoreo de principales stakeholders implicados en el accidente: Mantener el contacto de los stakeholders más importantes para la organización y estar al tanto de sus reacciones.

- Relacionamiento con stakeholders implicados en el accidente: Contactar con los stakeholders implicados en el accidente para prevenir posibles contingencias acciones y propalar mensajes clave.

- Asesoría en general: Soporte en todas las acciones que la empresa decida realizar, capacitación al vocero e informe sobre los movimientos de los grupos de interés.

- Se decide no realizar más conferencias de prensa o entrevistas durante la primera semana. Se mantendrá informada a la prensa por medios de comunicados. 
- En caso de que un medio requiera una comunicación específica, será dirigida hacia la Gerencia de Comunicaciones o a la Agencia de Relaciones Públicas.

El gabinete de crisis provisional forma una mesa de trabajo en donde se definen las acciones para resarcir los errores hallados en el diagnóstico:

- Se define enviar, por la tarde de ese mismo día, un comunicado a la opinión pública comunicando el status del accidente y la atención a los familiares: estratégicamente ese será el tema central de toda comunicación en adelante.

- Se decide abrir un centro de atención presencial, con el equipo de trabajo social de la aerolínea, para los familiares de los afectados. Este centro, cuya dirección será confidencial, será en una sala reservada por la empresa, tanto en Lima y Arequipa, lejos de la sede central para evitar posibles enfrentamientos de los familiares. Estos centros contarán con atención: legal, psicológica y de ayuda social.

- Se realizan los comunicados internos, statements, documento de preguntas y $\underline{\text { respuestas, }}$ y mensajes claves para utilizarlo como base para el vocero y para comunicar a cada público de interés.

\section{1:30 a.m. - Control y manejo de los canales digitales}

\section{Facebook / Twitter}

Se realizará un flujo de respuestas para nuestras las redes sociales de la compañía. Pese a que solo se activarán Facebook y Twitter para emitir comunicados sobre el accidente, consideramos a todas las redes dentro del flujo de respuestas. Los comentarios de clientes sobre consultas de viajes seguirán siendo respondidos como antes. En el caso de las preguntas o quejas que estén ligadas al accidente, se deberá respetar el flujo.

Se han planteado respuestas de acuerdo con estos tres casos:

- Reclamo o queja de cliente por cambio de día/horario de vuelo.

- Comentarios sobre el accidente.

- Comentario sobre accidente (en caso sea un familiar afectado).

\section{Implementación del $\underline{\text { dark site }}$}


En este espacio, dentro de la web de Viaje Lindo, se encontrará un recopilado de todos los comunicados que la compañía ha puesto a disposición pública desde que ocurrió el accidente, más la lista de heridos y fallecidos. Esta página controlará o minimizará los efectos negativos del accidente, ya que mantendrá informado a los públicos de interés y disminuirá la incertidumbre.

\section{1:30 a.m - Reunión del Gerente de Recursos Humanos con el área de asistencia social.}

Ante una noticia de gran magnitud, como el fallecimiento de un ser querido, se despliegan acciones para atender a los pasajeros y familiares por parte del área de asistencia social. Toda comunicación directa con los familiares se canalizará por el área de Asistencia Social.

Al ser un tema de heridos y/o fallecidos, se prioriza la atención presencial: Las llamadas o visitas a nuestros centros de atención al cliente se canalizarán por esta área. Las noticias del estado del familiar no se deben dar por personal no autorizado.

Sumado a ello, se abrirá la atención también dentro de las oficinas administrativas para los colaboradores afectados con la pérdida de sus compañeros de trabajo. En esta sala se brindará asistencia social y psicológica y estará disponible durante toda la jornada laboral.

El personal de asistencia social se desplegará de la siguiente manera:

Tabla 1.17

\begin{tabular}{|l|l|l|}
\hline \multicolumn{2}{|l|}{ Lugar } & Atención \\
\hline \multirow{2}{*}{ Lima } & Centro de atención presencial & Familiares \\
\cline { 2 - 3 } & Oficinas administrativas & Colaboradores \\
\hline Arequipa & Centro de atención presencial & Familiares \\
\cline { 2 - 3 } & Hospital & Familiares y heridos \\
\hline Call center & - & Familiares \\
\hline
\end{tabular}

\section{Acciones:}

- El Gerente de Recursos establece las funciones del área en esta crisis: 
- Reunir información del estado de los pasajeros.

- Llamar a la persona de contacto de cada pasajero.

- Información sobre indemnización (la compañía cubre el $100 \%$ de todos los pasajeros).

- Atender a cada familiar personalmente en las oficinas designadas.

- Visitar a los accidentados y a sus familias.

- Monitorear a las familias e informar al área de Comunicaciones los casos potenciales de crisis, como demandas.

- Atender a los colaboradores afectados por la muerte de los 3 tripulantes de la compañía.

- Se hace entrega de los statements a mencionar a las familias ante las visitas presenciales o llamadas telefónicas.

- Se designa un abogado laboral de la compañía y un psicólogo para que acompañe a cada asistente en la atención a los familiares.

- Se designa un psicólogo y asistente social para atender a los colaboradores afectados con la pérdida de sus compañeros de trabajo.

\section{2:00 p.m - Reunión con Gerentes de la compañía.}

El CEO de la compañía solicitará una reunión con todos los Gerentes. Esto con la intención de poder bajar la información a todos los colaboradores de Viaje Lindo y que este sea el primero en saber la situación actual de la compañía antes que los medios públicos. Es importante que todos los colaboradores se mantengan informados para disminuir rumores y desinformaciones.

\section{Acciones:}

- Itinerario de reunión.

- CEO comunica los hechos del suceso de acuerdo al comunicado redactado en la reunión del gabinete de crisis.

- En el caso de los Gerentes situados en provincia, se realiza una conexión vía Skype.

- CEO anuncia en la reunión:

- El comunicado interno que saldrá a la compañía. 
- La responsabilidad de cada Gerente o Jefe de discurrir la correcta información a sus equipos.

- Se define las 2:00 p.m como la hora de la reunión extraordinaria de los equipos.

\section{2:30 p.m. - Primer comunicado interno.}

Luego de la reunión con los Gerentes, sale el 1er comunicado interno de la compañía vía e-mail hacia todos los colaboradores. Este será de insumo para poder conversar en las reuniones extraordinarias de los equipos y tendrá, de tema central, el lamento de lo sucedido y el homenaje a los colaboradores fallecidos en el vuelo.

\section{2:30 p.m. - Reunión con jefes de áreas de atención al cliente.}

Luego de la reunión con los Gerentes, el CEO se reúne con todos los jefes de área de atención al público presencial, online o telefónica. Es importante la reunión de estas personas porque sus áreas son la cara al público en todo momento y tienen que estar preparados para afrontar toda situación que se presente a causa del accidente y saber qué y cómo responder en cada caso.

\section{Acciones:}

- Itinerario de reunión

- Se comunican los hechos del suceso escritos en los mensajes claves acordados en la reunión del gabinete de crisis.

- Se entregan los statements a decir por parte de los asesores de venta presencial, online y vía telefónica.

- Se entregan los nombres de los pasajeros afectados y su estado actual.

- La agencia de Relaciones Públicas aconseja comportamientos a la hora de enfrentar al público.

\section{2:00 p.m. - Inicio de acciones de contingencia externas}

La compañía realizará acciones para mostrarse en apoyo con los familiares de las víctimas. Esto para demostrar empatía y blindar la ebullición de la crisis. Con estas acciones también, se busca priorizar la atención de los medios públicos en la 
preocupación de la aerolínea por los familiares y quitar la atención de los medios en los errores cometidos el primer día.

\section{Acciones:}

- Envío de statements a las áreas de atención a cliente, ventas, y canal online (community management).

- Se cambia el logo de todas las redes sociales de la compañía al color negro en señal de luto.

- Se abren las oficinas de atención a familiares y colaboradores en Lima y Arequipa.

\section{2:00 p.m. - Reunión extraordinaria}

Luego de haber recibido el primer comunicado interno, todos los equipos se reúnen 15 minutos para que los Gerentes puedan anunciar la situación de la compañía y se puedan responder preguntas o dudas. El propósito de la reunión es mantener a todos informados y eliminar la incertidumbre y rumores que pueden correr por los pasillos de la compañía.

\section{2:00 p.m. - Salida del 1er comunicado público}

Se coloca el primer comunicado público por parte de la compañía. Este será entregado a los medios y colocado en la página web (dark site) y en las principales redes sociales de la compañía: Facebook y Twitter. El comunicado en Twitter viene acompañado de los hashtags: \#Vuelo335 \#EstamosConUstedes

De manera estratégica, en este comunicado se prioriza el lamento de la compañía y las acciones de apoyo tomadas para los familiares de las víctimas, con la intención de seguir transmitiendo información.

Se envía el comunicado en inglés para las familias de los extranjeros, parte de los pasajeros afectados.

\section{4:30 p.m. - Paralización de operación}

Se paraliza la flota del modelo 737-300 hasta que se conozcan los resultados de la investigación. 


\section{5:00 p.m. - Viaje de Gerente de Comunicaciones y CEO.}

Como estrategia de imagen, el CEO viaja a Arequipa.

\section{Acción:}

- CEO acuden al lugar del incidente para recaudar información. Acompaña un representante de la agencia de Relaciones Públicas.

- No se permiten entrevistas.

\section{5:00 p.m - Reprogramación de vuelos.}

Se publica un post en Facebook y Twitter anunciando el cambio de horario de algunos vuelos de la aerolínea debido a que se está priozando el traslado de familiares a la ciudad de Arequipa y a que el modelo Boeing 737 -300 ha dejado de operar.

Las nuevas fechas u horarios serán comunicadas vía e-mail a cada uno de los clientes afectados.

\section{ii. 3er día}

\section{8:00 a.m. - Reunión de Gabinete de Crisis}

A primera hora del día 3, se reúne el gabinete de crisis provisional para comentar acciones y pormenores de lo ocurrido el día 2.

\section{Acciones:}

- Se comentan los hechos ocurridos en las primeras 48 horas.

- Se resuelven dudas/consultas.

- Se realiza un status de funciones.

\section{Promesa de marca}

Se elimina, por tiempo indefinido, la promesa de marca "Seguridad y puntualidad a mejor precio" en toda pauta de comunicación externa, debido a la coyuntura del accidente.

09:00 a.m. - Reunión con Gerentes de la compañía. 
El CEO de la compañía solicitar una segunda reunión con todos los Gerentes. Esto con la intención de poder realizar un status del accidente y responder dudas o preguntas surgidas el día de ayer en sus equipos.

- Itinerario de reunión

- El CEO comunica las acciones realizadas el día anterior y se abre un espacio de preguntas. El Gerente de Comunicaciones se encarga de responder las preguntas.

\section{0:00 a.m. - Se realizan las reuniones extraordinarias en toda la compañía.}

Nuevamente los todos equipos de la compañía se reúnen 15 minutos para que los Gerentes puedan actualizar la situación de la compañía y se puedan responder preguntas o dudas.

\section{0:30 a.m. - Envío de comunicado interno a toda la compañía}

Salida del segundo comunicado interno a los colaboradores para informar la situación de la empresa en el tercer día del accidente y el funeral de los 3 colaboradores fallecidos.

\section{2:00 p.m. - Salida del segundo comunicado público.}

Salida del segundo comunicado a Facebook, Twitter y en el Dark Page. En este, se informa el status de fallecidos y heridos al finalizar el día, las acciones tomadas con los familiares y se recuerda los canales de atención exclusivos a familiares.

\section{iii. 4to día}

\section{9:00 a.m - Reunión con los pilotos y tripulantes de cabina}

Se realiza una reunión con los pilotos y tripulantes de cabina en donde se refuerzan los protocolos de seguridad de un vuelo y el compromiso por brindar y transmitir seguridad a cada uno de los pasajeros antes del despegue. Se pide a los pilotos y tripulantes estar presentes, tanto en la entrada y salida, de los pasajeros al avión porque serán la cara de la seguridad de la compañía.

\section{Baja de precios a los pasajes}

Se bajarán los precios de los pasajes de la aerolínea. Esto no será comunicado al público debido a la coyuntura. 


\section{iv. 5to día}

\section{Eliminación de nro. de vuelo}

Se elimina el número de vuelo 335, en homenaje a las personas fallecidas.

\section{v. Gto día}

\section{Taller de manejo de emociones}

Se realizarán talleres de manejo de emociones asociadas al duelo, abierto a todo colaborador afectado por la muerte de sus compañeros de trabajo o por la noticia del accidente en sí.

En estos talleres se plantean actividades que ayudarán a los colaboradores a enfrentar el duelo de la pérdida de una persona. Las inscripciones serán abiertas a todo colaborador que lo necesite y se realizarán al término de la jornada laboral. Paralelamente, el área social estará disponible todo el día con un Psicólogo para atender a los colaboradores.

Las actividades y/o tareas del taller serán, primordialmente conversaciones grupales sobre:

- Detectar emociones, pensamientos, sensaciones físicas y conductas tomadas a partir de la pérdida de un ser querido.

- El reto de aceptar y enfrentar la realidad.

- Manejo y control de las emociones.

- Adaptación a un medio en el que el fallecido está ausente.

El fin de este conversatorio es elaborar un camino del duelo en el cual expliquen hacia dónde se dirige cada uno con el dolor que siente el día de hoy, en ese momento, y hacia dónde quiere llegar. Con cada colaborador se puede ir explorando diferentes aspectos: cómo se sienten ahí, qué han dejado atrás y qué tienen por delante, qué necesitan y qué les ayudará para continuar.

Finalmente, la idea es que el taller pueda conectar a cada colaborador consigo mismo y con el lugar en el que se encuentra, y que vuelva a encontrar la confianza en sí mismo para hacerse cargo del proceso de aceptación de la pérdida de su compañero. 


\section{b. Fase de tensión}

En esta fase, la crisis empieza a diluirse con el pasar de los días y con la recuperación de los heridos. La noticia sale del foco de los medios y el público disminuye su interacción con la marca en las redes de la compañía. Sin embargo, la investigación del accidente aún continúa y el medio público está a la espera del resultado de las causas del accidente.

La compañía sabe que, con la revelación del resultado del accidente, volverá a estar en el ojo público y la crisis puede volver a agudizarse, probablemente más que antes. Por lo tanto, empezará a tomar acciones de blindaje para poder afrontarla.

\section{Relacionamiento con Boeing}

Es el stakeholder más importante de esta fase debido a que, junto con Viaje Lindo, es el culpable del accidente. Por ello, la agencia de Relaciones Públicas, junto con la Gerencia de Comunicaciones, se mantienen en constante comunicación con el área de comunicación externa de la empresa Boeing. Además, también se preocupan por reunir al CEO de Viaje Lindo con el presidente de Boeing (o el representante de la compañía en Perú).

Este relacionamiento tiene como objetivo acordar un alineamiento estratégico de apoyo y responsabilidad de culpa compartida entre las dos compañías, alineando los mensajes clave de ambas, que se entregarán a la opinión pública. Además, es importante que las dos empresas se relacionen para poder generar acuerdos y coordinar acciones en conjunto. A ninguna de las dos compañías les es positivo para su imagen entrar en conflicto.

Por otro lado, se redacta la nota de prensa próxima a lanzar al momento del dictamen de la investigación del accidente.

\section{c. Fase crítica}

Finalmente, por medio de un comunicado del MTC, salen los resultados de la investigación, lo cual trae consigo el rebote a los medios. En el comunicado se informa que la razón del accidente tuvo que ver con un problema en los flats de la aeronave y, por 
una incomunicación por las áreas correspondientes de Viaje Lindo para detener la operación de la flota $737-300$.

Por otro lado, en esta fase se activan los aliados que son líderes de opinión para que puedan emitir contenido en redes sobre lo que está haciendo la compañía actualmente por las familias, o emitir contenido sobre especificaciones técnicas de lo sucedido en el accidente. Ambas estrategias se utilizarán para transmitirle información al público y cambiarle el eje central a la noticia.

\section{Acciones de contingencias}

- En base a los acuerdos y mensajes claves pactados por ambas compañías, Viaje Lindo redacta el comunicado que emitirá cuando las causas del accidente sean revelados a los medios públicos. Este comunicado pasó previamente por revisión y conformidad por Boeing.

- La agencia de Relaciones Públicas comparte contenido a líderes de opinión aliados que comunicarán cómo la compañía se está haciendo cargo de las familias afectadas (por ejemplo, periodistas).

- La agencia de Relaciones Públicas comparte contenido a expertos en aeronáutica para que puedan salir a los medios comentando en qué consiste la falla del avión que ocasionó el accidente (por ejemplo, el abogado Julián Palacín o el geólogo Patricio Valderrama)

- Se realiza una encuesta de reputación a todos nuestros stakeholders para conocer cuál es la percepción actual de nuestra marca en la mente de ellos, comenzar a medir los rezagos que nos dejó la crisis y cómo podemos trabajar en cada frente.

\section{Post - Crisis}

Es importante resaltar que, pasada la crisis, nuestras acciones más inmediatas deberán estar enfocadas en recopilar toda la información que nos dejó la crisis para contar con herramientas y procedimientos que nos permitan prever una futura, como:

\section{Implementar un área de Asuntos Corporativos:}

1.1. Definir los objetivos y funciones del área según las necesidades de la empresa: Para poder implementar una nueva área dentro de la compañía, es 
necesario primero delimitar los objetivos que estén alineados a los del negocio. En este caso, los objetivos del área de Asuntos Corporativos resaltan más luego de la crisis atravesada:

Los objetivos del área de Asuntos Corporativos serán:

- Identificar los riesgos que puede afrontar la empresa en una sociedad cada vez más cambiante y exigente con respecto a la actividad empresarial.

- Mapear las oportunidades y riesgos, mapeo de stakeholders y definir prioridades de relacionamiento, proyectos específicos y planes de acción concretos para lograr objetivos medibles en el periodo de gestión.

- Velar por la reputación de la empresa por medio de acciones alineadas al propósito, misión, visión y valores de la misma.

- Fortalecer las relaciones gubernamentales de la empresa.

- Ser portavoces de la empresa manejando habilidades de comunicación para enfrentar la complejidad del entorno normativo del negocio, especialmente en procesos de gestión de crisis.

1.2. Definir la estructura del área: Delimitar las personas que conforman el equipo de Asuntos Corporativos como sus niveles jerárquicos según la necesidad de la empresa:

2. Gerente de Asuntos Corporativos

3. Jefe de Asuntos Corporativos

4. Coordinador de Asuntos Corporativos

5. Analista de Asuntos Corporativos

6. Practicante de Asuntos Corporativos

\section{Formar un Comité de Crisis:}

\subsection{Definir los integrantes del Comité de Crisis según las necesidades que} puedan tener ante una crisis: Luego del levantamiento de información en la primera etapa y conociendo donde están los riesgos más latentes, es importante formar el Comité de Crisis que estará liderado por el equipo gerencial, asesores legales y técnicos. Además, deberemos establecer otros integrantes que conformarán el Comité según el frente de donde provenga el riesgo: 
Tabla 1.18

\begin{tabular}{|l|l|l|}
\hline \multicolumn{1}{|c|}{$\begin{array}{c}\text { Comité de Crisis } \\
\text { (primera línea) }\end{array}$} & \multicolumn{1}{c|}{$\begin{array}{c}\text { Comité de Crisis } \\
\text { (segunda línea) }\end{array}$} & Apoyo al Comité \\
\hline Gerente General & Jefe de Mantenimiento & Agencia PR \\
\hline Gerente de Asuntos Corporativos & Jefe de Atención al Cliente & Agencia Digital \\
\hline Gerente de Recursos Humanos & Jefe de Tripulantes & Consultora Legal \\
\hline Gerente de Operaciones & Jefe de Pilotos & \\
\hline Gerente de Legal & Jefe de Recursos Humanos & \\
\hline Gerente de Comunicaciones & Jefe de Cargo & \\
\hline Gerente de Marketing & Jefe de Marketing & \\
\hline Gerente de Finanzas & Jefe de Seguridad & \\
\hline Jefe de Operaciones & Asistente de Bienestar Social & \\
\hline Jefe de Legal & Jefe de Seguros & \\
\hline
\end{tabular}

\subsection{Definir los objetivos y funciones de los integrantes del Comité de Crisis:}

Una vez determinado los miembros del Comité de Crisis, se formulará el objetivo general del comité y las funciones de cada miembro.

\subsection{Definir los sistemas de alerta por los cuales se deberá activar el Comité}

de Crisis: Teniendo claro el equipo que conformará el Comité de Crisis, y los objetivos y funciones de cada uno, se procederá a establecer un sistema de alerta en el cual se categorizará el riesgo y, según ello, se resolverá si es necesario o no convocar al Comité de Crisis:

Tabla 1.19

\begin{tabular}{|c|c|c|}
\hline Riesgo & Categoría & Resolución \\
\hline Caída de un avión & Alta & Se activa el Comité de Crisis \\
\hline $\begin{array}{c}\text { Robos realizados por el } \\
\text { personal }\end{array}$ & Alta & Se activa Comité de Crisis \\
\hline $\begin{array}{c}\text { Agresión de un } \\
\text { colaborador a un cliente }\end{array}$ & Medio & $\begin{array}{c}\text { Se analizan los hechos con Recursos Humanos. Si } \\
\text { el caso persiste, se activará el Comité de Crisis. }\end{array}$ \\
\hline
\end{tabular}




\begin{tabular}{|c|c|c|}
\hline $\begin{array}{c}\text { Queja de un pasajero por el } \\
\text { cambio de su vuelo. }\end{array}$ & Bajo & $\begin{array}{c}\text { Se realiza una atención personalizada para atender } \\
\text { el requisito del cliente. }\end{array}$ \\
\hline Reclamos en redes sociales & Bajo & Se responden los mensajes según el manual de \\
repuesta.
\end{tabular}

(Solo se han tomado como referencia 5 casos de riesgo)

\section{Desarrollo de un Manual de Crisis:}

3.1 Trabajar en conjunto con la agencia PR el diseño de la estructura del Manual de Crisis: Con el apoyo de la agencia $P R$, buscamos conocer e implementar la mejor estructura dentro del Manual de Crisis a través de una lectura clara y sencilla.

3.2. Definir los statements, mensajes claves, Q\&A y estructura de comunicados que contendrá el Manual de Crisis: Trabajar modelos y estructuras de herramientas que nos puedan servir de apoyo durante una crisis.

\subsection{Definir los protocolos de actuación que se ejecutarán durante una crisis:}

Diseñar una estructura de acciones que se realizará al momento de una crisis según el tipo de riesgo que la originó:
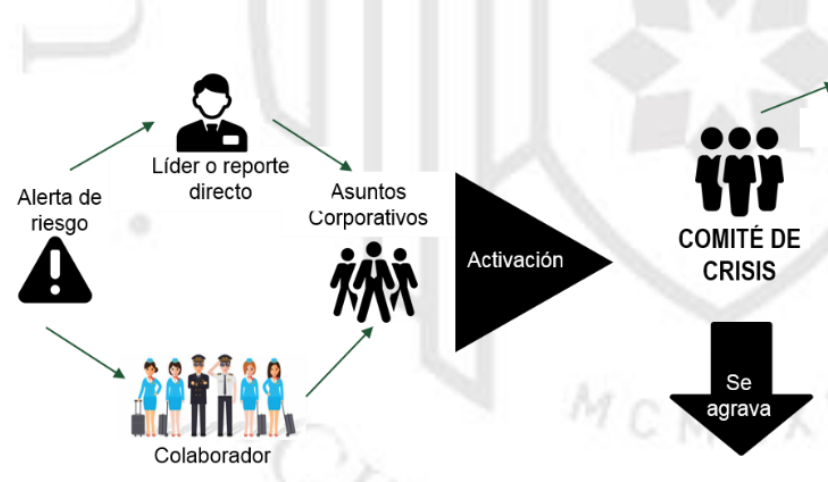

CRISIS
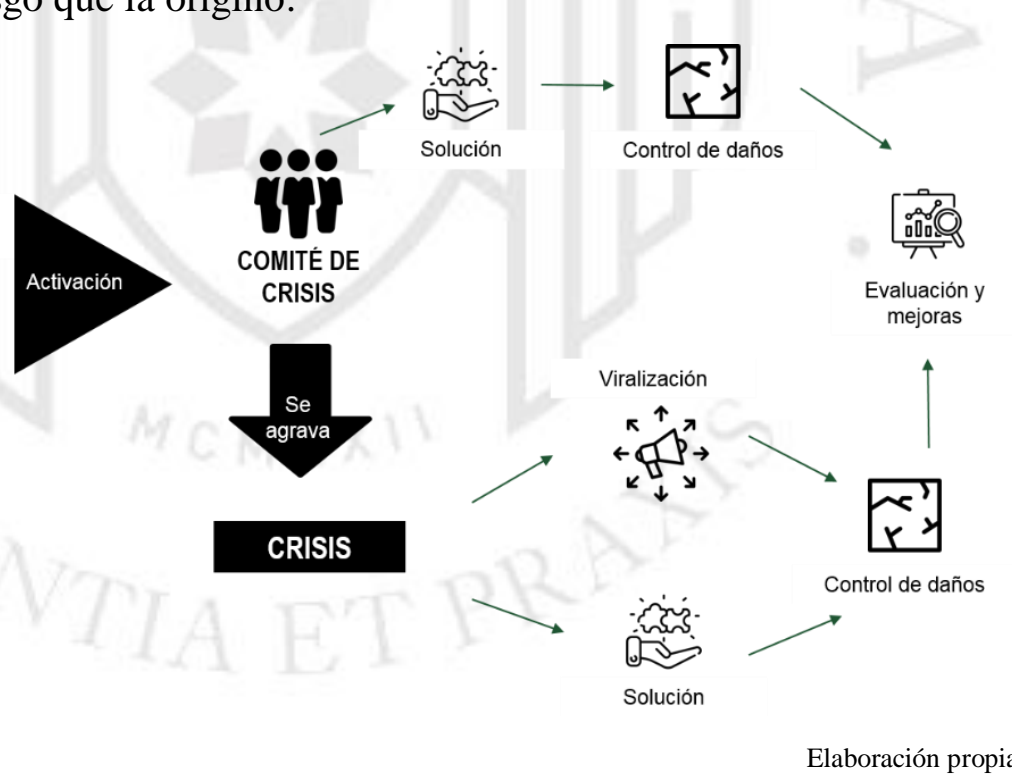

Hemos planteado dentro de nuestro Plan de Gestión de Crisis y Prevención de daños, frentes estratégicos con objetivos enfocados en prevenir, mitigar o contener futuras crisis. A partir de ello, desarrollaremos cada objetivo con sus respectivas acciones a mediano plazo. 


\section{A. Evaluación e identificación}

Objetivo: Realizar una investigación y recopilación de datos sobre la realidad corporativa.

\section{Identificar aspectos vulnerables de peligro y riesgo dentro de la empresa:}

\subsection{Realizar una auditoría interna para identificar posibles riesgos en las} operaciones: Por medio de una auditoría interna de seguridad y prevención, y con el apoyo de cada jefatura correspondiente, buscamos identificar qué operaciones pueden implicar un riesgo de crisis dentro de la empresa, ya sea por una mala gestión o por la falta de protocolos de seguridad.

1.2. Analizar la actividad de los canales internos con los colaboradores: Con apoyo de una consultora de comunicaciones, buscamos identificar el nivel de actividad que cuenta cada canal interno. Es decir, conocer los contenidos que difunden y con qué tanta frecuencia son actualizados para informar a los colaboradores. Además, se establecerán flujos de trabajo para todos los canales internos disponibles.

1.3. Realizar una encuesta para medir el clima laboral de la empresa: Con apoyo del área de Recursos Humanos, realizaremos una encuesta de clima laboral para conocer las percepciones que los colaboradores tienen hacia la empresa sobre ciertos indicadores:

- La claridad de los objetivos generales de la empresa.

- La claridad de los objetivos individuales de cada departamento.

- El nivel de comunicación interna.

- La calidad del trabajo en equipo.

- La eficacia del estilo de liderazgo de la empresa.

- Las condiciones generales y particulares del trabajo.

- Las oportunidades de carrera o promoción interna.

- La eficacia de las tareas de supervisión y mejora.

- Las políticas de compensación y retribución.

2. Identificar aspectos vulnerables de peligro y riesgo externos a la empresa: 
2.1. Levantar información del perfil de los stakeholders externos y la percepción que tienen hacia la compañía: Con el apoyo de IPSOS, realizaremos una investigación del perfil de stakeholders externos y de la percepción que ellos tienen hacia la empresa: Clientes, Proveedores, Autoridades y Medios de Comunicación.

\subsection{Elaborar un mapa de actores para identificar su grado de influencia con}

la empresa: Realizaremos un mapa de actores que contenga los principales stakeholders, identificando el nivel de poder y de interés con la empresa

2.3. Realizar un diagnóstico de nuestros canales digitales: Por medio de una agencia digital, realizar informes detallados que den cuenta de todo lo que está por mejorar y todo lo que sí funciona en los canales digitales (redes sociales y web).

\section{B. Cultura Corporativa}

Definir una cultura corporativa alineada a los principios de la empresa.

1. Fortalecer la confianza y seguridad de los colaboradores dentro de la organización.

1.1 Realizar un video institucional del Gerente General agradeciendo a los colaboradores por su compromiso durante esta etapa de crisis: Por medio de un video institucional, queremos enviar un mensaje a todos los colaboradores que se vieron expuestos y afectados por lo ocurrido durante este periodo de crisis. Este mensaje deberá estar liderado por el Gerente General de la empresa y su objetivo es transmitir agradecimiento, tranquilidad y confianza a todos los colaboradores sobre la situación de la compañía, así evitaremos un clima de incertidumbre.

1.2 Alinear los nuevos objetivos de la organización (post - crisis) con todos los colaboradores, a través del equipo gerencial: Por medio de una reunión de los Gerentes con todos sus equipos, se deberán desplegar los nuevos objetivos de la empresa post-crisis. 


\section{Crear un propósito alineado a los principios de la empresa}

2.1 Sesiones de perfil corporativo con colaboradores de diferentes áreas de la empresa: Realizar sesiones de focus group con los colaboradores destacados de la compañía, en cuanto a logros y tiempo laborando, para hacer una "lluvia" de ideas sobre qué refleja para ellos la organización. Lo importante en esta sesión es recoger todo insight, información, hecho o sentimiento que los colaboradores sienten por la aerolínea para llevarlo como insumo a las sesiones con los líderes.

2.2 Sesiones de alineamiento estratégico con el equipo Gerencial: Con la información recogida de los colaboradores se realizará la sesión de creación de un nuevo propósito para la empresa; es decir, la razón de ser de Viaje Lindo Airlines y el por qué hace las cosas. Éste reemplazaría la actual misión y visión de la empresa y le daría un nuevo aire a la marca.

\section{Fortalecer los valores corporativos en los colaboradores}

\subsection{Ejecución de un plan de comunicación interna para difundir e} interiorizar los valores corporativos: Diseñaremos un plan de comunicación interna enfocado en resaltar los valores de la empresa para que los colaboradores los interioricen y los pongan en práctica dentro de sus operaciones diarias. Los valores que se resaltarán dentro de este plan son los de: Seguridad y Puntualidad.

C. Liderazgo comunicacional

Fortalecer el perfil comunicacional y relacional de los Gerentes con los principales stakeholders

\section{Identificación de las competencias comunicacionales}

\subsection{Identificar fortalezas $y$ debilidades de cada miembro del equipo gerencial por medio de una consultora: Con el apoyo de una consultora, analizaremos las fortalezas y debilidades que presenta nuestro equipo gerencial respecto a su rol como líderes. Se realizará por medio de entrevistas y talleres con cada uno de los gerentes.}




\subsection{Realizar una evaluación de liderazgo a los gerentes calificado por su}

equipo: Por medio de una encuesta interna realizada a los colaboradores, se evaluará el desempeño de sus gerentes como líderes de equipo. Así podremos saber cómo los colaboradores perciben a sus líderes y en qué aspectos les gustaría que mejoren. Se considerarán los siguientes criterios:

- Reconocimientos al equipo

- Confianza que transmite al equipo

- Capacidad de expresar ideas

- Honestidad y transparencia

- Capacidad de innovación

- Destreza al manifestar desacuerdos sin imponerse

\section{Capacitar portavoces internos y externos}

2.1. Realizar sesiones Media Training con los voceros de la organización: Con el apoyo de una consultora, y con la experiencia de la última crisis, vamos a analizar qué tan preparado está nuestro equipo gerencial para responder ante situaciones de alta presión como lo es una crisis. En estas sesiones se desarrollarán simulacros de crisis de riesgos que podrían ocurrir en la empresa.

- Difundir los mensajes corporativos y la visión de la compañía.

- Complementar los esfuerzos comerciales de comunicación de la compañía.

- Educar a la población y a la prensa sobre temas estratégicos del negocio.

- Destacar los atributos de la marca: puntualidad y seguridad.

- Mantener una buena relación con los medios de comunicación.

2.2. Realizar un taller de coaching para el Gerente General sobre habilidades blandas y manejo de equipos: A diferencia del taller de Media Training, en este coaching se capacitará de forma personal al principal vocero de la compañía: el CEO. Teniendo como antecedentes lo realizado en la última crisis, el coach trabajará con el CEO en el desarrollo de competencias comunicacionales para que pueda tener un mejor acercamiento con los colaboradores. 


\subsection{Realizar un taller de liderazgo y habilidades blandas para todo el equipo}

gerencial: Luego de haber realizado un análisis respecto al liderazgo del equipo gerencial, se realizará un taller con el objetivo de fortalecer las competencias menos desarrolladas de cada uno. Se desarrollarán las siguientes habilidades y competencias para un buen liderazgo:

- Autoconocimiento - Intrapersonal Skills

- Gestión de Personas - Interpersonal Skills

- Comunicación

- Liderar desde la inteligencia emocional

\section{Fortalecimiento de la reputación}

Gestionar una buena imagen corporativa para tener una reputación que nos sirva como recurso estratégico durante una crisis.

\section{Relacionamiento con medios de comunicación}

1.1. Realizar conferencias de prensa para comunicar logros y novedades de

la empresa: Para fortalecer nuestro posicionamiento como empresa líder, realizaremos conferencias de prensa sobre los avances de la compañía, ya sean tecnológicos, certificaciones de seguridad y/o de servicios, compras y campañas que involucren a nuestros clientes, etc.

\subsection{Brindar entrevistas 1 a 1 por parte de nuestros voceros sobre temas} relacionados al sector: Contactaremos a los medios de comunicación para involucrar a nuestros líderes en temas relacionados al sector por medio de entrevistas en los principales noticieros/periódicos/revistas del país.

\subsection{Tener participación en medios escritos a través de notas} prensas/artículos/columnas de opinión de nuestros voceros: Fortaleceremos la presencia de nuestros voceros de forma externa por medio de columnas de opinión, comentarios en notas de prensa y artículos que ellos mismos realicen. 
2. Rectificar el compromiso de la compañía con el medio ambiente y la sociedad alcanzando estándares de seguridad y medio ambiente en todas sus actividades operativas y administrativas.

2.1 Implementar una política de gestión ambiental. Con el objetivo de incorporar la gestión de sostenibilidad en todas las rutinas operativas de la compañía, se creará una Política de Sostenibilidad. Esta permitirá impulsar la sostenibilidad en la estrategia comercial y diseñar iniciativas que generen valor compartido para todos los grupos de interés de Viaje Lindo. El Directorio será el encargado de supervisar las metas y los objetivos de sostenibilidad pactados en la política.

2.2. Identificar oportunidades y comprometer las principales actividades de la compañía con los Objetivos de Desarrollo Sostenible (ODS) para contribuir al logro de las metas de la ONU: Viaje Lindo se comprometerá en alinear todas sus actividades u operaciones bajo los Objetivos de Desarrollo Sostenible de cara a la agenda 2030 de la ONU. De esta manera, la empresa podrá corregir actividades ya en ejecución, o instaurar nuevas, todas bajo la misma meta: cumplir alguno de los 17 ODS.

2.2. Implementar las normas de seguridad desarrolladas por la ISO para garantizar la calidad y seguridad de los procesos: Presentaremos nuestra solicitud a BASC para que realicen una auditoría a nuestras operaciones y certifiquen como seguros todos nuestros procesos.

2.3 Realizar el reporte de Sostenibilidad del presente año: Continuaremos reportando anualmente nuestros impactos (positivos y negativos), principales logros, retos de las distintas dimensiones del negocio, resultados financieros, compromiso con los clientes, seguridad de los pasajeros y de los empleados, gestión ambiental y desarrollo social y económico, etc.

2.4 Comunicar a los medios los logros de responsabilidad social de la compañía: Somos una empresa que ya es recordada por sus buenas iniciativas ambientales, por lo que ahondaremos en comunicar más nuestros programas que operan actualmente hacia todos nuestros públicos de interés. 


\section{Generar alianzas con autoridades públicas y privadas}

3.1. Participación en eventos o actividades del interés de nuestros stakeholders: Nuestros principales líderes asistirán a los eventos públicos o privados como voceros de la organización que brindan su participación a la actividad o como acto de presencia para desarrollar networking con otros invitados:

- Seminarios de aviación

- Eventos por parte de las Municipalidades

- Charlas y eventos realizados por el Ministerio del Trabajo y de Transportes y Comunicaciones

- Conferencias relacionadas al sector 


\section{SUSTENTACIÓN}

En este capítulo se sustentarán las estrategias planteadas en ambos planes de gestión de crisis, uno realizado de forma inmediata para contener y mitigar la crisis que atraviesa Viaje Lindo Airlines (Crisis Actual), y el otro enfocado en ejes estratégicos planteados en la prevención de futuras crisis y control de daños (Prevención de Crisis).

Cabe resaltar que para algunas de nuestras acciones planteadas, hemos tomado como referencia hechos similares de crisis que han atravesado otras aerolíneas a nivel mundial. Además, de grandes casos de éxito de marcas muy reconocidas que han sabido superar el proceso de crisis y continuar siendo líderes en su sector.

\section{A. Crisis Actual:}

\section{Punto de partida:}

Lo primordial para nosotros, el equipo de comunicaciones, es entender exactamente qué es lo que sucedió, qué factores podemos asumir como parte de nuestra culpa y, en base a ello, diseñar nuestro plan de gestión de crisis de forma inmediata para desplegar las acciones. Para ello, realizamos un cronograma con los sucesos más importantes para analizar el accidente.

Tabla 1.20

\begin{tabular}{|c|c|c|c|c|c|}
\hline $\begin{array}{l}\text { 1. Pedido de } \\
\text { nuevos } \\
\text { aviones: }\end{array}$ & $\begin{array}{l}\text { 2. Envío } \\
\text { de nueva } \\
\text { flota. }\end{array}$ & $\begin{array}{l}\text { 3. Inicio de } \\
\text { operaciones } \\
\text { de la nueva } \\
\text { flota de } \\
\text { aviones }\end{array}$ & $\begin{array}{l}\text { 4. Anuncio de } \\
\text { fallos por parte } \\
\text { de Boeing. }\end{array}$ & $\begin{array}{l}\text { 5. Envío de información a } \\
\text { VLA. }\end{array}$ & $\begin{array}{c}6 . \\
\text { Accidente }\end{array}$ \\
\hline $\begin{array}{l}\text { VLA, con el } \\
\text { objetivo de } \\
\text { seguir } \\
\text { creciendo y } \\
\text { fortaleciendo } \\
\text { su propósito } \\
\text { de seguridad, } \\
\text { pide a } \\
\text { Boeing la } \\
\text { adquisición } \\
\text { de 15 } \\
\text { modernos }\end{array}$ & $\begin{array}{l}\text { VLA } \\
\text { recibe los } \\
\text { nuevos } \\
\text { aviones a } \\
\text { mediados } \\
\text { de mayo } \\
\text { (no se } \\
\text { especifica } \\
\text { fecha } \\
\text { exacta). }\end{array}$ & $\begin{array}{l}\text { El sábado } 01 \\
\text { de junio, } \\
\text { VLA pone } \\
\text { en } \\
\text { operación } \\
\text { este nuevo } \\
\text { lote de } \\
\text { aviones. }\end{array}$ & $\begin{array}{l}\text { En junio (no se } \\
\text { especifica fecha } \\
\text { exacta) Boeing } \\
\text { anunció fallos en } \\
\text { un reducido } \\
\text { número de } \\
\text { aviones. } \\
\text { Mediante un } \\
\text { comunicado de } \\
\text { prensa, el CEO } \\
\text { se compromete a }\end{array}$ & $\begin{array}{l}\text { El viernes } 07 \text { de junio, con } 6 \\
\text { días ya realizando operaciones, } \\
\text { llega la información por la } \\
\text { noche a las oficinas de VLA. } \\
\text { Sin embargo, esta no llegó a } \\
\text { manos de las personas } \\
\text { encargadas en las áreas } \\
\text { respectivas de la línea aérea, }\end{array}$ & $\begin{array}{l}\text { El } \\
\text { domingo } \\
09 \text { de } \\
\text { junio, se } \\
\text { produce } \\
\text { el } \\
\text { fatídico } \\
\text { accidente } \\
\text { que deja } \\
\text { una cifra } \\
\text { total de } \\
70\end{array}$ \\
\hline
\end{tabular}




\begin{tabular}{|l|l|l|l|l|}
\hline aviones a & & apoyar a las & & fallecidos \\
inicios del & & aerolíneas que & & y2 \\
año 2019. & & $\begin{array}{l}\text { presenten } \\
\text { potenciales } \\
\text { fallos. }\end{array}$ & & \\
& & & \\
\hline
\end{tabular}

(Cuadro de sucesión de hechos)

Luego de analizar el orden de los sucesos, podemos inferir, con motivos académicos, que el anuncio que brindó Boeing sobre las fallas que reportaron sus aviones fue comunicado la misma noche que llegó la información a las oficinas de VLA. Esto quiere decir que esta nueva flota de aviones, en el caso de VLA, ya tenía exactamente 6 días en operación y no presentaron ningún inconveniente antes de cada vuelo. Además, un dato importante a resaltar es que Boeing lanza este aviso a las aerolíneas que habían adquirido esta flota de aviones en los últimos 8 meses; es decir, otras aerolíneas tenían más tiempo en actividad con esta flota, sin presentar ningún fallo potencial durante las revisiones técnicas antes de cada vuelo.

Otro dato para tener en cuenta es que Boeing anuncia en su comunicado realizar las revisiones necesarias a la nueva flota enviada y, de presentarse alguna falla, recién en ese momento tomarían acción para mandar los repuestos (Staff, 2019). En ningún momento pide que los vuelos sean detenidos.

Con este análisis concluimos que el fallo que anuncia Boeing en los slats de los aviones no era fácil de percibir por las revisiones técnicas de las aerolíneas. Pese a que la información no llegó a las personas responsables de la empresa, y es ahí donde recae nuestra responsabilidad, los aviones ya tenían días realizando operaciones previa revisión técnica.

Es importante resaltar que la aeronáutica tiene una instrucción, llamada "no-go", en el cual el avión obligatoriamente debe eximirse de volar y, en caso se encuentre en vuelo, el avión debe realizar un aterrizaje de emergencia. En este caso, ninguna autoridad competente como la Federal Aviation Administration (FAA) o Boeing dio la orden al piloto, por lo que el avión debió seguir su operación con normalidad. La FAA dio 10 días de plazo para la revisión de todos los aviones y la empresa estaba dentro de ello. 
A esto hay que añadirle que VLA nunca ha tenido un accidente aéreo de este tipo en sus 23 años operando en el Perú y, desde sus inicios, ha sostenido que sus aeronaves pasan por un riguroso control y mantenimiento, lo que reafirma su promesa de marca: "Seguridad y puntualidad a un mejor precio".

Para llegar a esta conclusión, hemos comparado este caso con un hecho real de la misma empresa Boeing. El 29 de octubre de 2018 y el 10 de marzo de 2019, se reportaron dos accidentes aéreos de las aerolíneas Ethiopian Airlines y Lion Air. Ambas presentaron varias similitudes; por ejemplo, que el fallo se registró minutos después del despegue y que, en ambos casos, el capitán reportó dificultades en el manejo. El accidente se debió a una falla en los sensores de altitud y velocidad, un conflicto resultante con el sistema automatizado MCAS y la incapacidad de la tripulación para desactivar a este último (Infobae, 2019). Esta información sobre los datos técnicos del funcionamiento del MCAS, que previamente no fue brindada a las aerolíneas ni pilotos, fue finalmente enviada por Boeing a sus clientes.

En este caso, las aerolíneas no podían entender la razón de los accidentes ni tomar responsabilidad respecto a las revisiones técnicas ya que desconocían dónde estaba el problema. Con este ejemplo, nos damos cuenta de que una aerolínea no puede emitir ningún tipo de información sin conocer todos los detalles del accidente. Si bien en nuestro caso hubo una comunicación alertando este fallo, no se había reportado antes ningún percance dentro de los vuelos ya realizados, por lo que el fallo también pudo haberse evidenciado durante el vuelo como factores determinantes de este accidente

Identificamos como factores determinantes de este accidente:

Tabla 1.21

\begin{tabular}{|l|l|}
\hline \multicolumn{1}{|c|}{ Por parte de Boeing } & \multicolumn{1}{|c|}{ Por parte de Viaje Lindo Airlines } \\
\hline $\begin{array}{l}\text { Envío de información tardía sobre los fallos } \\
\text { de la flota Boeing 737-300 }\end{array}$ & $\begin{array}{l}\text { Mal flujo de comunicación entre el proveedor } \\
\text { la aerolínea responsable de recibir la } \\
\text { información. }\end{array}$ \\
\cline { 1 - 2 } $\begin{array}{l}\text { Falta de un asesoramiento más urgente } \\
\text { sobre los fallos que presentaban sus } \\
\text { aviones. }\end{array}$ & \\
\hline
\end{tabular}




\begin{tabular}{|l}
\hline $\begin{array}{l}\text { Mal flujo de comunicación entre ellos y sus } \\
\text { clientes al momento de enviar la } \\
\text { información. }\end{array}$ \\
\hline $\begin{array}{l}\text { No tener un control adecuado en las } \\
\text { revisiones de sus flotas antes de ser } \\
\text { vendidas. }\end{array}$
\end{tabular}

\section{$\underline{\text { Un cambio de actitud }}$}

Ya ocurrido el accidente, hemos visto cómo la falta de un plan de prevención de crisis y control de riesgos ha evidenciado las deficiencias que la empresa tiene en varios frentes externos e internos, afectando la reputación y el posicionamiento que había logrado con sus públicos como una empresa "puntual y segura". La razón principal de la crisis parte de una falla técnica reportada por Boeing de manera tardía a sus clientes, quienes no pudieron comprobar ningún fallo en los flats pese a que la nueva flota tenía cierto tiempo operando. Sin embargo, son las malas decisiones y la falta de asesoramiento ante este tipo de eventos lo que terminan de agravar más la crisis, haciendo notar una falta de compromiso y sensibilidad con los afectados: una reacción no inmediata al accidente, un vocero que no estaba preparado para responder a medios y una actitud que utilizó como estrategia comunicacional la "transferencia de responsabilidades" hacia Boeing.

En este contexto, antes de diseñar las acciones de nuestro plan, partimos teniendo un cambio de postura reactiva, que la empresa ha manifestado en el día 1 del accidente, a una postura proactiva. En una postura proactiva, la Gerencia General deberá trabajar en colaboración con otras áreas para la toma de decisión de acciones, el control de riesgos y el enfoque de esfuerzos en mejorar frentes que se han mostrado menos atendidos que los demás.

"Los directores proactivos son capaces de mantener el autocontrol en sus labores cotidianas, incluso durante crisis o situaciones adversas. No se dejan llevar por los sentimientos, los impulsos o las emociones. Son personas que han aprendido a no dejarse arrastrar por los entornos y mantener la calma de cara a la toma de decisiones más oportunas. "' (School, 2017)

A partir de esta nueva postura ante la crisis, nuestra actitud estratégica de comunicación cambiará a una de “discreción controlada”, lo que significa que la información que brinde la empresa se dará mediante el ritmo que nosotros determinemos. Este ritmo será 
definido a partir de los avances de la investigación del accidente; ya que, pese a que Boeing haya avisado días previos al vuelo sobre su fallo en la aeronave, no podemos afirmar las causas reales del accidente sin antes tener los resultados de la investigación por parte de las autoridades.

Por ello, hemos dividido la crisis de acuerdo a dos hechos catalizadores del ojo público, a las que llamamos "fases críticas": el accidente y la investigación. Ambas se caracterizan por ser momentos de máxima exposición de la compañía al medio público y por requerir una actitud proactiva.

1. El accidente: ocurre la caída del avión (con ello empieza su investigación).

2. La salida de investigación: salen los resultados de las causas del accidente a los medios.

Debido a que el tiempo de vida de una crisis es corta, entre esas dos fases, está la fase que llamamos "fase de tensión", ya que la compañía toma una actitud más reactiva y se prepara para reaccionar a una próxima "fase crítica", que será la publicación de los resultados de la investigación. Esta "fase de tensión" se caracteriza por tener menos exposición de la compañía en el medio público.

\section{Justificación de estrategias para contener la crisis:}

Nuestro plan de crisis y control de daños tiene como principal objetivo: Resguardar la reputación y continuidad de la compañía, protegiendo su imagen y reputación con todos los grupos de interés.

Para poder lograr el objetivo principal planteado, hemos desarrollado dos objetivos específicos enfocados en dos ejes estratégicos:

1. Identificar un equipo de crisis: Reorganizar un nuevo comité de crisis provisional, delimitando las funciones y responsabilidad que le compete a cada uno de los miembros mediante un plan de trabajo. Este comité provisional solo tendrá funciones durante la crisis; es decir, hasta que las investigaciones del caso hayan concluido y todos los afectados hayan sido atendidos. Luego de ello, se desintegrará y se conformará un comité de crisis oficial. 
2. Atención a los Stakeholders: Mantener a todos los grupos de interés implicados en el accidente, constantemente informados de los pasos que tomará la compañía, desde el primer día del accidente hasta el término de su investigación.

El primer eje nace bajo la necesidad de contar con un equipo organizado con funciones y responsabilidades particulares para contener esta crisis. Si bien en esta situación no se cuenta con el tiempo necesario para identificar a los colaboradores más idóneos e integrar el comité, "no existe una composición y un número ideal de personas que deban componer el comité aunque debe haber dos tipos de personas: las relacionadas con la resolución funcional del conflicto y las encargadas de enlazar y coordinar a los distintos departamentos y áreas de la compañía" (Costa, 2005). Contar con un comité de crisis en este caso, significa analizar, desde todas las perspectivas de la compañía, cuáles son las mejores acciones ante cada situación que la crisis nos vaya presentando.

Podemos justificar la presencia del comité bajo estos criterios:

- Liderazgo compartido: Si bien existe una cabeza en la organización como lo es el CEO, ante una crisis las decisiones a tomar deben partir bajo una evaluación de un equipo especializado en todos los frentes que presenten riesgos.

- Decisiones estratégicas: Contar con un equipo con profesionales muy bien capacitados en su materia, te permite formular estrategias que respondan a todas las necesidades del negocio, sin dejar pasar ningún detalle que pueda incrementar la gravedad de la crisis.

- Definen una postura: El comité de crisis permite establecer una postura compartida con todos los líderes de la compañía, la cual luego se desplegará a todos los colaboradores que la componen. Enfrentar la crisis con una postura homogénea y mensajes claves que refuerzan lo que la empresa quiere expresar, te dan un punto a favor sobre la situación.

- Fortalece al equipo: Definitivamente involucrar a tus colaboradores en la toma de decisiones para resolver una crisis, que pueda significar el cierre de tu compañía, simboliza la confianza que tienes sobre cada uno para que comparta sus puntos de vista y ejecute las acciones que lidera. Una vez terminada la crisis, el equipo que compuso el Comité durante esta etapa estará más comprometido con el resurgir de la compañía. 
Por otro lado, hemos decidido tener como segundo frente atender a nuestros stakeholders ya que ellos deben ser nuestra principal preocupación ante un evento como este. Necesitamos resolver sus inquietudes, reafirmar nuestro compromiso con ellos, acompañarlos en este proceso y, sobre todo, mantenerlos informados respecto a nuestras acciones. Esta postura nuestra de velar por ellos, nos posiciona como una empresa solidaria y transparente que en todo momento sobrepone el bienestar de las personas de lo comercial. Es importante resaltar bajo qué criterios hemos escogido como prioritarios a algunos stakeholders y cómo impactarán nuestras acciones a ellos en la evolución de la crisis:

A. Familiares: En esta segunda etapa (día 2), buscamos mostrarnos como una empresa solidaria y sensibilizada con el dolor de los familiares. Las acciones enfocadas a ellos serán el punto de partida para todo el plan de gestión que desarrollaremos para contraatacar los malos comentarios generados a raíz del accidente y las malas decisiones de la empresa en el día 1.

\section{Criterios:}

- Propósito de la empresa: VLA prioriza en sus valores el cuidado, tanto de las personas encargadas de las operaciones como de sus clientes. En línea con ello, debemos reafirmar nuestro compromiso con ellos con todo el apoyo que les sea necesario.

- Exposición en medios: Los medios de comunicación tendrán como principal centro de atención los reclamos de los familiares. Considerando este escenario, VLA debe anticipar cualquier situación que pueda significar un agravante para la crisis, como lo puede ser la historia del niño huérfano, poniéndose en contacto con todos los familiares afectados y mostrando su total disposición en ayudarlos.

- Evitar demandas: Lo que menos quiere ahora la empresa es tener a su equipo de Legal respondiendo a las numerosas demandas de los familiares. Nuevamente la anticipación es clave para este aspecto.

- Reputación corporativa: Si bien es difícil levantar tu imagen con tan solo pocos días de ocurrido el accidente, mostrarte con una actitud abierta a colaborar con todos los familiares, la cual se refuerza en tus mensajes externos, puede ayudarte a que esta crisis no se agrave y que no se siga afectando tu imagen. 
B. Colaboradores: A raíz de la crisis, muchos colaboradores mostraron su malestar de trabajar en VLA al no ser reconocidos por el trabajo que hacen, incluso trabajando horas extras. En esta segunda etapa debemos trabajar de la mano con los líderes para comunicar la importancia que tienen ellos para la organización. Esta crisis es un punto de quiebre también para trabajar sobre frentes que no estaban siendo considerados por la empresa.

Criterios:

- Filtración de información: Como ya lo destaca el caso, los colaboradores pueden ser nuestros principales aliados como enemigos. Es importante reforzar en ellos los mensajes de la empresa ante la crisis.

- Convertirlos en voceros: Debemos convertir a todos nuestros colaboradores en voceros de la empresa. Es importante que los líderes generen espacios de diálogo con sus equipos donde puedan compartir la información y mensajes establecidos por el Comité de Crisis.

- Evitar los rumores: Lo mejor es mantener a tus colaboradores bien informados, evitar el chisme es clave para no generar ese clima de intriga donde los colaboradores no sepan qué puede pasar con su trabajo debido a la situación que atraviesa la empresa.

C. Medios de Comunicación: Durante esta etapa de crisis, los medios serán los jueces de todas las acciones externas que nosotros realicemos (notas de prensa, comunicados en canales digitales, entrevistas). Es importante tener una buena relación con ellos para que transmitan la información de forma transparente.

Criterios:

- Pueden ser tus aliados: $\mathrm{Si}$ tenemos la atención de todos los medios, aprovechemos la oportunidad de transmitirles las acciones que la empresa está realizando a favor de las familias de los afectados. Debemos centrarnos en una postura donde lo más importante ahora es el bienestar de los familiares y colaborar con las investigaciones. 
D. Boeing: Las relaciones con Boeing deben ser cordiales durante todo el proceso de la crisis. Recordemos que el accidente ocurre por más factores relacionados a Boeing que a VLA. A estas alturas es mejor unir esfuerzos para esclarecer los hechos. Asimismo, establecer un mismo mensaje luego de las investigaciones, ya que finalmente ambos se responsabilizan por lo ocurrido.

\section{Criterios:}

- Socio estratégico: Si bien Boeing pueda ser el causante principal del accidente, sigue siendo una empresa multinacional con mayor experiencia en el sector la cual nos podría dar un mejor soporte para sobrellevar este proceso de crisis. Además de contar con su apoyo para la indemnización con las familias como ya lo ha hecho en casos anteriores.

- Aporte para la investigación: Nadie conoce mejor la aeronave accidentada que Boeing, es importante entablar una buena relación con ellos para conocer de antemano, por medio de los especialistas que mandarán para analizar la situación, qué es lo que realmente ocurrió. De esta forma, estaríamos mejor preparados para futuras acciones luego de que salgan las investigaciones.

E. Clientes: Luego del accidente, muchos de nuestros clientes se verán afectados por la cancelación de su vuelo y/o cambio de fecha debido a la detención de la nueva flota y por priorizar el traslado de los familiares de los accidentados. Es importante resaltar como mensaje para ellos de que todas estas acciones, que pueden encontrar muy incómodas, son realizadas por su seguridad.

Criterios:

- Dependemos de ellos: Una vez superada la crisis, dependemos de los clientes para volver a levantar las ventas y recuperar lo invertido durante la crisis. Debemos tener la comunicación más asertiva con ellos (bajo statements) para no generar un mayor malestar.

- Percibir nuestra preocupación: Si bien parar todas las nuevas flotas adquiridas pueda significar una gran pérdida de dinero, debemos reforzar el mensaje de que lo hacemos por la seguridad de nuestros clientes y que no pondremos en peligro su bienestar, así tengamos que afectar nuestras operaciones. 
F. Autoridades: Queremos ser una empresa transparente durante todo el proceso de investigación, facilitando el ingreso total a nuestras operaciones a las autoridades para las investigaciones necesarias.

Criterios:

- Responsables de las investigaciones: Para seguir demostrando nuestra preocupación por los familiares e investigaciones, debemos tener total apertura a cualquier indicación que las autoridades pertinentes nos soliciten con motivo de esclarecer lo sucedido.

\section{Justificación de acciones para contener una crisis:}

Sobre las acciones establecidas para los ejes estratégicos, justificaremos las que impliquen un costo o una mayor exposición en medios y que tengan una total participación del área de comunicaciones.

a. Envío de notas de prensa

Hemos desarrollado 3 notas de prensa a lo largo de toda la gestión de la crisis. Estas serán rebotadas orgánicamente a través de los medios de comunicación y de las Redes Sociales debido a la coyuntura de la noticia. Al ser un accidente de interés público, los medios se interesan por sacar la mayor cantidad de información posible, sin costo alguno, para mantener informada a la población. Por ello, para Viaje Lindo, una prioridad fue informar. Mientras más se informe, menos incertidumbre habrá.

- Referencia: Indicadores de medios.

\section{b. Agencia PR}

Consideramos importante contratar una agencia de Relaciones Públicas, ya que ellas se especializan en la gestión de una crisis reputacional. Además, es importante tener una visión objetiva (fuera de la empresa), ya que te ayudará a ver el panorama más amplio para encontrar soluciones rápidas para poder enfrentar la crisis. Esta agencia debe trabajar de la mano con el área de Asuntos Corporativos, velando por la imagen de la empresa, anticipando y sabiendo cómo reaccionar a crisis, y fomentando el relacionamiento con todos los grupos de interés. 
c. Redes Sociales

Cuadro de contenidos

Hemos decidido eliminar toda pauta publicitaria en redes sociales hasta el término de la investigación oficial del accidente, ya que consideramos no oportuno comunicar temas comerciales cuando la prioridad es manifestar la postura de la empresa sobre el accidente.

Oficializaremos la vuelta a la normalidad de la página con una publicación donde se publicarán los canales de contacto para poder informarse el estado actual de los pasajeros $\mathrm{u}$ otra información adicional que el público requiera. A partir de ello, volveremos a publicar contenido comercial y volveremos a activar la pauta.

Para poder tener una referencia del comportamiento e impacto que tuvo Viaje Lindo en redes sociales, utilizamos una aerolínea que se asemeja a este caso. Decidimos optar por los canales digitales de la aerolínea Lion Air, ya que es la aerolínea que cuenta con las mismas características de Viaje Lindo y con casi los mismos años en el mercado.

Un detalle importante es que Lion Air tuvo un accidente aéreo a fines de octubre de 2018, lo que nos permite evaluar un antes y un después en sus redes sociales y tener una estimación de cómo le afecta, a una compañía de esta envergadura, una crisis reputacional en redes.

Tabla 1.22

\begin{tabular}{|c|c|}
\hline Viaje Lindo Airlines & Lion Air \\
\hline Fundación: 1995 & Fundación: 1999 \\
\hline Empresa en crecimiento & Empresa en crecimiento \\
\hline Está buscando una cuota de & Es la mayor aerolínea de bajo costo en \\
\hline $\begin{array}{c}\text { El 09 de junio de 2019, el vuelo 335 de } \\
\text { Viaje Lindo, operado con un Boeing 737 } \\
\text { MAX de tan solo 1 mes de antigüedad se }\end{array}$ & $\begin{array}{c}\text { Lion Air, operado con un Boeing 737 MAX 8 } 8 \\
\text { de tan solo 2 meses de antigüedad se estrella } \\
\text { en el mar en las cercanías de Yakarta trece }\end{array}$ \\
\hline
\end{tabular}


estrella en Arequipa, a bordo iban 172 pasajeros y solo 72 sobrevivieron. minutos después del despegue, a bordo iban 189 pasajeros y ninguno sobrevivió

Tomando de referencia las páginas digitales de Lion Air, podemos decir que antes del accidente las páginas de Viaje Lindo tuvieron comportamientos distintos al después de lo ocurrido. Evaluamos sólo las páginas que emitieron algún comunicado sobre el accidente: Facebook, Twitter e Instagram.

- Tiempo de estudio: 1 semana.

Facebook 58,475 fans:

\begin{tabular}{|l|c|c|c|}
\hline & Semana Típica & Semana de Crisis & Dif. \\
\hline Número de publicaciones & 6 & 26 & $+333.33 \%$ \\
\hline Número de comentarios & 190 & 1077 & $+466.84 \%$ \\
\hline Número de compartidos & 24 & 1387 & $+5679.16 \%$ \\
\hline Número de "me gusta" & 226 & 6653 & $+2401.13 \%$ \\
\hline
\end{tabular}

Herramienta Fanpage Karma.

Twitter 12,105 seguidores:

\begin{tabular}{|l|c|c|}
\hline & Semana Típica & Semana de Crisis \\
\hline Número de RT & 0 (no hubo actividad) & 204 \\
\hline Número de favoritos & 0 (no hubo actividad) & 298 \\
\hline Número de comentarios & 0 (no hubo actividad) & 93 \\
\hline
\end{tabular}

Herramienta Fanpage Karma.

Instagram 15,4952 seguidores (semana del 29 de oct al 5 nov): 


\begin{tabular}{|l|c|c|c|}
\hline & Semana Típica & Semana de Crisis & Dif. \\
\hline Número de likes & 15990 & 22273 & $39.29 \%$ \\
\hline Número de publicaciones & 4 & 1 & $-75 \%$ \\
\hline $\begin{array}{l}\text { Número de comentarios por } \\
\text { publicación }\end{array}$ & 7058 & $\begin{array}{l}\text { Eliminó los } \\
\text { comentarios }\end{array}$ & - \\
\hline
\end{tabular}

Herramienta Fanpage Karma.

Como podemos observar, en la semana de la crisis aérea la interacción en las redes sociales en Facebook, Twitter e Instagram aumentó considerablemente respecto a una semana típica. Ello quiere decir que las redes sociales para estos casos de crisis son muy importantes, no solo para los cibernautas, sino para la compañía.

- Para los cibernautas: Las redes sociales son un medio donde pueden emitir su opinión sobre la crisis que afronta la compañía. En este caso, por ejemplo, lo utilizan también para escribir mensajes de duelo, apoyo a los familiares y mantenerse informados de los movimientos de la compañía.

- Para la compañía: Las redes sociales son un medio donde se puede contener la crisis siempre y cuando sea utilizando como un canal de información y sea manejado por un profesional preparado para enfrentar los cuestionamientos del público. Gracias al alcance de las redes sociales, por la accesibilidad y a la viralización de las noticias, esta información llegará fácilmente a todo el público.

Hoy en día, no utilizar de manera correcta las redes sociales puede ser un factor determinante para el éxito, o fracaso, de una crisis empresarial. Estas deben usarse para brindar la información necesaria, atender cualquier eventualidad, en el menor tiempo posible y evitar la potencial oleada viral de negatividad.

\section{B. Prevención de Crisis:}

En esta segunda etapa, sustentamos las herramientas y estrategias que consideramos necesarias para que Viaje Lindo Airlines esté mejor preparada ante una futura posible crisis. Estas herramientas, sustentadas a continuación, tienen como antecedente la última experiencia de crisis que atravesó la empresa y serán insumo para una próxima. 
Medidas de Prevención: Una vez realizada la investigación previa y con un mejor conocimiento de los posibles riesgos que podrían surgir en diversos frentes, ya podemos diseñar los procesos, herramientas, funciones y materiales que nos ayudarán a prever, contener o mitigar futuras crisis.

Consideramos necesario implementar un área de Asuntos Corporativos estrictamente enfocada en velar temas de reputación de la empresa. Si bien el área de Comunicaciones cumplió este rol durante la primera crisis, es importante contar con un área focalizada no solo en ejecutar el plan de acción, sino también en velar por temas de relacionamiento, responsabilidad social, comunicación externa e imagen de la compañía; sobre todo considerando la magnitud de la última crisis y el proceso de recuperación que atravesará VLA.

Además, es necesario que el área de Comunicaciones vele más por fortalecer los canales internos que ya cuenta la empresa. Si contamos con un flujo de trabajo establecido por cada canal, podremos tener responsables listos de difundir la información necesaria durante un proceso de crisis.

Posterior a ello, ya con el apoyo de la nueva área, planteamos formar un Comité de crisis, preparado para definir objetivos y funciones durante estas situaciones y un Manual de Crisis, que será el documento formal de la ejecución de acciones y protocolos durante la crisis. Ambas acciones son fundamentales para poder definir la postura de la empresa, alineada al propósito de la misma, durante este tipo de eventos.

\section{Justificación de estrategias para prevención de crisis a mediano plazo:}

Asimismo, justificaremos las acciones que VLA deberá realizar a mediano plazo para revertir la crisis y convertirla en una oportunidad de mejora en todas sus operaciones.

1. Evaluación e Identificación: Las empresas que atraviesan una crisis y están preparadas, tienen mayores posibilidades de contenerla e incluso salir fortalecida luego de superarla. Con esto queremos decir que Viaje Lindo Airlines debe estar preparada ante cualquier situación de riesgo que pueda ocurrir a futuro. Para ello, el primer paso es conocer cómo está preparada tu empresa en todos los frentes. 
"El propósito general de la gestión de conflictos potenciales es hacer posible que la organización identifique de manera temprana aquellos conflictos que pudieran tener un cierto impacto sobre la consecución de sus objetivos, de modo que se puedan solucionar los posibles problemas a la detección de sus primeros indicios." (Herrero)

La última experiencia de VLA en la última crisis, grafica la falta de preparación que tuvieron para responder ante este accidente. Nosotros proponemos, como primer eje estratégico, realizar un diagnóstico tanto interno como externo para identificar los aspectos vulnerables de peligro y riesgo de la empresa.

\section{Frente Interno}

Para conocer mejor nuestras operaciones de forma interna, hemos propuesto primero trabajar de la mano con una auditora que nos brinde un reporte de posibles riesgos dentro de nuestras operaciones. Es necesario trabajar con alguien externo ya que, además de su conocimiento de identificar potenciales riesgos, nos brindan un análisis objetivo.

En segundo lugar, hemos decidido analizar la actividad de nuestros canales internos, con esto queremos identificar si nuestros colaboradores reciben e interiorizan la información que brinda la empresa a través de comunicaciones. Como se resalta en el caso, existen canales que escapan del manejo del área de Comunicaciones, por lo que será importante evaluar con qué canales oficiales debería contar la empresa y retirar los que no influyan en los colaboradores. Así se puede centralizar mejor la información durante una crisis.

Por último, consideramos necesario conocer cómo está el clima laboral real de la empresa. Si bien la auditoría planteada al inicio nos muestra resultados respecto a las operaciones, es importante no perder de vista cómo se sienten nuestros colaboradores, ya que son un frente importante que también podría desembocar en posibles riesgos de crisis. Teniendo claro cómo se sienten ellos, se podrían trabajar campañas enfocadas en mejorar esos aspectos de clima. Así, durante una crisis podrás contar con el apoyo total de los colaboradores.

\section{Frente externo}


Hemos planteado como primer paso conocer el perfil de todos nuestros stakeholders. De la mano de una consultora $P R$, podemos solicitar el desarrollo de un perfil de cada público para que, en base a ello, podamos elaborar estrategias pensadas en futuras posibles crisis que respondan estrictamente a cada uno.

En segundo lugar, consideramos importante elaborar un mapa de actores para identificar qué tanta influencia pueden tener con la empresa. Con ello, podemos definir el orden de nuestras acciones durante una crisis según el impacto que tendrá en cada público, priorizando a los de influencia alta.

Finalmente, queremos realizar un diagnóstico de nuestros canales digitales con el apoyo de una agencia digital. El motivo es conocer qué aspectos podemos mejorar y qué acciones implementar para que no se desaten posibles riesgos de crisis digitales.

2. Cultura Corporativa: Proponemos acciones a mediano plazo enfocadas en fortalecer la cultura corporativa, ya que luego de una crisis de esta magnitud, el mal clima laboral y algunas molestias de los colaboradores con la gestión de la empresa salen a la luz. Es por ello que consideramos como una gran oportunidad trabajar acciones inmediatas en el ámbito cultural para poder generar un vínculo afectivo entre los colaboradores y la empresa. Del mismo modo, estas acciones nos permitirán también eliminar cualquier rumor que surja después del accidente. Bajo esta idea, hemos propuesto tres acciones que nos permitan, a mediano plazo, fortalecer la cultura corporativa de la empresa.

Primero, para poder trabajar cualquier aspecto de la cultura corporativa necesitamos generar un vínculo afectivo entre el máximo representante de la empresa, CEO, con los colaboradores. Consideramos importante que el CEO sea el encargado de enviar un mensaje a todos los colaboradores que se han visto afectados de alguna manera por la exposición de la empresa durante la crisis. Los principales mensajes dentro de este video deberán estar enfocados en:

- Agradecimiento a todos los colaboradores por su compromiso antes, durante y después de la crisis.

- Fortalecer los valores de la organización y la renovación de su compromiso por brindar el mejor servicio con los más altos estándares de seguridad. 
- Desmentir cualquier rumor que esté circulando en la empresa.

- Resaltar la historia de la empresa y su compromiso que tiene con el mercado peruano desde hace 15 años y con temas relacionados a la responsabilidad social.

- Resaltar la importancia de mantenerse más unidos y dar lo mejor de cada uno para que VLA siga liderando en el mercado peruano.

En segundo lugar, hemos propuesto que los equipos gerenciales tengan un espacio de reunión de forma mensual para que puedan compartir con sus equipos los nuevos objetivos de la organización post-crisis e ir actualizando sobre los avances de la empresa. Es importante generar estos espacios para que los colaboradores interioricen estos nuevos objetivos y se comprometan a dar lo mejor desde su lugar para alcanzarlos. También, se busca generar un mejor vínculo afectivo entre jefes y colaboradores para que se puedan establecer espacios de reconocimientos informales que incentiven a los colaboradores a seguir mejorando.

Finalmente, una vez que el CEO y el equipo Gerencial haya generado un vínculo más cercano con los colaboradores después de la crisis, podemos trabajar en fortalecer los valores de la organización mediante un plan de comunicación interna transversal que fortalezca e interiorice los valores de la empresa en el día a día de los colaboradores. El plan de comunicación se apalancará en los dos valores de seguridad y puntualidad. Consideramos que si queremos recuperar la confianza de nuestros clientes hacia afuera respecto a nuestros controles de seguridad y calidad, primero debemos interiorizarlo de forma interna en nuestros colaboradores para que cualquier operación se ejecute en línea a nuestros valores corporativos. Además, llevaremos a cabo las sesiones necesarias para planificar la formulación de un nuevo "propósito", el cual reemplazará la actual misión y visión de la compañía. Este propósito enmarcará la razón de ser de Viaje Lindo, brindará un mismo camino, congruencia y compromiso a los todos colaboradores de la compañía y le dará el toque de "refresco" que la marca necesita para resurgir.

3. Liderazgo Comunicacional: Proponemos el liderazgo comunicacional como otro eje estratégico dentro de nuestra matriz porque consideramos primordial, ante una crisis, la comunicación entre los líderes y sus equipos. Si queremos tener a nuestros colaboradores como portavoces oficiales de la empresa durante una crisis, es importante 
que el jefe o gerente esté preparado para ello y tenga un buen acercamiento al momento de narrar lo sucedido y delegar las funciones a cada miembro de su equipo.

Como señala Mariajosé Gavilán, "En los contextos de crisis los líderes son una pieza fundamental para promover la motivación, brindar la seguridad y la transparencia necesaria para mitigar las reacciones adversas, y mantener un buen nivel de compromiso de los colaboradores. El líder es el protagonista que ofrece la visión y establece el contexto para que los equipos de trabajo se movilicen hacia la acción propositiva." (Gavilán, 2018)

Hemos propuesto identificar primero cómo son las competencias comunicacionales de nuestros gerentes. Con ello, vamos a poder trabajar con una empresa de capacitaciones que nos brinde los servicios de Coaching y Media Training para que nuestro equipo gerencial pueda desarrollar competencias comunicacionales que carecen. Consideramos trabajar con una empresa especialista en el tema, con el soporte de nuestra área de Recursos Humanos, porque tienen un mejor conocimiento respecto a todas las situaciones que puede atravesar un portavoz oficial de la compañía y sobre cómo ellos podrían afrontarlo con los diversos medios.

4. Fortalecimiento de la Reputación: Por último, proponemos fortalecer la reputación de la empresa por medio del relacionamiento con medios de comunicación, actividades de responsabilidad social y alianzas con autoridades públicas y privadas, ya que consideramos que tener una buena reputación nos servirá como recurso estratégico durante una crisis.

El buen relacionamiento con los medios de comunicación nos permitirá a futuro que muchos de ellos, en vez de cuestionar y lanzar cualquier tipo de información sobre futuras crisis, dialoguen primero con nosotros para confirmar cualquier tipo de información que esté circulando

Para sobrellevar la post - crisis, trabajaremos de la mano con la Responsabilidad Social. Si bien esta se encarga de reducir, mitigar y compensar todos los impactos negativos, o potencialmente negativos, hacia los públicos de interés bajo la triada: medioambiental, sociedad y economía; ésta también trabaja como punto de apalancamiento de la reputación. La RSE contribuye en la reputación de una empresa ya que satisface las expectativas de todos los grupos de interés de la compañía. 
Para empezar una cultura de RSE, publicaremos una Política de Sostenibilidad la cual permitirá orientar y direccionar las normas y responsabilidades de cada área de la organización frente a sus operaciones. En este documento estarán las bases para que todas las acciones de la compañía estén pensadas en pro de la sostenibilidad económica, social y medio ambiental. Esta política debe ser divulgada, entendida y acatada por todos los miembros de la organización para comenzar a ser una empresa sostenible.

Es importante resaltar que todas las acciones de Responsabilidad Social de la compañía estarán alineadas a los Objetivos de Desarrollo Sostenible, pronunciados por la ONU en 2016. Estos objetivos, además de contribuir con las personas, el planeta y la prosperidad para un desarrollo sostenible, brindan un mismo camino a todas las actividades y las replantea para un mismo objetivo. En 2016, el Grupo de Acción sobre Transporte Aéreo (ATAG por sus siglas en inglés) publicó un estudio que identifica los ODS a los que el sector aéreo puede contribuir más efectivamente.

"Descubrimos que el transporte aéreo de alguna manera respalda 14 de los 17 Objetivos de Desarrollo Sostenible, desde trabajo decente y crecimiento económico hasta educación de calidad y reducción de las desigualdades. Al continuar creciendo de manera sostenible, la aviación puede ser una fuerza para bien por muchos años en adeltante." - Michael Gill, Director Ejecutivo de ATAG.

Es importante también que la empresa continúe con sus esfuerzos por destacar gracias a sus iniciativas medio ambientales y, sobre todo, las comunique. Si no se comunica, no existe. Por lo que la aerolínea debe informar a todos sus públicos de interés los programas medio ambientales que ya trabaja actualmente y cuál ha sido su impacto. En ello resaltamos la utilización del biocombustible, como insumo para los aviones. De esta manera, se puede considerar que la empresa tiene un compromiso medio ambiental y es consecuente todos los años con él.

El lanzamiento del Reporte de Sostenibilidad debe considerarse también todos los años, ya que demuestra un compromiso por la compañía y pone en transparencia todas las acciones e impactos, sean buenos o malos, de la aerolínea hacia todos sus grupos de interés. Es importante trabajar una campaña de comunicación al lanzar el reporte, ya que el objetivo de este es que todos los grupos interesados puedan leer y conocer las operaciones de Viaje Lindo. 


\section{RECOMENDACIONES}

A partir de lo anteriormente desarrollado, recomendamos:

1. Para un efectivo manejo de crisis es importante mantener al gabinete de crisis reunido continuamente para mantenerlo informados sobre la situación actual de la empresa. De esta manera, no solo podrán conocer cuáles son las futuras amenazas y debilidades de la aerolínea, sino que también podrán trabajar acciones para poder anticiparlas o saber cómo reaccionar. Todo ello debe estar plasmado en un Manual de Crisis, que sirva como herramienta para la gestión de la comunicación a la hora de enfrentarse a situaciones de crisis.

2. En una crisis, sobre todo una que ha tenido pérdidas de vidas, una empresa nunca debe desentenderse del problema y culpar a un tercero, ya que puede infligir en su reputación. La empresa siempre debe asumir su responsabilidad y pedir disculpas públicas, así las investigaciones no hayan concluido. Por otro lado, si el vocero no ha sido preparado para enfrentar a la prensa, y no cuenta con herramientas de ayuda, no se le debe exponer a una rueda de preguntas abiertas.

3. Reactivar los canales de comunicación internos, estableciendo flujos de trabajo, que le permitan al equipo de Comunicaciones tener control sobre ellos.

4. Es indispensable que la compañía y sus proveedores mantengan una comunicación constante durante todos los procesos que lleven a cabo. Toda comunicación debe ser de doble vía y manejarse con total transparencia y claridad. De esta manera, se puede mantener un orden y registro de todos los procesos en la cadena de valor y los cambios que pueden haberse presentado. Así, frente a algún error o incumplimiento, ambas partes pueden rastrear el origen de la falla y tomar las acciones necesarias para resolver el problema lo antes posible.

5. Fortalecer las relaciones públicas para generar un relacionamiento con todos los públicos de interés de la compañía. La generación de alianzas, sean públicas o privadas, brindan mayor visibilidad a la compañía y, por ende, mayor reputación. Además, ayuda a desarrollar relaciones con mayor sostenibilidad con cada uno de los stakeholders.

6. Realizar encuestas de clima laboral anuales para obtener un diagnóstico de cómo se sienten los colaboradores en la empresa y cuál es la evolución de ese sentimiento año a año. A partir de los resultados, se puede conocer qué frente débil cubrir y ejecutar acciones para mejorar el clima para que Viaje Lindo sea un 
buen lugar para trabajar. Si los colaboradores se sienten satisfechos y contentos con su trabajo, la empresa tendrá una buena imagen y reputación, ya que todo empieza de manera interna.

7. Velar por la continuidad de los programas o iniciativas, externas e internas, de Responsabilidad Social que estén alineados al negocio. Estos son un soporte de la reputación de la empresa frente a todos sus stakeholders y fortalecen su imagen. Es importante trabajar primero en acciones internas y comunicarlo, ya que los colaboradores son los principales voceros de la reputación de la empresa. 


\section{REFERENCIAS}

Administration, F. A. (30 de agosto de 2019). News \& Updates. Obtenido de FAA Updates on Boeing 737 MAX:

https://www.google.com/url?q=https://www.faa.gov/news/updates/?newsId\%3D 93206\&sa=D\&ust=1569190652501000\&usg=AFQjCNHKx-VaMLpPit0M2bfvuwKFS5wMw

Blanco, T. P., \& Herrera, J. S. (2013). Imagen Corporativa. Madrid: ESIC.

ÇAKI, D. C. (Septiembre de 2014). MEASURING SERVICE QUALITY AND BRAND LOYALTY RELATIONSHIP IN TURKISH LOW COST AIRLINE MARKET: A CASE STUDY OF PEGASUS AIRLINES AND ANADOLUJET. Department of Business Administration.

Comercio, E. (7 de abril de 2016). El Comercio. Obtenido de https://elcomercio.pe/economia/peru/impacto-industria-aerea-pbi-peruano214531

Corpac. (s.f.). LA AVIACIÓN CIVIL Y EL MEDIO AMBIENTE. Obtenido de http://www.corpac.gob.pe/Main.asp?T=4209

Correa, H. F., \& Cruz, Á. P. (2015). VivaColombia revoluciona los precios del mercado con su modelo low cost. ARMENIA - QUINDÍO: UNIVERSIDAD EAFIT.

Costa, J. (2005). Master DirCom. La Paz: Grupo Design.

Economics, O. (2010). Beneficios Económicos del Transporte Aéreo en el Perú . Lima: Oxford Economics.

Eroğlu, O. (2015). The success of low cost carriers: the case of Southwest Airlines and Pegasus. Gumushane Universitesi.

Gavilán, M. (27 de junio de 2018). La República.net. Obtenido de https://www.larepublica.net/noticia/el-liderazgo-en-tiempos-de-crisis

Herrero, A. G. (s.f.). ISSUES MANAGEMENT: LA GESTIÓN DE ASUNTOS POTENCIALMENTE CONFLICTIVOS. Madrid: Centro de Estudios Superiores Felipe II (Universidad Complutense de Madrid) .

ICAO. (s.f.). ICAO Carbon Emissions Calculator. Obtenido de https://www.icao.int/environmental-protection/CarbonOffset/Pages/default.aspx

Indecopi. (s.f.). Derecho de los pasajeros en el transporte aéreo. https://www.indecopi.gob.pe/documents/2820519/2886637/Interactivo+Derecho+del+Pasajero+\%281\%29.pdf/585d66af-7fa5-b357-734a4eca0b261f0f. Obtenido de https://www.indecopi.gob.pe/documents/2820519/2886637/Interactivo+Derecho+del+Pasajero+\%281\%29.pdf/585d66af-7fa5-b357-734a$4 \mathrm{eca} 0 \mathrm{~b} 261 \mathrm{f} 0 \mathrm{f}$ 
Infobae. (14 de marzo de 2019). Mundo. Obtenido de Las razones ocultas detrás de las tragedias de los Boeing 737 MAX:

https://www.infobae.com/america/mundo/2019/03/14/las-razones-ocultasdetras-de-las-tragedias-de-los-boeing-737-max/

Josephs, L., \& Kimball, S. (2 de junio de 2019). CNBC. Obtenido de https://www.cnbc.com/2019/06/02/boeing-notifies-faa-of-737-max-parts-thatmay-be-susceptible-to-failure.html

Karlosperu. (29 de mayo de 2019). KARLOSPERÚ. Obtenido de https://www.karlosperu.com/con-nueva-pagina-web-y-adopcion-de-tecnologiasde-punta-viva-air-apuesta-a-consolidar-su-modelo-low-cost/

Pancorbo, C. d. (2014). Tendencias Turísticas en el mercado español . Segovia: Universidad de Valladolid.

Porter, M. (2010). Creación y sostenibilidad de un rendimiento superior. Ediciones Pirámide.

RPP. (5 de junio de 2019). RPP Noticias. Obtenido de Economía: https://rpp.pe/economia/economia/gobierno-propone-subsidiar-vuelos-a-zonasaisladas-donde-no-hay-oferta-noticia-1201061

School, E. B. (6 de septiembre de 2017). Obtenido de https://retosdirectivos.eae.es/como-adoptar-una-actitud-proactiva-en-la-gestion-deempresas/

Staff, F. E. (4 de Junio de 2019). Flight Safety Foundation. Obtenido de https://flightsafety.org/faa-some-737s-may-have-faulty-wing-slat-components/

TNews. (25 de enero de 2018). TNews. Obtenido de https://tnews.com.pe/soloperuvian-y-lc-peru-crecieron-en-participacion-de-mercado-en-el-2017/

Villar, P. (3 de octubre de 2018). El Comercio. Obtenido de Negocios: https://elcomercio.pe/economia/negocios/sky-airline-low-cost-destinara-2aviones-nuevos-flota-peru-noticia-563911

Williams, G. (2001). Will Europe's charter carriers be replaced by "no-frills" scheduled. Journal of Air Transport Management.

Wittmann, R. (2006). ¿Hubo una revolución en la lectura a finales del siglo XVIII? En G. Cavallo, \& R. Chartier, Historia de la lectura en el mundo occidental (págs. 435-472). México D.F.: Santillana. 


\section{ANEXOS}

\section{$\underline{\text { Anexo } 1}$}

\section{Aeronavegabilidad - Ley de Aeronáutica Civil Ley No 27261.}

Procedimientos para la certificación y el mantenimiento de la aeronavegabilidad:

Generalidades al respecto, las Regulaciones Aeronáuticas del Perú y demás normas complementarias considerarán, necesariamente, los siguientes aspectos:

Aplicación

- Número de grupos motores

- Limitaciones operacionales

- Características que pueden comprometer la seguridad

- Pruebas de conformidad.

Vuelo

- Generalidades

- Performance

- Cualidades de vuelo

Estructuras

- Generalidades

- Velocidades aerodinámicas

- Cargas de vuelo

- Cargas en tierra y en el agua

- Cargas diversas

- Flameo, deformación y vibraciones

- Resistencia a la fatiga

Diseño

Motores

- Diseño, construcción y funcionamiento 
- Homologaciones, condiciones y limitaciones declaradas

- Ensayos.

Hélices

- Diseño, construcción y funcionamiento

- Homologación, condiciones y limitaciones declaradas

- Ensayos.

Instalaciones del sistema moto propulsor

- Generalidades

- Disposición y funcionamiento.

Instrumentos y equipo

- Instrumentos y equipo necesarios

- Instalación

- Equipo de seguridad y supervivencia

- Luces de navegación y luces anticolisión.

Limitaciones de utilización e información

- Generalidades

- Limitaciones de utilización

- Información y procedimientos de utilización

- Información referente a la performance

- Manual de vuelo del avión

- Indicaciones y letreros.

Mantenimiento de la aeronavegabilidad

- Generalidades

- Información sobre el mantenimiento

- Información sobre el programa de mantenimiento

- Información sobre el mantenimiento resultante de la aprobación del diseño de tipo. 
Seguridad Al respecto

- Lugar de riesgo mínimo para colocar una bomba.

- Protección del compartimento de la tripulación de vuelo

- Diseño interior.

\section{$\underline{\text { Anexo } 2}$}

- Entrevista a Martín Palomino Zapata

Jefe de Litigios y Aduanas en Latam Airlines Perú

\begin{tabular}{|c|l|l|}
\cline { 2 - 3 } \multicolumn{1}{c|}{} & \multicolumn{1}{c|}{ Accidente } & \multicolumn{1}{c|}{ Incidente } \\
\hline Definición & $\begin{array}{l}\text { Todo suceso relacionado con la utilización de } \\
\text { una aeronave tripulada, que ocurre entre el } \\
\text { momento en que una persona entra en la } \\
\text { aeronave, con la intención de realizar un } \\
\text { vuelo, y el momento en que han } \\
\text { desembarcado. }\end{array}$ & $\begin{array}{l}\text { Aquel suceso que, no } \\
\text { llegando a ser un } \\
\text { accidente, afecta o puede } \\
\text { afectar la seguridad de las } \\
\text { operaciones. }\end{array}$ \\
\hline Consecuencias & $\begin{array}{l}\text { 1. Lesiones mortales o graves. } \\
\text { 2. La aeronave sufre daños o roturas } \\
\text { estructurales que afectan su aeronavegabilidad } \\
\text { o exigen una reparación importante. } \\
\text { 3. La aeronave desaparece o es totalmente } \\
\text { destruida. }\end{array}$ & \\
\hline
\end{tabular}

1. Todo accidente de aviación será investigado por la Comisión de Investigación de Accidentes de Aviación (CIAA), que determinará sus causas y establecerá las medidas para evitar que se repitan (art. 154.1 de la LAC)

2. La Comisión está conformada por:

Un Representante del MTC

Un abogado designado

Un especialista en operaciones aéreas

Un especialista en aeronavegabilidad

El jefe del Plan Nacional de Búsqueda y Salvamento

3. La CIAA actúa de manera paralela a la intervención judicial / policial (art. 154.3 LAC) 
4. La aeronave no puede ser movilizada hasta que la CIAA lo autorice (art. 154.2).

5. Si se toma conocimiento de un accidente o incidente, se debe comunicar inmediatamente a una autoridad (art. 155.1 de la LAC)

6. La CIIA emite un informe final con recomendaciones, que no está orientado a determinar responsabilidades.

7. Constituyen infracciones (esto lo determina la Junta de Infracciones de Aeronáutica Civil):

- Retirar componentes o trasladar una aeronave que ha sufrido un accidente (Muy Grave: Suspensión de las autorizaciones).

- Negarse a colaborar en la investigación de un accidente (Muy Grave: Suspensión de las autorizaciones)

8. ¿Podrían suspenderme/revocarme el permiso de operación?

$\mathrm{Si}$, para contar con un permiso de operación se requiere comprobar que se tiene capacidad legal, técnica y económico-financiera. Dependiendo de la causa del accidente, podría determinarse que no se cuenta con capacidad técnica, lo cual conllevaría a la revocación del permiso de operación.

\section{$\underline{\text { Anexo } 3}$}

Tomando de referencia las páginas digitales de Lion Air, podemos decir que antes del accidente las páginas de Viaje Lindo tuvieron estos comportamientos:

Estudios

- Página web

\begin{tabular}{|l|l|l|l|}
\hline Tráfico & Visitas & Tiempo de visita & Promedio de páginas vistas \\
\hline $46.69 \%$ & 3.258 .000 & $00: 15: 16$ & 14.69 \\
\hline
\end{tabular}

Herramienta Similar Web

Facebook 58,475 fans

\section{Conteo semanal:}

Número de "Me gusta" recibidos 


\begin{tabular}{|l|l|}
\hline Índice de Rendimiento de la Página & $13.0 \%$ \\
\hline Evolución semanal & $0.2 \%$ \\
\hline Interacción de las publicaciones & $0.51 \%$ \\
\hline Número de publicaciones & 6 \\
\hline Publicaciones / día & 0.75 \\
\hline Total de Reacciones, Comentarios, Compartidos & 1784 \\
\hline Número de comentarios & 190 \\
\hline Crecimiento (total) & 135 \\
\hline Compartidos por publicación & 24 \\
\hline Comentarios por publicación & 29 \\
\hline Me gusta por publicación & 226 \\
\hline Número de me asombra por publicación & 0,6 \\
\hline Número de me divierte por publicación & 1,6 \\
\hline Número de me encanta por publicación & 12 \\
\hline Número de me entristece por publicación & 9,3 \\
\hline Número de me enoja por publicación & 0,1 \\
\hline & \\
\hline
\end{tabular}

Herramienta Fanpage Karma

\section{Instagram 15,4952 seguidores}

\section{Conteo semanal:}

Número de Me gusta 19,606 


\begin{tabular}{|l|l|}
\hline Interacción de las publicaciones & $2.59 \%$ \\
\hline Número de publicaciones & 5 \\
\hline Publicaciones / día & 0.625 \\
\hline Total de Reacciones, Comentarios, Compartidos & 20,016 \\
\hline Número de comentarios & 410 \\
\hline Crecimiento (total) & 1131 \\
\hline
\end{tabular}

Herramienta Fanpage Karma.

Twitter 12,105 seguidores

\section{Conteo (semanal)}

\begin{tabular}{|l|l|}
\hline Número de Me gusta & 0 \\
\hline Interacción de las publicaciones & $0.0 \%$ \\
\hline Número de publicaciones & 0 \\
\hline Publicaciones / día & 0 \\
\hline Total de Reacciones, Comentarios, Compartidos & 0 \\
\hline Crecimiento (total) & 24 \\
\hline
\end{tabular}

Herramienta Fanpage Karma.

\section{LinkedIn}

\begin{tabular}{|l|l|}
\hline Seguidores & 15.938 \\
\hline Publicaciones & 0 \\
\hline
\end{tabular}

Herramienta Fanpage Karma.

Ocurrido el accidente de Lion Air, estos fueron los comportamientos de sus redes

(Evaluamos sólo las páginas que emitieron algún comunicado sobre el accidente:

Facebook, Twitter e Instagram):

Facebook (semana del 29 de oct al 5 nov): 
Número de likes por publicación

Número de comentarios por publicación

Twitter (semana del 29 de oct al 5 nov):

\begin{tabular}{|l|l|l|}
\hline Número de RT por publicación & 204 & \\
\hline Número de favoritos por publicación & 298 & \\
\hline Número de comentarios por publicación & 93 & \\
\hline
\end{tabular}

Instagram (semana del 29 de oct al 5 nov):

\begin{tabular}{|l|l|l|}
\hline Número de likes por publicación & & \\
\hline Número de comentarios por publicación & & \\
\hline
\end{tabular}

\section{$\underline{\text { Anexo } 4}$}

- Entrevista a Maribel Toledo Ocampo

CEO de Toc Asociados

Mapear a quiénes les vas a comunicar. Tus frentes de comunicación: Medios, familiares, Boeing (socio estratégico), público interno, y reguladores.

$\checkmark$ Designar un equipo de trabajo para c/u

$\checkmark$ No puedes salir a los MM.CC antes de tus otros frentes. Tu prioridad 1 es Familiares (informados y geográficamente delimitados).

$\checkmark$ La conferencia de prensa no es lo mejor ante un error tan grande, porque da la posibilidad de preguntas.

$\checkmark$ Un comunicado es lo mejor. Esa debe ser la primera acción.

$\checkmark$ Estructura de un comunicado: Lamentar, informar número de heridos, empatía con los familiares y enumerar las acciones tomadas e informar a la opinión publica cada cuanto tiempo, a través de que canal, se va a seguir comunicando.

$\checkmark$ Un primer comunicado no debe decir la indemnización, puede ir después 
$\checkmark$ "Hemos tomado contacto con los familiares en la oficina tal... "Está en proceso de investigación" "colaboraremos con las investigaciones y los mantendremos informados continuamente a través de comunicados"

$\checkmark$ El error es que se centraron solo en comunicarse con los medios.

$\checkmark$ Los Manuales de crisis son un armatoste que nadie lee. Debería tener una versión resumida casi de cartilla

$\checkmark$ Información clave de qué debe responderse en un comunicado:

○ Qué pasó

- Quién fue responsable

○ Quiénes y cuántos fueron los afectados

- Tipos de incidencia

- Consecuencias

$\checkmark$ El admitir tu culpa puede implicar que no te dejen volar nunca más.

$\checkmark$ Generadores de opinión o periodistas principales: gente mapeada que puede hablar sobre el problema.

$\checkmark$ Tomarnos 1 hora más en armar un comité: cada persona se hace cargo de un público.

$\checkmark$ Lo ideal hubiese sido que Boeing saque un comunicado.

$\checkmark$ Exponer a otro vocero.

$\checkmark$ Cambiar de CEO es una posibilidad. Pero tiene una serie de costos: estas asumiendo que fue tu culpa.

$\checkmark$ El nuevo vocero debe salir con el statement "estamos en un proceso de investigación" y enfocándole la atención de la información a los familiares.

$\checkmark$ Hacer un Q\&A.

$\checkmark$ No hacer entrevistas 1 a 1 es muy riesgoso.

$\checkmark$ Puedes dar una conferencia, pero sin abierta a preguntas. Solo se lee el comunicado.

$\checkmark$ Para resolución de crisis, cambias al CEO para sacar del foco a la empresa. Que el juicio sea a la persona.

$\checkmark$ "En aras de que la comunidad esté informada Estaremos en constante comunicación brindándoles informes detallados cada (periodicidad)"

$\checkmark$ "Esta nueva administración será más rigurosa aún en el control de..."

$\checkmark$ Puedes informar cosas que ya los medios dieron (Redes Sociales) 
$\checkmark$ Lo ideal es que en cualquier otro negocio pares tu operación, pero en este rubro no debes porque puede generar otra crisis.

$\checkmark$ No colocaría el nombre de los muertos, daría un canal de consulta.

$\checkmark$ La constante información permite difuminar los primeros errores.

$\checkmark$ Exhortar a la interna que Boeing reconozca su falla. "Tal como informamos en su momento confirmamos que la elaboración de los aviones tuvieron una falla de origen..." "Tal como dijimos en su momento, Boeing..." el error del CEO se minimiza aquí.

$\checkmark \quad 1$ comunicado lamentas y asumes sin mencionar lo de Boeing, como si no hubiese existido el anterior.

$\checkmark$ Nuestra reacción debería ser "tras las investigaciones del caso..." remueves a la plana directiva.

$\checkmark$ Contar con más de 1 asistente social.

$\checkmark$ No contar con call center para brindar noticia.

$\checkmark$ Vigilantes un comunicado de 3 líneas "no estamos autorizados en brindar ninguna información" "derivar a familiar al número o dirección" “comuníquese con la agencia xxx para mayor información" así sea información que ya salió.

$\checkmark$ Hablar con las cabezas de los familiares.

$\checkmark$ Implementar un área especial para atenderlos como es debido

$\checkmark$ El call center debe derivar "como se llama su familiar" y derivar acercarse al área especial, para evitar filtraciones de información.

$\checkmark$ "Sabemos el cariño que tienen de nuestra compañía y seguramente querrás comunicar. Te recordamos que ya hay voceros asignados..." para que los colaboradores no hablen del tema.

$\checkmark$ Se debió hacer una respuesta más rápida, empática, pudo ser simplemente un comunicado.

\section{$\underline{\text { Anexo } 5}$}

\section{6/2/2019 Update: FAA Statement}

Boeing has informed the FAA that certain 737NG and 737MAX leading edge slat tracks may have been improperly manufactured and may not meet all applicable regulatory requirements for strength and durability. 
Following an investigation conducted by Boeing and the FAA Certificate Management Office (CMO), we have determined that up to 148 parts manufactured by a Boeing subtier supplier are affected. Boeing has identified groups of both 737NG and 737MAX airplane serial numbers on which these suspect parts may have been installed. $32 \mathrm{NG}$ and 33 MAX are affected in the U.S. Affected worldwide fleet are 133 NG and 179 MAX aircraft.

The affected parts may be susceptible to premature failure or cracks resulting from the improper manufacturing process. Although a complete failure of a leading edge slat track would not result in the loss of the aircraft, a risk remains that a failed part could lead to aircraft damage in flight.

The FAA will issue an Airworthiness Directive to mandate Boeing's service actions to identify and remove the discrepant parts from service. Operators of affected aircraft are required to perform this action within 10 days. The FAA today also alerted international civil aviation authorities of this condition and required actions.

\section{Anexo 6:}

Cuadro de inversión - Plan de prevención de crisis.

\begin{tabular}{|l|l|}
\hline \multicolumn{1}{|c|}{ Motivo } & \multicolumn{1}{c|}{ Precio } \\
\hline Fee Mensual - Agencia de Relaciones Públicas & S/ 28,000 \\
\hline Medición de la huella de carbono & $\$ 16,000$ \\
\hline Ipsos - Estudio de Mercado & S/ 44,000 \\
\hline GFK - Estudio de Marca & S/ 59,900 \\
\hline Sesión de media training & S/ 13,000 \\
\hline Sesiones de Propósito de marca & S/ 5,200 \\
\hline Reporte de Sostenibilidad & S/ 12,500 \\
\hline Video Institucional & S/ 3,000 \\
\hline Sesión de construcción de propósito de marca & S/ 10,000 \\
\hline Sesión de coaching & S/ 12,000 - 24,000 \\
\hline Taller de manejo de emociones & S/ 9,200 \\
\hline Taller de liderazgo y habilidades blandas & S/ 650 por persona \\
\hline
\end{tabular}




\section{Anexo 7:}

Calendarización de actividades post-crisis.

\begin{tabular}{|c|c|c|c|c|c|c|c|c|c|c|c|c|c|c|c|c|c|c|c|c|c|c|c|c|c|c|c|c|c|c|c|c|c|c|c|c|c|c|c|c|}
\hline \multicolumn{3}{|c|}{ Matriz Táctica } & \multicolumn{4}{|c|}{ JULIO } & \multicolumn{4}{|c|}{ AGOSTO } & \multicolumn{3}{|c|}{ SETIEMBRE } & \multicolumn{4}{|c|}{ OCTUBRE } & \multicolumn{6}{|c|}{ NOVIEMBRE DICIEMBRE } & \multicolumn{3}{|c|}{ ENERO } & \multicolumn{3}{|c|}{ FEBRERO } & \multicolumn{3}{|c|}{ MARZO } & \multicolumn{2}{|c|}{ ABRIL } & \multicolumn{4}{|c|}{ MAYO } & \multicolumn{2}{|c|}{\begin{tabular}{|l|l|} 
JUNIO \\
IUIs
\end{tabular}} \\
\hline Frente Estratégico & Tástica & Acciones & S1 & S2 & \begin{tabular}{|l|r|r|r}
53 & \\
\end{tabular} & \begin{tabular}{l|l}
5 & $\mathrm{~s}$ \\
\end{tabular} & \begin{tabular}{l|l}
$\mathrm{S} 1 \mathrm{~s}$ \\
$\mathrm{~s}$
\end{tabular} & \begin{tabular}{l|l}
52 & 5 \\
\end{tabular} & \begin{tabular}{l|l}
53 & 5 \\
\end{tabular} & \begin{tabular}{l|l}
54 & 5 \\
\end{tabular} & \begin{tabular}{l|l}
51 & 52 \\
152
\end{tabular} & \begin{tabular}{|l|l|l}
2 & 53 \\
2 &
\end{tabular} & \begin{tabular}{l|l}
3 & 54 \\
\end{tabular} & S1 & S2 & \begin{tabular}{|l|l|} 
S3 & S \\
\end{tabular} & \begin{tabular}{l|l}
54 \\
$S$
\end{tabular} & \begin{tabular}{l|l} 
s1 \\
\end{tabular} & $\begin{array}{ll}52 & 53 \\
2\end{array}$ & \begin{tabular}{l|l}
3 & 54 \\
\end{tabular} & & & $\begin{array}{l}5354 \\
\end{array}$ & S1 & & $3 \mathrm{~S}$ & S1 & & $\begin{array}{l}354 \\
\end{array}$ & 51 & \begin{tabular}{l|l}
52 & 53 \\
\end{tabular} & 54 & \begin{tabular}{l|l} 
S1 \\
\end{tabular} & S2 53 & S4 $\mathrm{s}$ & & 53 & $\begin{array}{lll}\mathrm{S} \\
\end{array}$ & 5152 & \begin{tabular}{|l|l|}
53 & 54 \\
\end{tabular} \\
\hline \multirow{6}{*}{$\begin{array}{c}\text { Evaluación e } \\
\text { Identificación: } \\
\text { Realizar una investigación } \\
\text { y recopilación de datos } \\
\text { sobre la realidad } \\
\text { corporativa. }\end{array}$} & \multirow{3}{*}{$\begin{array}{c}\text { Identificar aspectos } \\
\text { vulnerables de peligro y } \\
\text { riesgo dentro de la } \\
\text { empresa }\end{array}$} & $\begin{array}{l}\text { Realizar una auditoria interna para } \\
\text { identficar posibles riesgos en las } \\
\text { operaciones }\end{array}$ & $x$ & $\mathrm{x}$ & $\mathrm{x}$ & $x \mid x$ & $\mathrm{x}$ & $x$ & & & & & & & & & & & & & & & & & & & & & & & & & & & & & & & & \\
\hline & & $\begin{array}{l}\text { Analizar la actividad de los canales } \\
\text { internos con los colaboradores }\end{array}$ & & & & $x \mid \gamma$ & $\mathrm{x}$ & $x$ & & & & & & & & & & & & & & & & & & & & & & & & & & & & & & & & \\
\hline & & $\begin{array}{l}\text { Realizar una encuesta para medir el } \\
\text { clima laboral de la empresa }\end{array}$ & & & & & $\mathrm{x}$ & $x \mid x$ & $x \mid x$ & $x$ & & & & & & & & & & & & & & & & & & & & & & & & & & & & & & \\
\hline & \multirow{3}{*}{$\begin{array}{c}\text { Identificar aspectos } \\
\text { vulnerables de peligro y } \\
\text { riesgo externos a la } \\
\text { empresa }\end{array}$} & $\begin{array}{l}\text { Levantar información del perfil de los } \\
\text { stakeholders externos y la } \\
\text { perceppoión que tienen hacia la } \\
\text { compañia. }\end{array}$ & $x$ & $\mathrm{x}$ & $\mathrm{x}$ & $\mathrm{x}$ & & & & & & & & & & & & & & & & & & & & & & & & & & & & & & & & & & \\
\hline & & $\begin{array}{l}\text { Elaborar un mapa de actores para } \\
\text { identificar su grado de influencia con } \\
\text { la empresa }\end{array}$ & & & & & $\mathrm{x}$ & $\mathrm{x}$ & & & & & & & & & & & & & & & & & & & & & & & & & & & & & & & & \\
\hline & & $\begin{array}{l}\text { Realizar un diagnóstico de nuestros } \\
\text { canales digitales. }\end{array}$ & & & & & & $x$ & \begin{tabular}{l|l}
$x$ & $x$ \\
\end{tabular} & $x \mid x$ & $x \mid x$ & $\begin{array}{l}x \\
\end{array}$ & & & & & & & & & & & & & & & & & & & & & & & & & & & & \\
\hline \multirow{5}{*}{$\begin{array}{c}\text { Definir una cultura } \\
\text { corporativa alineada a los } \\
\text { principios de la empresa. }\end{array}$} & $\begin{array}{c}\text { Fortalecer la confianza y } \\
\text { seguridad de los }\end{array}$ & $\begin{array}{l}\text { Realizar un video institucional del } \\
\text { Gerente General agradeciendo a los } \\
\text { coloboradores por su compromiso } \\
\text { durante la etapa de crisis. }\end{array}$ & & & $\mathrm{x}$ & & & & & & & & & & & & & & & & & & & & & & & & & & & & & & & & & & & \\
\hline & $\begin{array}{l}\text { colaboradores dentro de } \\
\text { la organización. }\end{array}$ & $\begin{array}{l}\text { Alinear los nuevos objetivos de la } \\
\text { organización (post - crisis) con } \\
\text { todos los colaboradores, a través del } \\
\text { equipo gerencial. }\end{array}$ & & & & & & & & & $x \mid x$ & $x \mid x$ & & & & & & & & & & & & & & & & & & & & & & & & & & & & \\
\hline & $\begin{array}{l}\text { Crear un propósito } \\
\text { alineado a los principios }\end{array}$ & $\begin{array}{l}\text { Sesiones de perfil corporativo con } \\
\text { colaboradores de diferentes áreas de } \\
\text { la empresa. }\end{array}$ & & & & & & & & & & & & & & & & & & & & & & $x \mid$ & $x \mid x$ & & $x \mid$ & & & & & & & & & & & & & \\
\hline & de la empresa & $\begin{array}{l}\text { Sesiones de alineamiento } \\
\text { estratégico con el equipo Gerencial }\end{array}$ & & & & & & & & & & & & & & & & & & & & & & & & & & $\mathrm{x}$ & $x \mid x$ & & & & & & & & & & & \\
\hline & $\begin{array}{l}\text { Fortalecer los valores } \\
\text { corporativos en los } \\
\text { colaboradores }\end{array}$ & \begin{tabular}{|l|} 
Ejecución de un plan de \\
comunicación interna para difundire $e$ \\
interiorizar los valores corporativos
\end{tabular} & & & & & & & & & & & & & & $x \mid x$ & $x \mid x$ & $\mathrm{x}$ & $x \mid x$ & & & & & & & & & & & & & & & & & & & & & \\
\hline & $\begin{array}{l}\text { Identificación de las } \\
\text { competencias }\end{array}$ & $\begin{array}{l}\text { Identificar fortalezas y debilidades de } \\
\text { cada miembro del equipo gerencial } \\
\text { por medio de una consultora }\end{array}$ & & & & & & & & & & & & & & \begin{tabular}{|l|l}
$x$ & $x$ \\
$y$
\end{tabular} & \begin{tabular}{c|c}
$x$ & $x$ \\
$x$
\end{tabular} & $\mathrm{x}$ & & & & & & & & & & & & & & & & & & & & & & \\
\hline $\begin{array}{l}\text { Liderazgo comunicacional: } \\
\text { Fortalecer el perfil }\end{array}$ & & $\begin{array}{l}\text { Realizar una evaluación de liderazgo } \\
\text { a los gerentes, calificado por su } \\
\text { equipo de trabajo. }\end{array}$ & & & & & & & & & & & & & & & & & & & $\mathrm{x}$ & $\mathrm{x}$ & \begin{tabular}{l|l}
$x$ & $x$
\end{tabular} & & & & & & & & & & & & & & & & & \\
\hline \begin{tabular}{c|} 
comunicacional y \\
relacional de los Gerentes
\end{tabular} & & $\begin{array}{l}\text { Realizar sesiones Media Training } \\
\text { con los voceros de la organización }\end{array}$ & & & $\mathrm{x}$ & & & & & & & & & & & & & & & & & & & & & & & & & & & & & & & & & & & \\
\hline & $\begin{array}{l}\text { Capacitar portavoces } \\
\text { internos y externos }\end{array}$ & $\begin{array}{l}\text { Realizar un taller de coaching para el } \\
\text { Gerente General sobre habilidades } \\
\text { blandas y manejo de equipos }\end{array}$ & & & & & $\mathrm{x}$ & & & & & & & & & & & & & & & & & & & & & & & & & & & & & & & & & \\
\hline & & $\begin{array}{l}\text { Realizar un taller de liderazgo y } \\
\text { habilidades blandas para todo el } \\
\text { equipo gerencial }\end{array}$ & & & & & & & & & & & & & & & & & & & & & & $x$ & & & & & & & & & & & & & & & & \\
\hline & & $\begin{array}{l}\text { Realizar conferencias de prensa para } \\
\text { comunicar logros y novedades de la } \\
\text { empresa. }\end{array}$ & & & & & & & & & & & & $\mathrm{x}$ & & & & $\mathrm{x}$ & & & $\mathrm{x}$ & & & $x$ & & & $\mathrm{x}$ & & & $x$ & & & $\mathrm{x}$ & & & $\mathrm{x}$ & & $\mathrm{x}$ & & \\
\hline & $\begin{array}{l}\text { Relacionamiento con } \\
\text { medios de comunicación }\end{array}$ & \begin{tabular}{|l|} 
Brindar entrevistas 1 a 1 por parte de \\
nuestros voceros sobre temas \\
relacionados al sector.
\end{tabular} & & & & & & & & & & & & & & & & & $\mathrm{x}$ & & & & & & $x$ & $\mathrm{x}$ & & & & & $x$ & & & & & & $x$ & & & \\
\hline $\begin{array}{l}\text { Fortalecimiento de la } \\
\text { reputación: Gestionar una } \\
\text { buena imagen corporativa }\end{array}$ & & \begin{tabular}{|l|} 
Tener participación en medios \\
escritos a través de notas \\
prensas/articulos/columnas de \\
opinión de nuestros voceros.
\end{tabular} & & & & & & & & & & & & $\mathrm{x}$ & & & & $\mathrm{x}$ & $\mathrm{x}$ & & $\mathrm{x}$ & & & $x$ & $x$ & $x$ & $\mathrm{x}$ & & & $x$ & $x$ & & $\mathrm{x}$ & & & $\mathrm{x}$ & $x$ & $\mathrm{x}$ & & \\
\hline $\begin{array}{l}\text { para tener una reputación } \\
\text { que nos sirva como }\end{array}$ & & $\begin{array}{l}\text { Implementar una politica de gestión } \\
\text { amiental. }\end{array}$ & & & & & & & & & & & & & & & & & & & $\mathrm{x}$ & \begin{tabular}{|l|l|l}
$x$ & $x$ \\
\end{tabular} & \begin{tabular}{l|l}
$x$ & $x$ \\
\end{tabular} & & & & & & & & & & & & & & & & & \\
\hline $\begin{array}{l}\text { recurso estratégico } \\
\text { durante una crisis. }\end{array}$ & $\begin{array}{l}\text { Actividades de } \\
\text { responsabilidad social }\end{array}$ & \begin{tabular}{|l|}
$\begin{array}{l}\text { Implementar las normas de } \\
\text { seguridad desarrolladas por la ISO } \\
\text { para agarantizar la calidad y } \\
\text { seguridad de los procesos. }\end{array}$ \\
\end{tabular} & & & $\mathrm{x}$ & $x \mid x$ & $\mathrm{x}$ & $\mathrm{x}$ & & & & & & & & & & & & & & & & & & & & & & & & & & & & & & & & \\
\hline & & $\begin{array}{l}\text { comprometer las principales } \\
\text { Reallzar el reporte qe sostent|ाIवad }\end{array}$ & & & & & & & & & & & & $x$ & & & & & & & & & & $x$ & \begin{tabular}{l|l}
$x$ & $x$ \\
$x$
\end{tabular} & $x$ & & & & & & & & & & & & & & \\
\hline & & 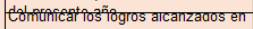 & & & & & & & & & & & & $\begin{array}{c}x \\
x\end{array}$ & & & & $x$ & & & $|x|$ & & & $|x|$ & & & $x \mid$ & & & $x$ & & & $x$ & & & $x$ & & $x$ & & \\
\hline & 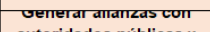 & 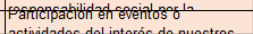 & & & & & & & & & & & & & & & & & & & 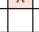 & & & 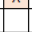 & & & & & $x$ & ה & $x$ & & 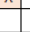 & $x$ & & & $x$ & & & $\mathrm{x}$ \\
\hline
\end{tabular}

